
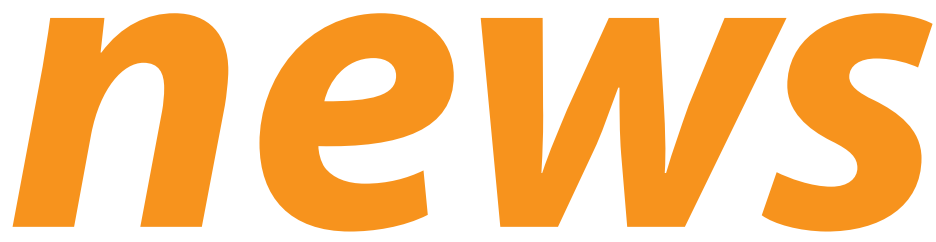

Vol 17 - No 2 - June 2009

Understanding sea level: Ways forward from the past

\section{Editors:}

Mark Siddall, William G. Thompson,

Claire Waelbroeck and Louise Newman

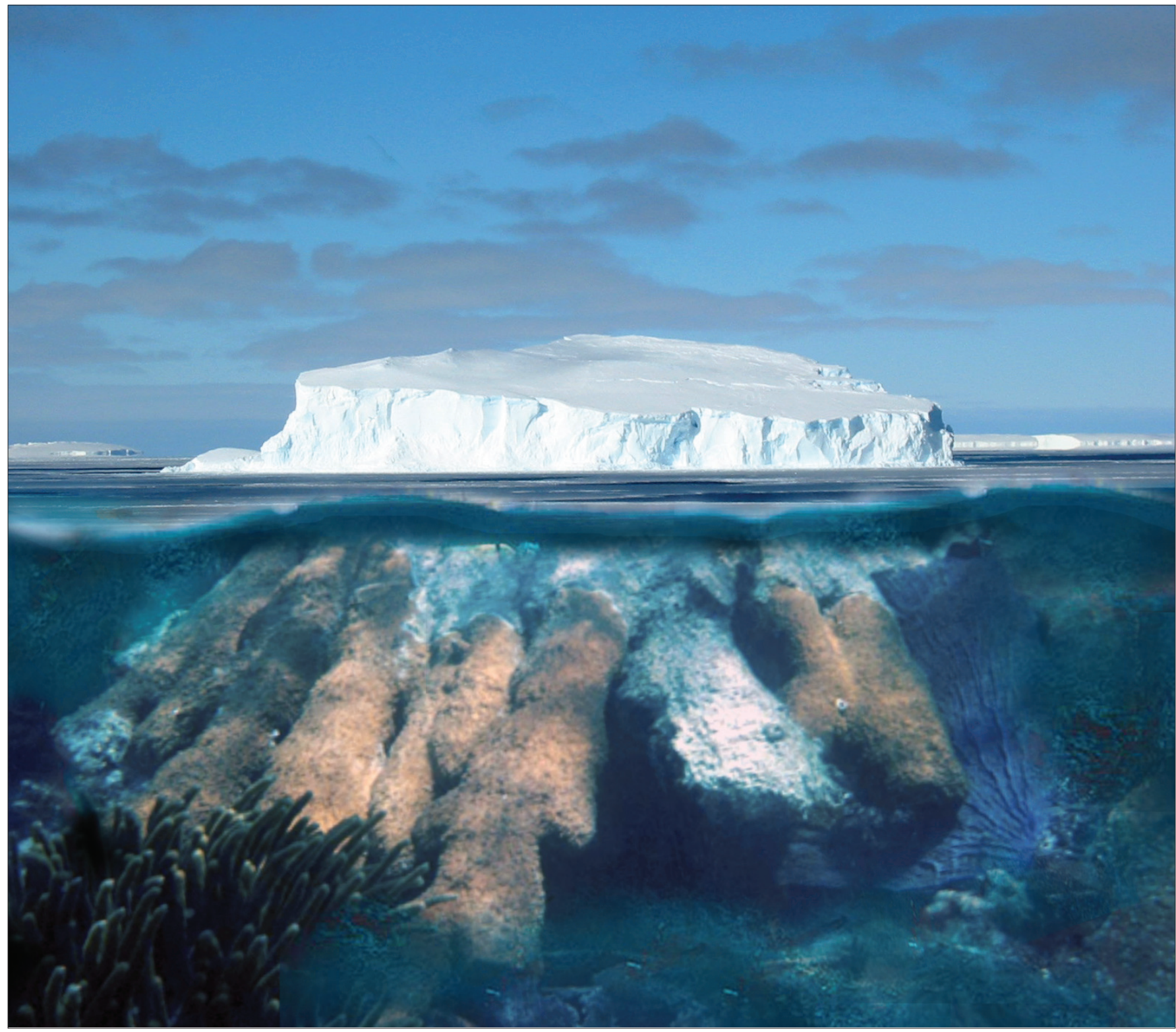

Are tropical corals the key to understanding past changes in polar ice volume? What role do they have to play in helping us better understand the future? This issue of PAGES news highlights current research that aims to address these and other questions on past changes in sea level, and the implications for predictions of future sea level rise. 


\section{Inside PAGES}

Nominations for the PAGES SSC

At the end of 2009, Jérôme Chappellaz (France), Eystein Jansen (Norway), Peter Kershaw (Australia) and Ricardo Villalba (Argentina) will rotate off the PAGES Scientific Steering Committee (SSC). PAGES welcomes nominations for new members and has extended the deadline to the 15 June 2009. The SSC provides guidance for the PAGES project and oversees major scientific activities. Members are chosen based on scientific excellence and status in their communities, as well as to provide a balance of paleoscientific expertise and national representation, and for their potential to drive forward the Foci and Themes of the PAGES Science Plan. In this round, we are particularly interested in maintaining our coverage of the Southern Hemisphere, which will otherwise be depleted at the end of the year. A list of current members and nomination details can be found at www. pages-igbp.org/people/sscmembers/ Other news in the PAGES SSC; Cathy Whitlock (USA) was recently voted on to PAGES
Executive Committee (EXCOM), replacing Julie Brigham-Grette (USA), who rotated off at the end of 2008.

\section{News from other SSCs}

The steering committee for the PAGES/ CLIVAR Intersection (www.clivar.org/ organization/pages/pages.php) recently voted in Valerie Masson-Delmotte to join Gavin Schmidt as Co-Chair. Valerie replaces Eystein Jansen, who had held this position since 2003. Additionally, there has been a change of leadership on the IMAGES (www. images-pages.org/) Steering Committee, with Larry Peterson replacing Eelco Rohling as Chair. PAGES welcomes Valerie and Larry and looks forward to continuing collaborations under their leadership.

\section{EGU Medals}

Congratulations to Thomas Stocker (former PAGES Swiss Director) and Eric Wolff (PAGES SSC member) on their 2009 European Geosciences Union (EGU) medals. Thomas was awarded the Hans Oeschger Medal

\section{Tales from the...field?}

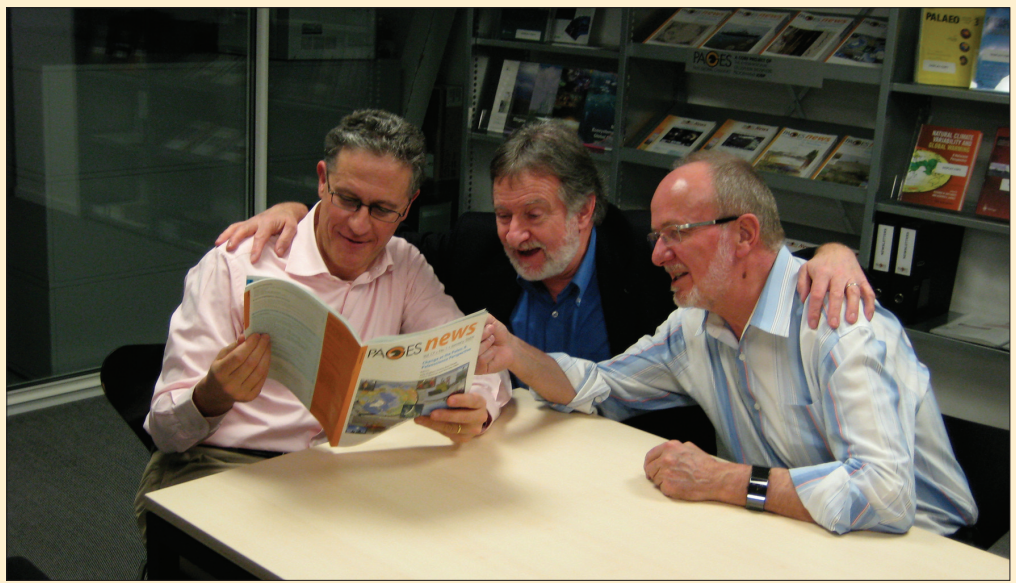

The "field" might be a little different now for these three scientists but PAGES news is still a must read! At the recent opening of the new PAGES and Oeschger Centre joint offices, Thomas Stocker (Co-Chair IPCC WG1), Peter Gehr (Uni. Bern) and Heinz Wanner (PAGES Co-Chair) took time out to look over the most recent issue. for his contributions to the understanding of the role of the oceans in past climate changes and for his involvement in ice core studies. Eric Wolff was awarded the Louis Agassiz Medal for his contributions to the study of the chemical composition of snow cover and ice cores and their use in the determination of past climates, pollution and atmospheric chemistry.

\section{PAGES YSM \& OSM update}

PAGES is gearing up for the $1^{\text {st }}$ Young Scientists Meeting (6-7 July 2009) and $3^{\text {rd }}$ Open Science Meeting (8-11 July 2009) in Corvallis, Oregon, USA. We are delighted with the high level of abstracts submitted, and by the overwhelming interest of young scientists in these meetings. Program details are available online. Corvallis colleagues have put together a number of post-OSM fieldtrips that look like great fun. For information on these and more go to www.pagesosm.org/

\section{"Polar Paleoscience" addendum}

As an addendum to the Polar Paleoscience special section of the last PAGES news (January, 17(1)), two science highlights, Kuijpers et al., and Sangiorgi et al., have been included in the open section of this newsletter, pages 76 and 78 , respectively.

\section{Next issue of PAGES news}

The third issue for 2009 will contain a special section on advances in paleolimnology, guest edited by Reinhard Pienitz (currently a Guest Scientist at the PAGES IPO) and André Lotter. While the deadline to contribute to this special section has passed, contributions to the open section of the newsletter, unrelated to the special topic, are still welcome before 1 July 2009. Guidelines can be found at www. pages-igbp.org/products/newsletters/ instructions.html

\section{PAGES Calendar 2009}

06 - 07 Jul 2009 - Corvallis, USA

(2) PAGES $1^{\text {st }}$ Young Scientists Meeting: Retrospective Views on Our Planet's Future www.pages-osm.org/ysm/

\section{8 - 11 Jul 2009 - Corvallis, USA}

(3) PAGES $3^{\text {rd }}$ Open Science Meeting: Retrospective Views on Our Planet's Future www.pages-osm.org/osm/

\section{4 - 27 Aug 2009 - Mytilene, Greece} (5) $2^{\text {nd }}$ Past Interglacials (PIGS) Workshop www.pages-igbp.org/calendar/
21 - 25 Sep 2009 - Woods Hole, USA

(5) Understanding future sea level rise: The challenges of dating past interglacials www.pages-igbp.org/calendar/

02 - 05 Nov 2009 - Hyères-les-Palmiers, France (2) $1^{\text {st }}$ ADOM workshop: High-mid latitude northern atmospheric circulation changes during the last climate cycle www.pages-igbp.org/science/adom/adom-north.html 


\section{Editorial: Past ice sheet dynamics and}

sea level-placing the future in context P A L S E A

Mark Siddall ${ }^{1}$, William G. Thompson ${ }^{2}$ and Claire Waelbroeck $^{3}$

'Department of Earth Sciences, University of Bristol, UK; mark.siddall@bristol.ac.uk

${ }^{2}$ Department of Geology and Geophyiscs, Woods Hole Oceanographic Institution, USA; ${ }^{3}$ Laboratory of Climate and Environmental Sciences,

Pierre-Simon Laplace Institute, Atomic Energy Commissariat, National Centre of Scientific Research, Gif-sur-Yvette, France.

Paleo-evidence can contribute long-term perspective on future sea level/ice sheet change in both a quantitative sense and in the sense of understanding longer-term dynamics (see Abe-Ouchi et al., this issue). This special edition of PAGES news led by the PALSEA (PALeo SEA level) Working Group covers recent advances in the field of paleo sea level (see Dutton et al., Andersen et al., and Stirling and Andersen, this issue) and ice sheet reconstruction (see Clark, this issue). The focus is on the application of this data to a better understanding of contemporary and future sea level and ice sheet change, as well as directions for future research.

\section{New questions for paleodata are driven by the limitations of the 'modern-only' approach}

Continuing eustatic sea level rise includes contributions from thermal expansion, reductions in glaciers and ice caps, and reductions in polar ice sheets. Although there are important uncertainties in observing and predicting each of these components, the contribution from thermal expansion over the last millennium is relatively well understood (Gregory et al., 2005). Furthermore, the contribution from glaciers and ice caps (and the related uncertainty) is set to decrease over the course of the coming century as these reserves of ice finally disappear. This leaves the ice sheet contribution and its related uncertainties.

Ice sheets are notoriously difficult to understand (Alley et al., 2005). Unlike the biosphere, atmosphere and ocean, ice sheets are solid and opaque and do not lend themselves to direct observation (Fig. 1). Modern observations of ice sheets consist of surface observations and limited observations of processes that occur at the bed, grounding line, and within the ice sheets.

Despite these difficulties, significant advances in observing modern ice sheets have been made over recent decades, in particular with the advent of satellite gravimetric techniques. Evidence from satellite imagery has also been key in documenting the rapid collapse of ice shelves and subsequent acceleration of ice streams in response. However, the short duration of direct observations of ice sheet change (several decades) from satellite observations ( $<20$ years) limits these data to understanding sub-centennial processes (see Bamber, this issue). Key questions, such as the long-term effect of the collapse of fringing ice shelves deep into the ice sheet interior, remain unanswered. Similar limitations apply to the tide-gauge sea level record, which is, at most, several centuries long (Church and White, 2006; Jevrejeva et al., 2008).

\section{Lessons for the future from paleo- archives}

In the broadest sense, paleodata informs us that there have not always been significant ice sheets on Earth. Periods without ice sheets had corresponding high temperatures and atmospheric $\mathrm{CO}_{2}$ concentrations. We know that during the mid-Pliocene warm period sea level was 5 to $40 \mathrm{~m}$ higher than today and global temperature was some several degrees warmer (see Raymo et al., this issue). Indeed, during the last interglacial period, global temperature was milder than today and sea level was some 3 to $6 \mathrm{~m}$ higher. It is noteworthy that for similar (if not identical) climate conditions to those predicted for the coming centuries, the ice sheets of the past were significantly smaller than today. Colder conditions are linked to larger ice sheets. According to the Paleoclimate Model Intercomparison Project, the Last Glacial Maximum was 3 to $5^{\circ} \mathrm{C}$ colder than today (IPCC, 2007) and sea level was 120 to $140 \mathrm{~m}$ below modern (Fairbanks, 1989; Yokoyama et al., 2000).

As well as providing context for the broad relationship between global sea level and temperature, paleodata gives us perspective on rates of contemporary sea level rise. For example, Flemming et al. (1998) found that sea level rose at an average rate of 0.04 to $0.07 \mathrm{~m}$ per century over the last $7 \mathrm{ka}$. Furthermore, they found a reduced rate of sea level rise over the last 2 ka compared to the period between 7 and $2 \mathrm{ka}$. This compares with the IPCC estimate over the $20^{\text {th }}$ century based on tide-gauge data of 0.12 to $0.22 \mathrm{~m}$ rise, giving a clear indication that contemporary sea level rise is anomalous in the context of late Holocene sea level change. Further, important

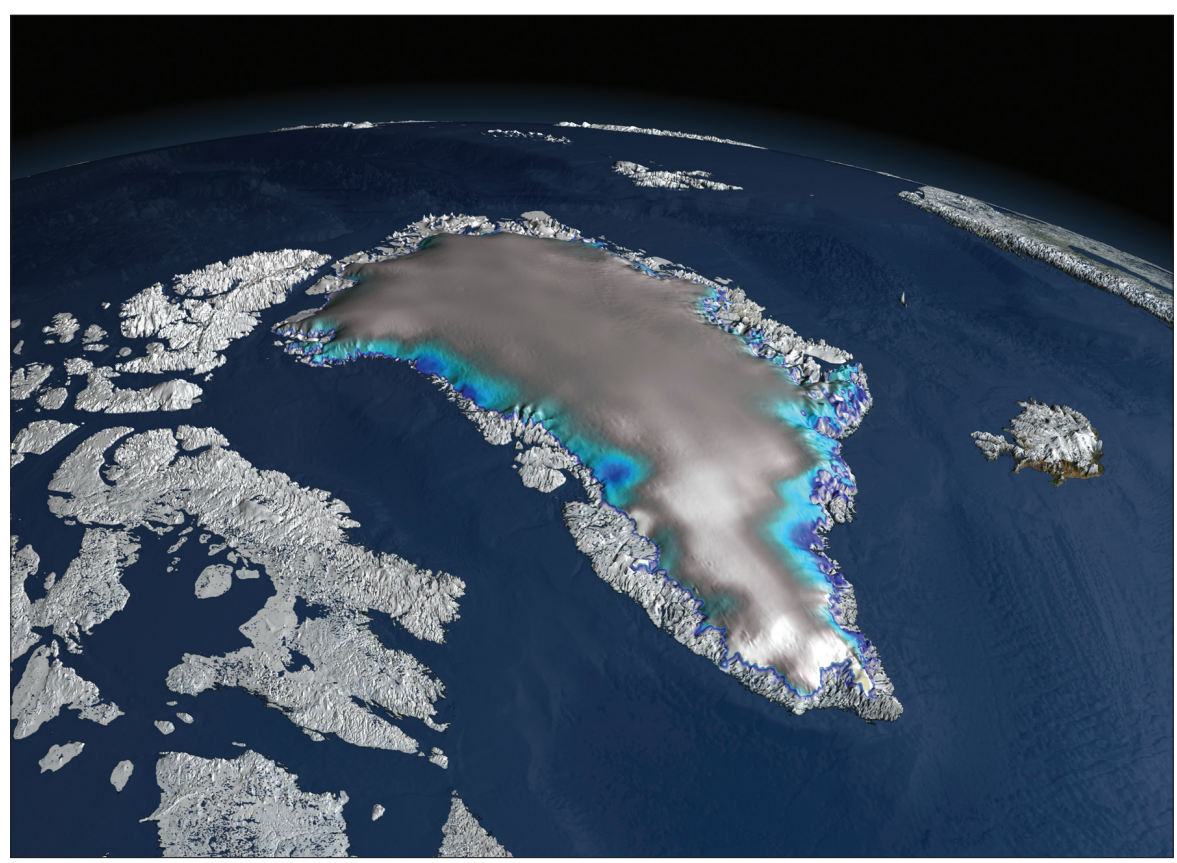

Figure 1: Changes in elevation over the Greenland Ice Sheet between 2003 and 2006 from the ICESat elevation satellite. Thickening is shown in white and thinning is shown in blue, while gray indicates no change. Care must be taken in considering the implications of this image — changes in height do not necessarily translate to changes in mass because ice can melt, lose trapped air and refreeze in a denser configuration. The observation of a large, opaque object is inevitably difficult and indirect. Furthermore, the short duration of such observations places limits on the weight one can place on these observations. Paleo sea level and ice sheet reconstructions can help plug some of these gaps. Credit: NASA/Goddard Space Flight Center Scientific Visualization Studio. The Next Generation Blue Marble data is courtesy of Reto Stockli (NASA/GSFC). 
lessons can be learnt by studying evidence for Holocene sea level and ice sheet change in the context of regional climate change, such as the Medieval Warm Period and the Little Ice Age (see Kelly and Long, and Yu et al., this issue). In turn, Holocene changes must be considered in the light of the large changes in ice volume and sea level during the termination of the last glacial period (T1). During T1, the interaction between ice sheets, ocean circulation and global warming greatly perturbed the ice sheets and can be regarded as a case study for large changes in global climate on decadal to centennial timescales (see PALSEA, 2009). In particular, relative sea level variations during this period may help reveal which ice sheets collapsed in response to climate change during $\mathrm{T} 1$ (see Milne, this issue). Other periods in the past also have lessons for millennial-scale climate variability (see Gonzalez and Dupont, this issue).

Paleodata can help constrain the sensitivity of ice volume and sea level change to broader climate change. It can help place limits on future rates of change and it can give a multi-decadal and multi-centennial context to sea level and ice sheet change. The contributions in this edition of PAGES news will give recent examples of this work.

\section{Note}

For more information on the PALSEA Working Group please visit www.climate.unibe. ch/ siddall/working_group.html

\section{References}

Alley, R.B., Clark, P.U., Huybrechts, P. and Joughin, I., 2005: Ice-sheet and sea-level changes, Science, 310: 456-460.

Fleming, K., Johnston, P., Zwartz, D., Yokoyama, Y., Lambeck, K. and Chappell, J., 1998: Refining the eustatic sea-level curve since the Last Glacial Maximum using far- and intermediate-field sites, Earth and Planetary Science Letters, 163(1-4): 327-342. DOl:10.1016/S0012-821X(98)00198-8 ().

Gregory, J.M., Lowe, J.A. and Tett, S.B.T., 2006: Simulated global-mean sea-level changes over the last half-millennium, Journal of Climatology, 19(18): 4576-4591.

IPCC, 2007: Summary for Policymakers. In: Solomon, S. et al., (Eds), Climate Change 2007: The Physical Science Basis. Contribution of Working Group I to the Fourth Assessment Report of the Intergovernmental Panel on Climate Change, Cambridge University Press, Cambridge, United Kingdom and New York, USA.

PALSEA, 2009: The sea-level conundrum - case studies from paleoarchives, Journal of Quaternary Science, in press.

\section{Recent Antarctic and Greenland ice-mass fluxes from satellite observations and their significance}

\section{JonAthan BAmber}

Bristol Glaciology Centre, School of Geographical Sciences, University of Bristol, UK; j.bamber@bristol.ac.uk

\section{Understanding contemporary ice sheet behavior is crucial for estimating future trends but the useful satellite observation period of $\sim 20$ years is too short. Paleodata, especially from the Holocene, have the potential to help us interpret the contemporary observations.}

Reliable, large-scale observations of the mass trends of the ice sheets do not extend very far back in time. The earliest data set covering the whole of Greenland and $80 \%$ of Antarctica began with the launch of ERS-1 in 1991. Since then, other satellites and sensors have provided unique insights into the time-evolving behavior of the ice sheets. Two pressing issues emerge from these observations. The first is the lack of consistency between estimates of the mass balance (Fig. 1), and the second is whether the large and rapid fluctuations in ice dynamics observed are a secular response (i.e., a one-way trend) to external forcing or just part of the "normal" variability in flow that is constantly taking place. Considerable weight and importance has been placed on the apparent increasing mass loss from both Greenland and West Antarctica over the last decade (e.g., Fig. 1). The implication is that this trend is a secular response to external forcing (Hansen, 2007) but the record is too short to confirm this with any certainty. Resolving this issue is crucial, and this is where the paleo record of ice sheet variability, particularly during the Holocene, could, and perhaps must, provide some of the answers.

Since the mid 1990s, our view of ice sheet dynamics has undergone a profound paradigm shift (Bamber et al.,

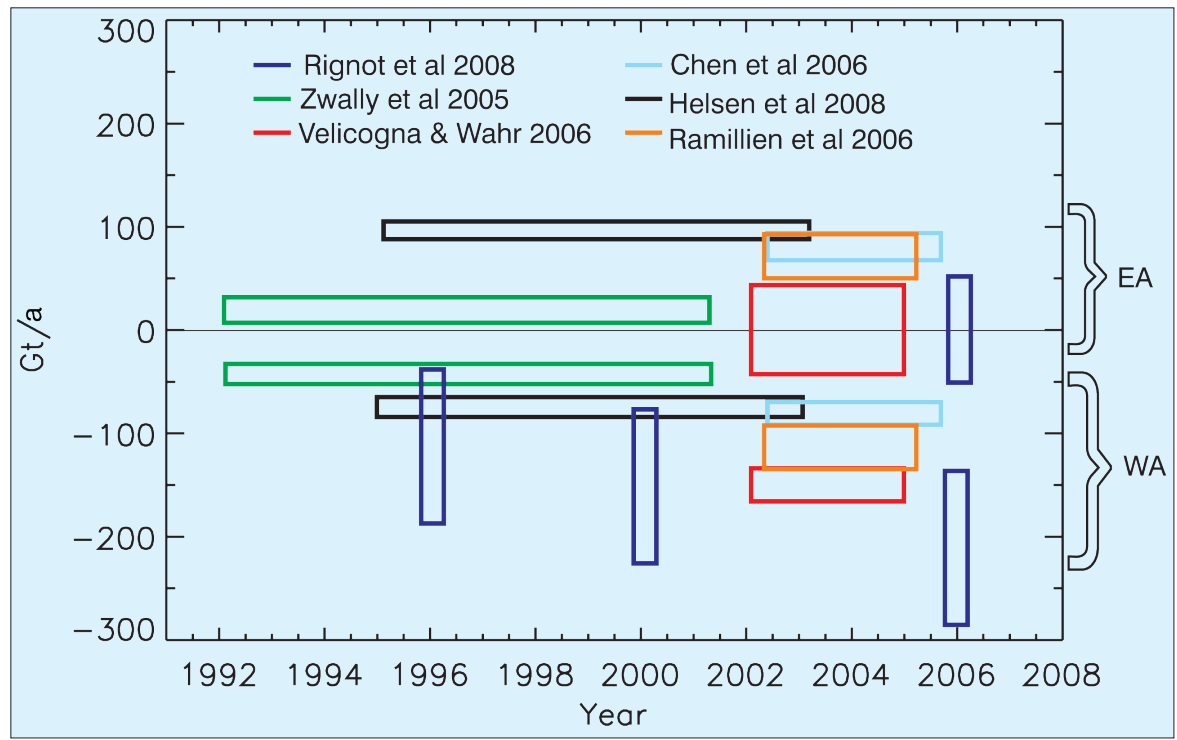

Figure 1: Estimates of the mass balance of the West (WA) and East (EA) Antarctic ice sheets (gigatonnes per year, Gt/a) from a variety of observations and authors. The width of the bars indicates the time period for the estimate and the thickness represents the uncertainty. Zwally et al., (2005) is estimated from satellite radar altimetry. Helsen et al., (2008) is a reassessment of radar altimetry data using a firn compaction model driven by climate model data. (Rignot et al.,, 2008) is from mass budget estimates combining velocity and thickness data with modeled snowfall. Chen et al., 2006, Ramillien et al., 2006, Velicogna and Wahr, 2006 are from gravity measurements from GRACE (Gravity Recovery and Climate Experiment).

the response time of ice sheet dynamics was on the order of $10^{3}-10^{4}$ years. The numerical ice sheet models developed during the 1980s supported this "wisdom" (Huybrechts and de Wolde, 1999). These models operated at relatively course resolution, typically $40 \mathrm{~km}$, with certain simplifications to the physics employed that were considered reasonable at the continental scale. As a consequence, the models were not able to resolve individual ice streams (Fig. 2). During the last decade, with the advent of satellite-based repeat pass synthetic aperture radar interferometry (InSAR), a radically different view has emerged. For example, between 1997 and 2000, the largest outlet glacier (by discharge volume) in Greenland, Jakobshavn 


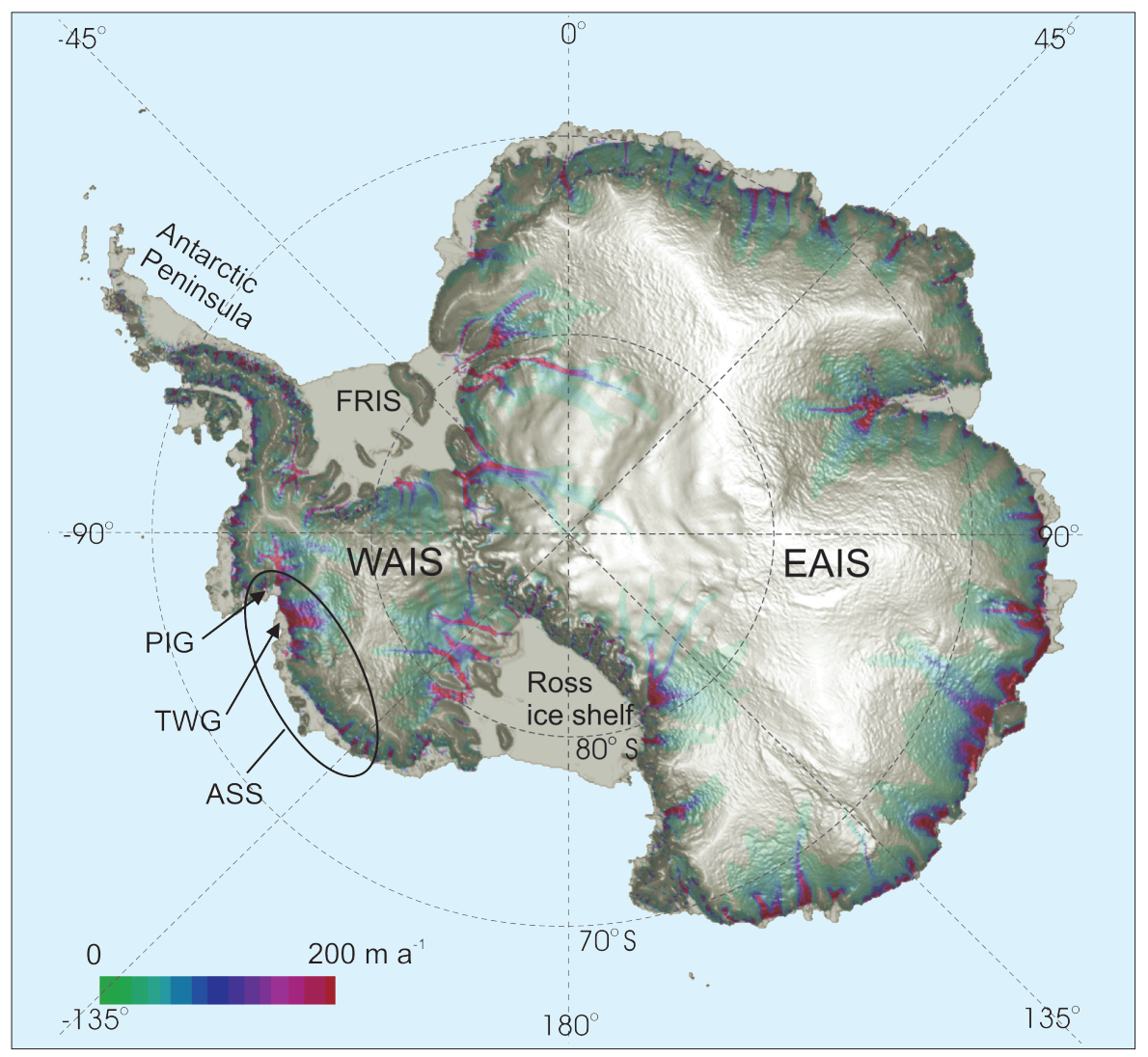

Figure 2: Surface topography (gray) and surface-ice velocities ( $\mathrm{m} / \mathrm{a}$ ) (colored) for the West (WAIS) and East (EAIS) Antarctic Ice Sheet, indicating the locations of the ice streams and outlet glaciers along the margins of the ice sheet. Pine Island Glacier (PIG) and Thwaites Glacier (TWG) are responsible for the majority of the mass loss in the Amundsen Sea Sector (ASS) of West Antarctica (Rignot and others, 2008). Also shown are the Ross and Filchner Ronne lce Shelves (FRIS)

Isbrae, doubled in velocity from around 6 $\mathrm{km} / \mathrm{a}$ to $12 \mathrm{~km} / \mathrm{a}$ (Joughin et al., 2004) (Fig. 3). Interestingly, similar observations, for a slightly different time period, showed the same rapid, simultaneous speed-up of two glaciers on the southeast coast of Greenland (Luckman et al., 2006). Smaller, but still substantial, speed-ups have also been observed for ice streams draining the West Antarctic Ice Sheet (WAIS) (Fig. 2). Some of these, in particular Pine Island Glacier (Fig. 1), have continued their acceleration, resulting in an increasingly negative mass balance since 1996 (Rignot et al., 2008).

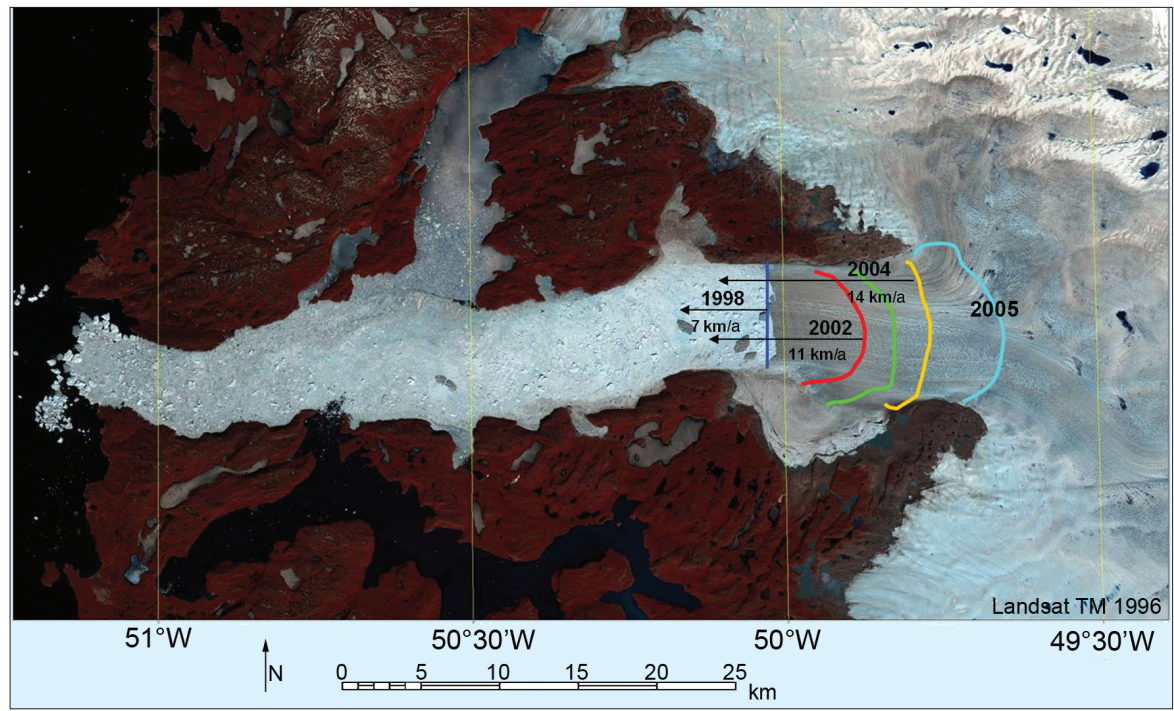

Figure 3: Landsat TM image of Jakabshavn Isbrae from 1996 showing the floating tongue and calving positions and velocities at various dates during the period of speed-up of the glacier, which is the largest (by discharge volume) in Greenland (Joughin et al., 2004). Figure courtesy K. Steffen.

Thus, although there is a lack of consensus about the absolute value for the mass balthat the trend has become increasingly negative for both Greenland and the WAIS cade that parts of the ice sheets is 2006$)$. What is not $\mathrm{kr}$ however, is whether the recent observo tions of rapid and large changes in motion are in any way unusual. Do they represent a secular trend in response to atmospheric and/or oceanic warming, as some have implied (Hansen, 2007), or is this simply normal ice sheet variability on a decadal timescale? The answer to this question is fundamental to i) our understanding of ice sheet behavior, ii) interpretation of the short, satellite-derived mass trends, and iii) predicting future ice sheet behavior. It would be fortuitous that we started our measurements at just the right time to observe the start of a secular, monotonic trend. On the other hand, it is noteworthy that similar trends are seen for both Greenland and the WAIS, and that they are not restricted to single drainage basins but appear to have a common forcing. It is important to note, however, that the ice sheets are also still likely to be responding to changes in forcing at the end of the last glacial around $12 \mathrm{ka}$ BP. As a consequence, they will be out of equilibrium with respect to the modern-day climate, and their reaction to external forcing is an integrated response to changes over multiple millennia.

A reasonable contention would be that the resolution of this question is well suited to a numerical modeling experiment. The models are, however, currently playing "catch up" with the observations. Considerable effort is being invested in the development of higher-order models that contain a more detailed representation of the physical processes that are now believed to be important for reproducing the observed behavior (Pattyn, 2003). There are, however, other issues that may render this problem difficult for numerical models to address in the medium term. In particular, the basal boundary conditions are an important constraint for the models but are poorly known. Geothermal heat flux, for example, may vary by a factor of twenty across Greenland and Antarctica (Fahnestock et al., 2001), yet the models generally assume a global mean value. Ice has an anisotropic rheology (i.e., its flow properties vary with direction) and can be a factor of ten weaker in one plane as opposed to another but, again, the models currently cannot deal with this. Further, for large swathes of East Antarctica there are no direct observations of ice thickness; a critical boundary condition for numerical modeling, as ice velocity is proportional to the fourth power of thickness.

The question then is can paleodata capture past variability in dynamics and ice sheet extent with sufficient fidelity to be able to address the pressing and important questions that have emerged from the contemporary record? Pilot stud- 
ies are beginning to address aspects of this. For example, there is intriguing evidence based on historical aerial photography from the $20^{\text {th }}$ century, in addition to dating of lateral moraines and trimlines, that the Jakobshavn Isbrae catchment (Fig. 3) has fluctuated in volume several times since the Little Ice Age (Csatho et al., 2008). Yet we do not know whether, or what, contemporaneous external forcing was responsible for these changes. Nonetheless, this study does suggest that the contemporary observations, for this ba$\sin$ at least, are not atypical. The work has also shown that it is possible to produce (some of) the data we need to help place the modern observations in a longer-term context. There are currently no equivalent studies for WAIS catchments or on a larger scale in Greenland. In fact, even the gross deglacial evolution of the WAIS is poorly known (Ackert et al., 2007). Let's hope this changes soon!

\section{References}

Bamber, J.L., Alley R.B. and Joughin I., 2007: Rapid response of modern day ice sheets to external forcing, Earth and Planatary Science Letters, 257: 1-13.

Bindschadler, R., 2006: The environment and evolution of the West Antarctic ice sheet: setting the stage, Philosophical Transactions of the Royal Society A: Mathematical Physical and Engineering Sciences, 364(1844): 1583-1605.
Huybrechts, P. and de Wolde, J., 1999: The dynamic response of the Greenland and Antarctic ice sheets to multiple-century climatic warming, Journal of Climate, 12(8): 2169-2188.

Joughin, I., Abdalati W. and Fahnestock, M., 2004: Large fluctuations in speed on Greenland's Jakobshavn Isbrae glacier, Nature, 432(7017): 608-610.

Shepherd, A. and Wingham, D., 2007: Recent sea-level contributions of the Antarctic and Greenland ice sheets, Science, 315(5818): 1529-1532.

For full references please consult:

www.pages-igbp.org/products/newsletters/ref2009_2.html

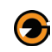

\title{
U-series dating of fossil coral reefs: Consensus and
}

\section{controversy}

\author{
Morten B. Andersen ${ }^{1}$, C.D. Gallup² ${ }^{2}$ D. Scholz ${ }^{3}$, C.H. Stirling ${ }^{4}$ and W.G. Thompson ${ }^{5}$ \\ 'Department of Earth Sciences, University of Bristol, UK; ${ }^{2}$ Department of Geological Sciences, University of Minnesota Duluth, USA; ${ }^{3}$ School of \\ Geographical Sciences, University of Bristol, UK; ${ }^{4}$ Department of Chemistry, University of Otago, New Zealand; ${ }^{5}$ Department of Geology and \\ Geophysics, Woods Hole Oceanographic Institution, USA; wthompson@whoi.edu
}

\section{New developments in U-series coral dating are sparking a healthy debate over how best to interpret coral ages from older fossil coral reefs, reinvigorating research in sea level changes during previous interglacial periods, and fostering a new appreciation of the challenges ahead.}

Understanding potential magnitudes and rates of future sea level change is an urgent societal and scientific problem. The history of sea level change provides crucial information about the links between climate forcing, response, and sea level change; as well as critical constraints on future sea level rise. The most direct method for reconstructing sea level history is uranium/thorium (U/Th) dating of fossil corals that once grew near the sea surface. This method has the potential to provide a detailed and well-dated record of sea level change for the last 700 ka. Given the relatively continuous growth of coral reefs in tropical seas and the precision of U-Th dating, the construction of a detailed and accurate sea level history should be a straightforward task. Despite decades of effort, this crucial goal remains elusive because many $\mathrm{U} / \mathrm{Th}$ ages are unreliable due to mobility of the relevant isotopes, a problem that worsens with increasing coral age. Recently, sea level research has been reinvigorated by new insight into the mechanisms of U-series isotope mobility in fossil corals and by significant improvements in analytical techniques.

\section{Identifying reliable coral ages}

Recent advances in analytical techniques have improved the precision of U/Th dating, extending the dating range to at least 700 ka (see Stirling and Andersen, this issue). Unfortunately, analytical challenges are not the only hurdle to be overcome in the pursuit of accurate U/Th coral ages. Isotope mobility often invalidates the "closed-system" assumption that is fundamental to radiometric dating techniques. Corals can either gain or lose uranium and thorium, changing the apparent age. Furthermore, many corals seem to be subject to a coupled loss or gain of ${ }^{234} \mathrm{U}$ and ${ }^{230} \mathrm{Th}$ isotopes (Fig. 1). The best explanation for this systematic addition appears to be the coupled addition of ${ }^{234} \mathrm{Th}$ (which rapidly decays to ${ }^{234} \mathrm{U}$ ) and ${ }^{230} \mathrm{Th}$ that is produced by the decay of ${ }^{238} \mathrm{U}$ and ${ }^{234} \mathrm{U}$ in the surrounding carbonate matrix. This effect results in a bias toward erroneously older apparent ages. These "open-system" artifacts represent a key challenge in translating $\mathrm{U} / \mathrm{Th}$ isotope ratio measurements into reliable coral ages. Two general strategies are employed to reduce the impact of these artifacts. The "screening" approach focuses on identifying closed-system corals using criteria such as initial ${ }^{234} \mathrm{U} /{ }^{238} \mathrm{U}$ and the ${ }^{231} \mathrm{~Pa} /{ }^{235} \mathrm{U}$ chronometer (e.g., Gallup et al., 1994), while the "correction" approach attempts to correct ages for opensystem effects (e.g., Thompson et al., 2003; Villemant and Feuillet, 2003; Potter et al., 2004; Scholz et al., 2004).

\section{Seawater ${ }^{234} U /{ }^{238} U$}

Both screening and correction approaches in U-series coral dating make an assumption about the initial ${ }^{234} \mathrm{U} / 238 \mathrm{U}$ of the coral, which is most often assumed to be similar to that of modern seawater. The validity of this assumption has some support from modeling of ocean ${ }^{234} \mathrm{U}$ residence times (Richter and Turekian, 1993), and data from aragonitic sediments suggest little evidence of a large long-term change over the last 800 ka (Henderson, 2002). In contrast, there is convincing evidence from initial ${ }^{234} U /{ }^{238} \mathrm{U}$ in corals that ocean ${ }^{234} \mathrm{U} /{ }^{238} \mathrm{U}$ was as much as $7 \%$ o lower during the last glacial period (e.g., Hughen et al., 2004). Although corals are not ideal archives of ocean ${ }^{234} \mathrm{U} / 238 \mathrm{U}$ because of open-system effects, information about past seawater ${ }^{234} \mathrm{U} /{ }^{238} \mathrm{U}$ may be gleaned from an isotope ratio diagram. The dominant trend, lying for the most part above the closed-system curve (Fig. 1), suggests that most corals appear to have gained both ${ }^{234} \mathrm{U}$ and ${ }^{230} \mathrm{Th}$, although the possibility of ${ }^{234} \mathrm{U}$ and ${ }^{230} \mathrm{Th}$ loss cannot be rigorously ruled out. Thus, the lower bounds of the data array may indicate the unaltered compositions defining seawater ${ }^{234} \mathrm{U} /{ }^{238} \mathrm{U}$ for a specific time period (e.g., Andersen et al., 2008), regardless of the specific alteration mechanism. For coral dating, any difference between the assumed and actual initial ${ }^{234} \mathrm{U} /{ }^{238} \mathrm{U}$ will produce a systematic offset from the true age for corals selected as "reliable" using screening criteria, and a similar offset for ages calculated using a correction approach. The sensitivity of ages to assumptions about initial ${ }^{234} \mathrm{U} /{ }^{238} \mathrm{U}$ can be directly 
assessed. For example, for an age of 125 ka the sensitivity is about 400 years/\%o so that a difference of $5 \%$ o between assumed and initial ${ }^{234} \mathrm{U} /{ }^{238} \mathrm{U}$ would produce an offset of approx. 2 ka (e.g., Thompson et al., 2003).

\section{Error estimation and model- dependent sensitivities}

Best practices for propagating measurement uncertainty are fairly well established, so that this source of age error is generally well quantified. However, all approaches to coral dating have inherent assumptions that, if violated, result in an erroneous age. Screened ages are only valid if the system has indeed remained closed. Corrected ages are accurate if, and only if, the processes producing the anomalies are those assumed by the applied model. If these sources of uncertainty are not addressed, errors will be generally underestimated. For example, the screening approach has traditionally used a range of initial ${ }^{234} \mathrm{U} / 238 \mathrm{U}$ around the modern seawater value to define "acceptable" ages. The range of acceptable values chosen is a source of error for the selected ages (Gallup et al., 1994). This uncertainty has an identical scaling to that introduced by

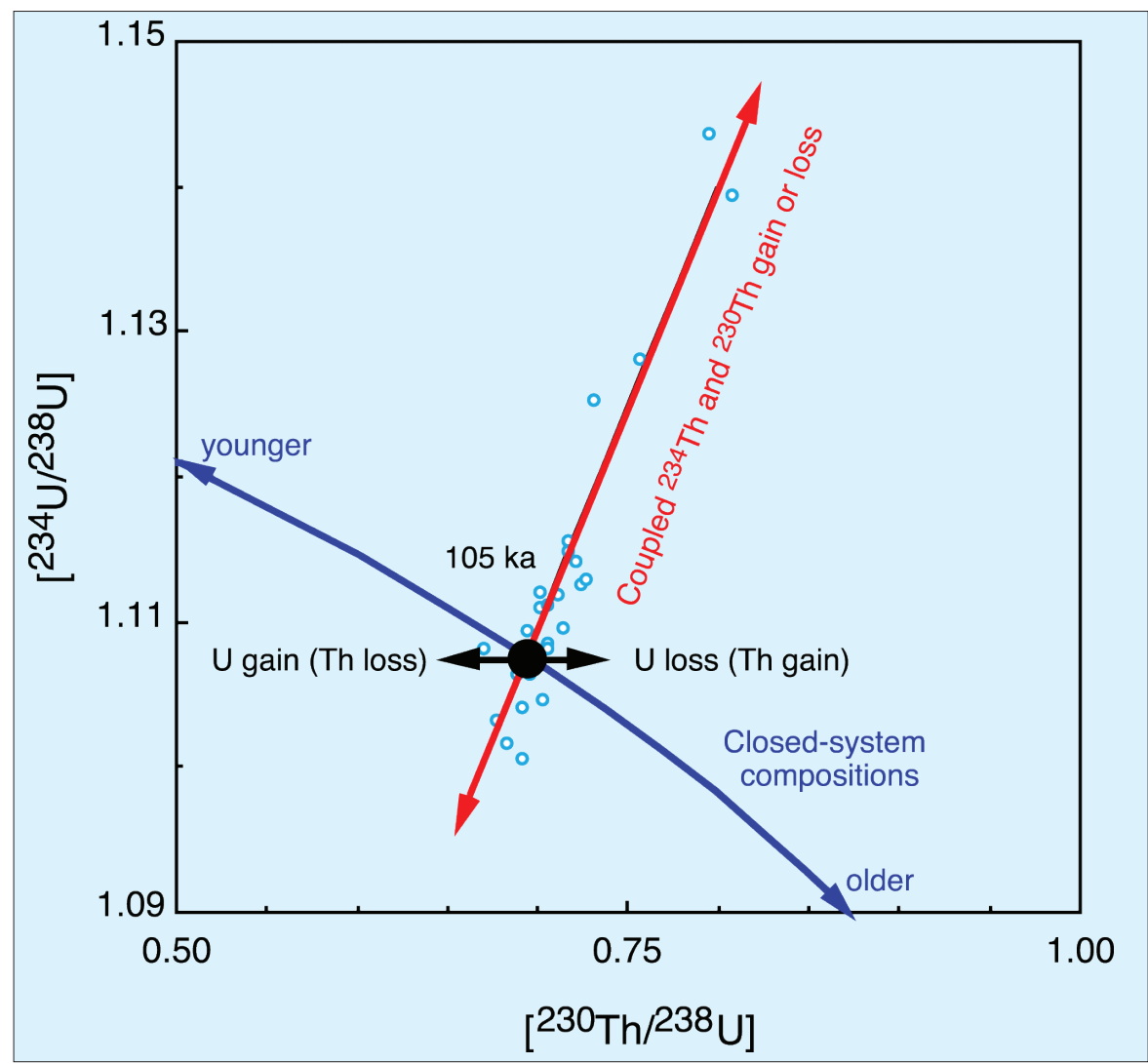

Figure 1: U/Th activity ratio diagram illustrating the major processes affecting U-series dating of older corals. The blue arc represents the range of closed-system isotopic compositions expected for corals that are approx. 65 to $165 \mathrm{ka}$ and have evolved from a modern seawater uranium isotope composition. Each point along this arc corresponds to a unique U/Th age. The large black circle is the expected isotopic composition of a coral that is $105 \mathrm{ka}$ old. The adsorption/loss of decay-produced ${ }^{234} \mathrm{Th}$ and ${ }^{230} \mathrm{Th}$ from/to the surrounding carbonate matrix will produce a range of composition in the direction of the red arrows. U or Th gain or loss will produce a range of compositions in the direction of the black arrows. The open blue circles are isotopic compositions of a suite of corals collected from the MIS 5c terrace on Barbados, West Indies, which should all be near $105 \mathrm{ka}$ in age. The changes in isotopic composition due to these processes are a significant source of age error.

\section{Stratigraphic context}

Given the high potential for age artifacts imposed by open-system effects, any independent constraints on true age are very helpful. Fundamental stratigraphic constraints are currently underutilized in coral dating. Although coral reefs are not simple layer-cake constructs, and models of reef development can be quite complex, the fundamental laws of stratigraphy are not suspended. Any given coral cannot be older than the substrate on which it grows. Detailed transects of vertical sections with large numbers of dated corals afford the opportunity to test the ages obtained against stratigraphic context. Age population statistics of corals that are closely associated within a discrete and well-defined stratigraphic unit provide useful information. The scatter in such ages is the sum of differences in true age, the scatter due to open-system effects, and measurement uncertainty. Analytical uncertainties are known, and scatter due to open-system effects can be estimated with replicate measurements of individual corals, yielding a first-order estimate of differences in true age.

\section{Standardizing age and error conventions}

Although screening criteria and correction approaches improve age accuracy, neither provides a guarantee of accuracy. The potential for significant artifacts in older coral ages due to the failure of underlying assumptions remains a major area of controversy in the $\mathrm{U}$-series dating community. The challenge going forward is to establish uniform practices for the reporting of coral age results, so that reported ages and uncertainties are directly comparable. It would be very helpful to establish agreed upon values for initial ${ }^{234} \mathrm{U} / 238 \mathrm{U}$ and estimates of the associated uncertainty, taking into account evidence for changes through time. The uncertainty in initial ${ }^{234} \mathrm{U} /{ }^{238} \mathrm{U}$ could be formally included in the age error, making the reported ages and their errors more readily comparable. In addition, all reporting of $\mathrm{U} / \mathrm{Th}$ coral ages should include a statement about the sensitivity of the ages to open-system behavior, indicating worst-case scenarios calculated for the specific set of screening criteria and age model assumptions used. Replicate ages from discrete pieces of individual corals and stratigraphic constraints are very useful for objective assessment of the maximum obtainable age accuracy. Although dating older corals remains a significant challenge, improved analytical precision and better understanding of open-system effects promise renewed 
progress in our effort to document sea level changes during earlier glacial cycles.

\section{References}

Andersen, M.B., Stirling, C.H., Potter, E.-K., Halliday, A.N., Blake, S.G., McCulloch, M.T., Ayling, B.F. and O'Leary, M. 2008: High-precision U-series measurements of more than 500,000 year old fossil corals, Earth and Planetary Science Letters, 265: 229-245.
Gallup, C.D., Edwards, R.L. and Johnson, R.G. 1994: The timing of high sea levels over the past 200,000 years, Science, 263: 796-800.

Potter, E.-K., Esat, T.M., Schellmann, G., Radtke, U., Lambeck, K. and McCulloch, M.T. 2004: Suborbital-period sea-level oscillations during marine isotope substages $5 \mathrm{a}$ and $5 \mathrm{c}$, Earth and Planetary Science Letters, 225(1-2): 191-204.

Scholz, D. and Mangini, A. 2007: How precise are U-series coral ages? Geochimica et Cosmochimica Acta, 71: 1935-1948.
Thompson, W.G., Spiegelman, M.W., Goldstein, S.L. and Speed, R.C. 2003: An open-system model for the U-series age determinations of fossil corals, Earth and Planetary Science Letters, 210: 365-381.

For full references please consult:

www.pages-igbp.org/products/newsletters/ref2009_2.html

\section{Using models to inform the field community: Far-field sea level data applications}

Glenn A. Milne

Department of Earth Sciences, University of Ottawa, Canada; gamilne@uottawa.ca

\section{Far-field sea level data contain information on past global ice volume and the source distribution of meltwater pulses. To extract this information in an accurate and effective manner requires site selection that is informed by model output.}

When ice sheets and glaciers exchange mass with the oceans, the resulting sea level response is spatially variable due to the influence of the mass redistribution on the solid Earth and the gravity field (Farrell and Clark, 1976). The spatial and temporal variability in the sea level response reflect the evolution of grounded ice, as well as the physical structure and properties of the Earth's interior. Observations of this response can therefore be inverted to infer information on past ice sheet evolution and solid Earth structure. This inversion procedure generally requires the use of a model that relates the relevant model parameters (ice evolution and solid Earth properties) to the observable quantity (sea level). In this short paper, the process of using far-field sea level observations (i.e., those distant from major glaciation centers) to constrain the past evolution of ice sheets is reviewed. Emphasis is placed on two recent papers that use model predictions to determine optimal locations to solve a particular problem (Clark et al., 2002; Milne and Mitrovica, 2008). In doing so, these studies promote a two-way dialog between the observational and modeling communities that is necessary for efficient progress in solving outstanding problems.

\section{Inferring past global ice volume}

A classic application of far-field sea level data is the inference of past global ice volume through estimates of eustatic sea level (e.g., Fleming et al., 1998). This is the component of sea level change associated with a raising or lowering of ocean surface height through mass exchange with the cryosphere, and is calculated by simply dividing the volume of grounded ice gain/ loss by the area of the ocean (and multiplying by the density ratio of ice to water to account for the volume change in the phase transition). This procedure has been ap- plied to infer past global ice volume at different times. For example, measurements of the sea level lowstand during the Last Glacial Maximum (LGM) have been used to infer the magnitude of grounded ice volume at that time (e.g., Yokoyama et al., 2000). Another important application is the use of sea level observations in the mid- to late-Holocene to infer ice volume changes prior to the industrial era (e.g., Nakada and Lambeck, 1989), as a reference of natural variability in the system.

Accurate application of this procedure is complicated by the fact that, even in farfield locations, the actual (observable) sea level change deviates significantly from the eustatic component of the change due to isostatic and tectonic processes (e.g., Clark et al., 1978). For this reason, even observations from tectonically stable areas must be corrected for isostatic effects before being used to infer a paleo ice volume (e.g., Milne et al., 2002). This correction procedure is based on a model and so is subject to some degree of error that depends on the accuracy of the model prediction at a given locality. The error can be minimized by choosing locations where: (1) sea level is close to the eustatic value, so as to limit the magnitude of the correction, and/or (2) the correction to be applied is relatively insensitive to uncertainties in ice/Earth model parameters. Milne and Mitrovica (2008) carried out a model sensitivity study to map

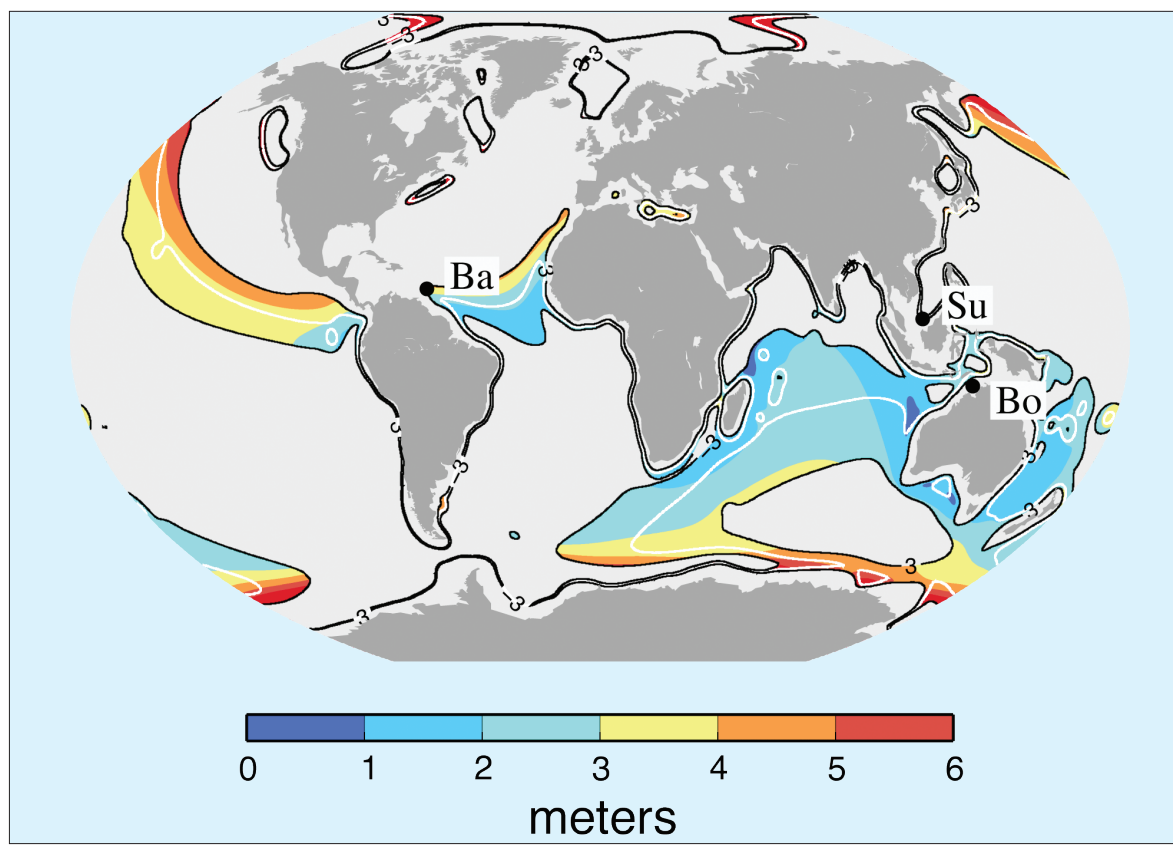

Figure 1: Output for a large suite of model runs based on a single ice model and 162 Earth viscosity models. Results are shown for the Last Glacial Maximum (LGM; 21 cal ka BP). White contours indicate where the (mean) predicted sea level is equal to (mean) eustatic sea level. Black contours indicate where these values deviate by $\pm 3 \mathrm{~m}$ (deviations $>3 \mathrm{~m}$ are masked by the light-gray shading). Colored contours show standard deviation of the predictions due to changes in Earth viscosity structure. Values of low standard deviation (blue colors) indicate where model predictions are insensitive to variations in Earth viscosity structure. Optimal localities for measuring sea level to estimate past ice volume are where the predicted sea level is close to the eustatic value (i.e., near the white contour) and the standard deviation is low (i.e., blue colors). Three locations where LGM sea levels have been measured are shown: Barbados (Ba), Bonaparte Gulf (Bo) and Sunda Shelf (Su). See Milne and Mitrovica (2008) for more details. 
out where these criteria are best satisfied. Figure 1 shows these results for the LGM. Similar maps were developed for a number of times from the LGM to the late Holocene. In principle, maps like that shown in Figure 1 can be generated for older times (e.g., last interglacial). However, the relatively poor constraints on global ice-evolution prior to the LGM will likely be a limiting factor in generating accurate maps for this earlier period.

\section{Inferring distribution of rapid ice mass loss during meltwater pulses}

Departures from eustasy complicate the extraction of an ice-volume signal from far-field sea level data. On the other hand, these departures contain the information required to infer the geometry of melt sources during periods of rapid sea level rise. This method, known as "sea level fingerprinting", is particularly powerful in farfield areas, as the spatial variability is dominated by gravitational changes that can be computed with a high degree of accuracy.

Successful application of the fingerprinting technique depends on the precision and distribution of data that capture a given melt event. Clark et al. (2002) applied the fingerprinting technique using data at Barbados (Fairbanks, 1989; Bard et al., 1990) and Sunda Shelf (Southeast Asia; Hanebuth et al., 2000) to consider which ice sheets were responsible for the $\sim 20 \mathrm{~m}$ rise in sea level between 14.5 and 14 cal ka BP (known as meltwater pulse IA - mwp-IA). Because of the limited number of data sets at their disposal, a unique solution was not found. However, the authors were able to rule out a southern Laurentide source since the predicted rise at Sunda is $40 \%$ larger compared to Barbados and the observed rise is of similar magnitude at each location. They went on to demonstrate that these two data sites are compatible with a number of source distribution scenarios and presented a figure (reproduced here as Fig. 2) to illustrate which melt scenarios are compatible with the available data constraints (from Barbados and Sunda). This figure also shows how data from other locations could add information to help solve the problem. For example, data from the Argentine shelf would prove highly effective in testing a scenario that included a dominant Antarctic source because the predicted rise at this site is significantly lower compared to the other sites considered for each of the three Antarctic source scenarios.

Determining the ice sheet(s) responsible for mwp-IA remains an outstanding problem that will require improved data control in both far- and near-field locations before a robust solution can be found.

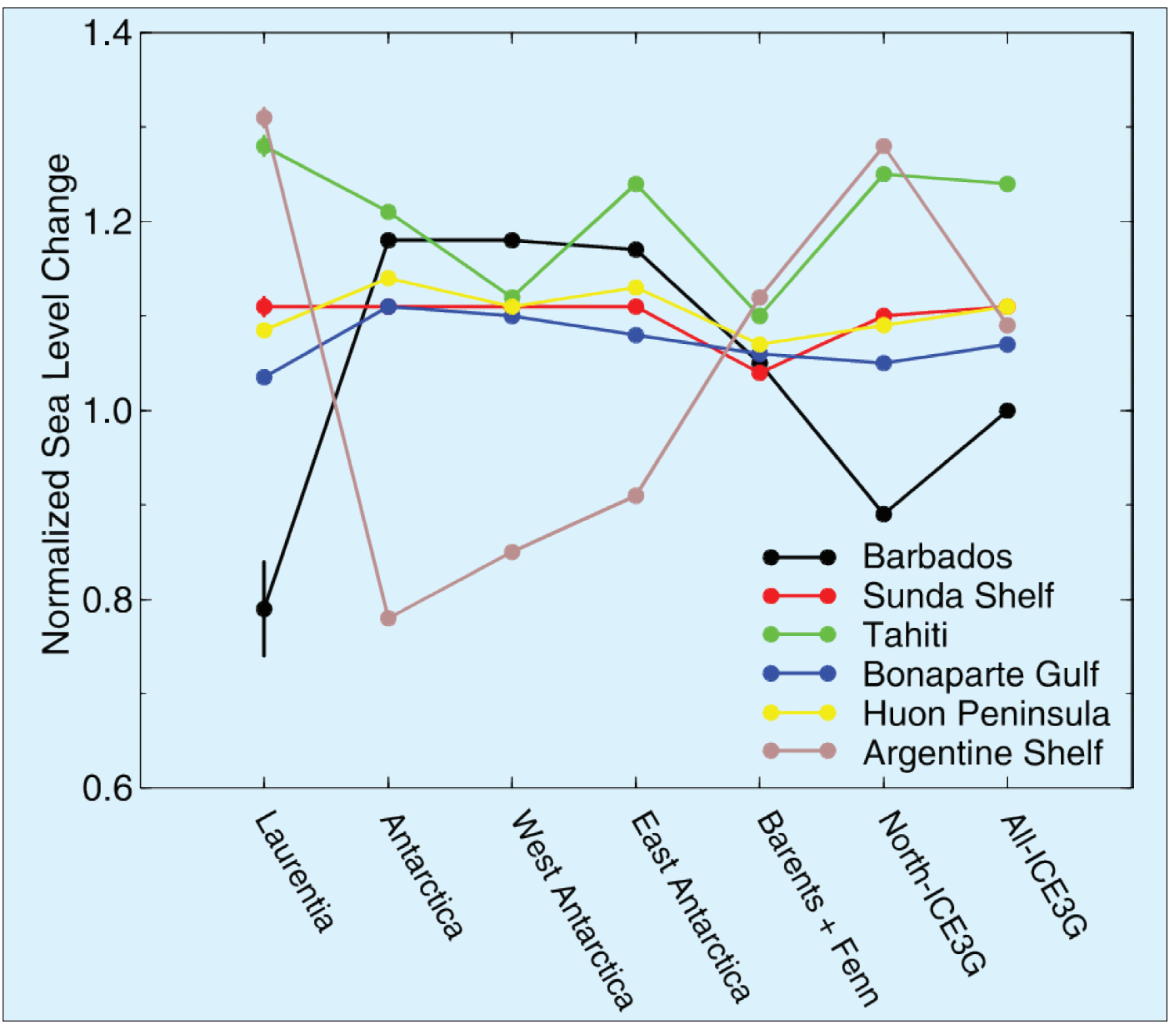

Figure 2: Sea level predicted at 6 sites (color-coded) for 7 distinct melt source scenarios ( $x$-axis). Each line shows the sea level rise predicted at a given location for the 7 source scenarios considered. This information can be used to choose sites that would be effective in better constraining the melt-source distribution of meltwater pulse IA. Good sites for discriminating between different scenarios are those that exhibit a large difference in predicted rise compared to other sites. For example, precise data from the Argentine Shelf would provide a powerful test of an Antarctic source scenario. Note, the predicted rise has been divided by the model eustatic value so that the results can be applied to fingerprint any rapid melt event regardless of magnitude. For example, an event of ice volume loss equivalent to $10 \mathrm{~m}$ eustatic rise would result in a sea level rise of $\sim 8 \mathrm{~m}$ (i.e., $~ 80 \%$ of the eustatic value) at the Argentine Shelffor an Antarctic source. See Clark et al. (2002) for more details.

Meltwater pulses demonstrate that ice sheets can lose a large amount of mass over only a few centuries (rates of change on the order of meters per century). What is the possibility of such events occurring in the future? An event like mwp-IA, with magnitude $\sim 20 \mathrm{~m}$, can be ruled out given that this event occurred during a time of near peak glaciation when a large volume of ice was grounded on shallow continental shelf (and therefore highly sensitive to climate change). However, it is less clear if rates of change similar to those produced during these extreme past events can be reproduced in the future given the current configuration of ice sheets. One way to address this question is to first better understand the forcing and responses that produced meltwater pulses. Once the source distribution is constrained, appropriate regional data and models can be applied to consider the most likely forcing and response mechanisms. Reproducing events like mwp-IA will certainly be a challenge for the current generation of glaciological models particularly if it was sourced primarily, from a single ice sheet.

\section{Summary}

Proxy sea level observations contain important information on how the cryosphere has responded to past climate change. In- terpretation of the paleo sea level record for this purpose is non-trivial due to the spatial complexity in the sea level response to land ice change. As a consequence, the use of a sea level model is required to obtain a robust inversion of sea level data, even at locations distant from the major glaciation centers. As illustrated above, the locations of data sites are crucial to arrive at well-constrained solutions to a given problem. The use of sea level models to identify optimal sites is a powerful way to focus future field initiatives so that robust solutions can be found in an efficient manner.

\section{References}

Clark, J.A., Farrell, W.E. and Peltier, W.R., 1978: Global changes in postglacial sea level: a numerical calculation, Quaternary Research, 9: 265-287.

Clark, P.U., Mitrovica, J.X., Milne, G.A. and Tamisiea, M., 2002: Sea-level fingerprinting as a direct test for the source of global meltwater pulse 1A, Science, 295: 2438-2441.

Farrell, W.E. and Clark, J.A., 1976: On postglacial sea-level, Geophysical Journal of the Royal Astronomical Society, 46: 647-667.

Fleming, K., Johnston, P., Zwartz, D., Yokoyama, Y., Lambeck, K. and Chappell, J., 1998: Refining the eustatic sea-level curve since the Last Glacial Maximum using far- and intermediate-field sites, Earth and Planetary Science Letters, 163(1-4): 327-342.

Milne, G.A. and Mitrovica, J.X., 2008: Searching for eustasy in deglacial sea-level histories, Quaternary Science Reviews, 27: 2292-2302.

For full references please consult:

www.pages-igbp.org/products/newsletters/ref2009_2.html 


\title{
PLIOMAX: Pliocene maximum sea level project
}

\author{
Maureen E. Raymo ${ }^{1}$, P. Hearty ${ }^{2}$, R. De Conto ${ }^{3}$, M. O'Leary ${ }^{4}$, H.J. Dowsett ${ }^{5}$, M.M. Robinson ${ }^{5}$ and J.X. Mitrovica ${ }^{6}$ \\ 'Department of Earth Sciences, Boston University, Massachusetts, USA; raymo@bu.edu \\ ²Bald Head Island Conservancy and Department of Environmental Studies, University of North Carolina, USA; ${ }^{3}$ Department of Geosciences, \\ University of Massachusetts-Amherst, USA; ${ }^{4}$ Department of Environmental and Geographical Sciences, Manchester Metropolitan University, UK; \\ ${ }^{5}$ U.S. Geological Survey, Reston Virginia, USA; ${ }^{\circ}$ Department of Physics, University of Toronto, Canada
}

\section{Accurate estimates of mid-Pliocene sea levels are necessary if we are to better constrain Greenland and Antarctic ice sheet stability in a warmer world.}

The mid-Pliocene climate optimum (3.3$2.9 \mathrm{Ma}$ ) provides both a natural analog and a testing ground for General Circulation Models (GCMs) used for prediction of global warming. However, the value of such model experiments is governed by the quality of available paleoclimate data, and no more important metric of global climate exists than polar ice volume. Estimates of mid-Pliocene sea level range from $+5 \mathrm{~m}$ to $>+40 \mathrm{~m}("+$ " represents the elevation of sea level relative to present) reflecting a huge range of uncertainty in the sensitivity of polar ice sheets, including the East Antarctic Ice Sheet (EAIS), to a modest global warming. It is the aim of the PLIOMAX project to reduce the level of uncertainty in Pliocene ice-volume estimates by undertaking a field geology program in Australia and engaging, in part through a web-based collaborative, a larger community of geoscientists in surveys of similar high-stand deposits around the world. Determination of the maximum mid-Pliocene sea level rise will allow climate modelers to better assess the level at which atmospheric $\mathrm{CO}_{2}$ concentrations might lead to significant melting of the Greenland Ice Sheet, West Antarctic Ice Sheet (WAIS), and EAIS.

\section{The mid-Pliocene warm period}

The scientific community relies heavily on the predictive capabilities of GCMs (IPCC, 2007) to assess likely future warming scenarios, however, the results of these models can vary greatly between groups, especially in their ability to model different components of the climate system. To address this problem of knowing which models are best, the modeling community puts significant effort into calibrating models against known past climate changes. In particular, many GCM experiments, including the UKMO-GCM (Haywood and Valdes, 2004), the GISS-GCM (Chandler et al., 1994), and the NCAR-Genesis GCM (Sloan et al., 1996) among others, have focused on the mid-Pliocene "climate optimum". This period was the most recent time that Earth's climate was consistently, and for an extended period of time, warmer than the Holocene; with global temperatures elevated by as much as $3^{\circ} \mathrm{C}$ with respect to modern values (Fig. 1; Ravello et al., 2004; Dowsett, 2007). Proxy $\mathrm{pCO}_{2}$ studies, based on techniques that still excite debate, estimate that atmospheric $\mathrm{CO}_{2}$ levels at this time ranged between 350 and 400 ppm, a maximum value that will soon be exceeded. However, the geoscience community has yet to provide an accurate estimate of one critical climate boundary condition and diagnostic of climate sensitivity, namely, the maximum sea level rise, or global ice volume, at this time. Without a firm knowledge of this important parameter, model validation efforts will be doomed to uncertainty.

Why is so little known of the midPliocene sea level, a metric that speaks directly to the stability of the Greenland and Antarctic Ice Sheets (East and West) in the face of a modest warming, and probable $\mathrm{CO}_{2}$ increase, relative to the preindustrial Holocene? Paleoceanographers face difficulties in accurately constraining ice volumes using the deep-sea geochemical records, due to the confounding effects of salinity, temperature, vital effects (i.e., species specific characteristics that can influence isotopic fractionation in foraminiferal shells) and carbonate diagenesis on very small isotopic and trace element signals. More direct field-based estimates of paleo sea level utilize fundamental principles of geomorphology, superposition, and morphostratigraphic succession, combined with absolute geochronological dating of the deposits. The most classic of such studies comes from a raised coastal terrace, the Orangeburg Scarp, located on the coastal margin of southeast USA. After correcting for post-depositional uplift, Dowsett and Cronin (1990) estimate a mid-Pliocene sea level rise of $+35 \pm 18 \mathrm{~m}$. Similar studies of the north and western margin of Alaska resulted in an estimate of $+40 \mathrm{~m}$ (Brigham-Grette and Carter, 1992; Kaufman and Brigham-Grette, 1993). A third classic study of Pliocene sea level, based on coring of a subsiding Pacific atoll, estimated +25 m (Wardlaw and Quinn, 1991). Finally, a few studies of Pliocene sea level have been made based on submarine and subaerially exposed shallow marine deposits. Miller et al. (2005) get a much lower estimate of Pliocene sea level, $+5 \mathrm{~m}$, while

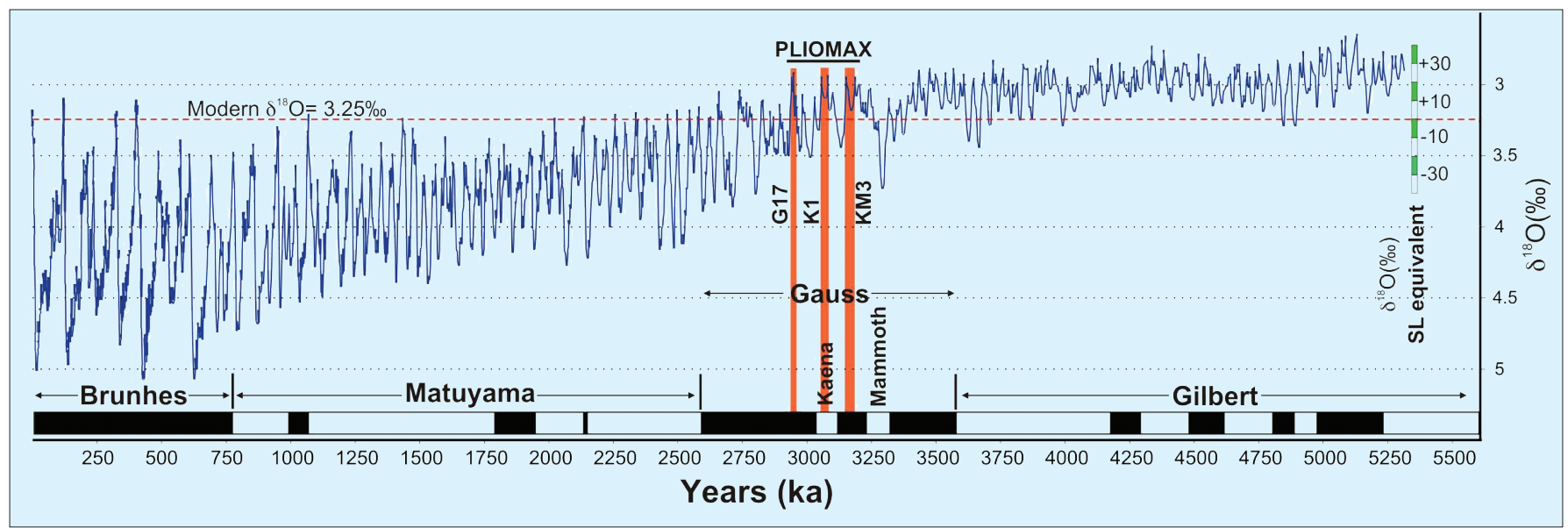

Figure 1: Ice-volume record for the Plio-Pleistocene using the LR04 benthic $\delta^{18} \mathrm{O}$ stack and timescale (Lisiecki and Raymo, 2005). Geomagnetic reversal stratigraphy is shown above the X-axis. PLIOMAX will target three super-interglacial events, G17, K1 and KM3 (orange bars) that are well constrained by magneto- and biostratigraphy. Oxygen isotope inferred sea level changes, assuming no temperature, salinity, diagenetic, or vital effect overprints are shown on the scale on the right. 
Naish and Wilson (2009) estimated sea level oscillations between +10 and $+30 \mathrm{~m}$ during the mid-Pliocene. Although these sea level estimates are highly variable with large uncertainties, most imply partial or complete deglaciation of Greenland and the WAIS and significant drawdown of the EAIS.

\section{Modeling Pliocene ice sheets}

Geologic estimates of maximum Pliocene sea level thus range from +5 to +40 m relative to present, with $+25 \mathrm{~m}$ typically used by the modeling community. In a recent simulation of Antarctic ice spanning the last $5 \mathrm{Ma}$ and using a new ice sheet model with realistic ice shelves and migrating grounding lines (Pollard and DeConto, 2009), the WAIS exhibited highly dynamic behavior, with dramatic retreats during a number of late Pliocene and Pleistocene Antarctic "super-interglacials". The present ice configuration (Fig. 2a) was compared with the smallest Antarctic ice volume obtained in the 5 Ma simulation (Fig. 2b), which is equivalent to $\sim 7 \mathrm{~m}$ of sea level that, if coeval with full Greenland deglaciation, would give a maximum sea level rise of $14 \mathrm{~m}$. In these simulations, most of the ice loss in Antarctica was from the marinebased WAIS and was mainly caused by increased sub-ice ocean melt rather than sea level rise or surface melt. Additional ice loss from Antarctica would require significant surface melt over the flanks of the terrestrial ice sheet, which may be underestimated in the simple parameterized climate used to drive the ice model, especially during the overall warmth of the Pliocene.

GCM and higher resolution regional climate model simulations over the Antarctic region at increasing levels of atmospheric $\mathrm{CO}_{2}$ (400 ppmv) and with warm austral summer orbits, so far fail to produce surface air temperatures capable of producing significant surface melt (R. DeConto, unpublished work in progress). Taken together with the results shown in Figure $2 \mathrm{~b}$, one may conclude that: a) Pliocene $\mathrm{CO}_{2}$ or levels of other greenhouse gases may be underestimated; $b$ ) the sensitivity of the GCM to $\mathrm{CO}_{2}$ is far too low (especially over the poles); $c$ ) the ice sheet model does not adequately represent some of the important underlying physics (e.g., sub-glacial hydrology); d) most sea level estimates for this time period, including the $+25 \mathrm{~m}$ average cited by many investigators, are too high, or e) some combination of the above. Note that an added complexity in paleo sea level reconstructions results from the tectonic displacement of or iceloading deflections of the original shoreline position, which can cause significant departures of observed sea level change from the eustatic (global changes in sea level due to water mass added or removed from the oceans) rise or fall due solely to the ice volume change (e.g., Moucha et al., 2008; Milne and Mitrovica, 2008).

\section{Summary}

A coordinated multidisciplinary approach to the problem of Pliocene sea level is needed; one that combines additional field studies with climate modeling and geophysical modeling of the mantle and crustal response to ice sheet loading. We hope the knowledge gained during our upcoming field expedition to Australia will contribute to narrowing the range of midPliocene sea level estimates and that parallel modeling efforts will guide and inform not only our investigations but also those in other regions of the world. Warming of the current climate system is unequivocal. The most conservative estimates suggest a further $1-2^{\circ} \mathrm{C}$ of global temperature rise can be expected, even if massive reductions in greenhouse gas emissions were to occur. It is because climate is locked into this temperature trajectory, at least in the near-term, that understanding climate and ice sheet dynamics under warmer conditions takes on added urgency. A robust estimate of eustatic sea level change during the mid-Pliocene warm period will provide an important target for the GCM climate modeling community actively engaged in experiments on this time period.

\section{References}

Chandler, M., Rind, D. and Thompson, R., 1994: Joint investigations of the Middle Pliocene climate II: GISS GCM Northern Hemisphere results, Global Planetary Change, 9: 197-219.

Dowsett, H.J., 2007: The PRISM Palaeoclimate Reconstruction and Pliocene Sea-Surface Temperature. In: M. Williams, et al. (Eds) Deep-time perspectives on climate change: marrying the signal from computer models and biological proxies, The Micropalaeontological Society Special Publications, The Geological Society of London.

Haywood, A.M. and Valdes, P.J., 2004: Modelling Middle Pliocene warmth: contribution of atmosphere, oceans and cryosphere, Earth Planetary Science Letters, 218: 363-377.

Lisiecki, L.E. and Raymo, M.E., 2005: A Pliocene-Pleistocene stack of 57 globally distributed benthic ${ }^{180} 0$ records, Paleoceanography, 20 PA1003, doi:10.1029/2004PA001071.

Pollard, D. and DeConto, R.M., 2009: Modeling West Antarctic Ice Sheet growth and collapse through the last 5 million years, Nature, 458: $329-332$

For full references please consult:

www.pages-igbp.org/products/newsletters/ref2009_2.html
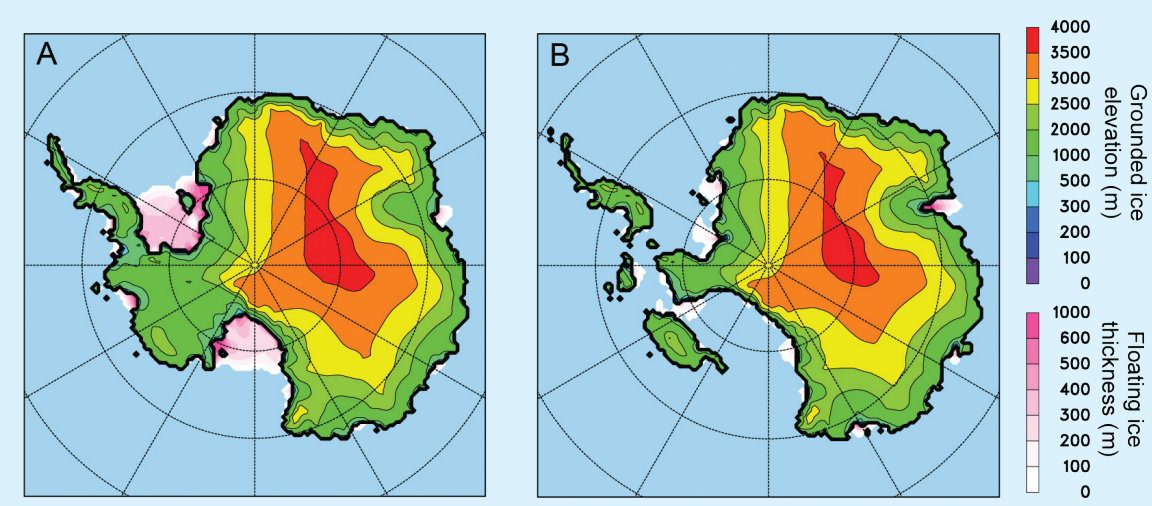

Figure 2: Ice elevations (grounded) and ice thickness (floating) in meters, for present day (A) and during a Pliocene interglacial (B) as simulated by an ice sheet-shelf model (Pollard and DeConto, 2009). The model is driven by a parameterized climatology and oceanic sub-ice melt rates derived from deep-sea core isotope records (Lisiecki and Raymo, 2005) and local insolation. The loss of ice in B is equivalent to $\sim 7 \mathrm{~m}$ of sea level rise, far less than that required to account for some Pliocene sea level estimates. 


\section{The dimensions of the Greenland Ice Sheet since the Last Glacial Maximum}

Meredith A. Kelly ${ }^{1}$ and Antony J. Long ${ }^{2}$

'Department of Earth Sciences, Dartmouth College, Hanover, USA; Meredith.A.Kelly@Dartmouth.edu

2Department of Geography, Durham University, UK

\section{The Greenland Ice Sheet survived the warming of the last deglaciation but nonetheless has experienced significant changes in size since the Last Glacial Maximum, thus contributing to global sea level change.}

The Greenland Ice Sheet (Fig. 1) is the only remaining Northern Hemisphere ice sheet that survived the climate warming following the Last Glacial Maximum (LGM; $\sim 22-19 \mathrm{ka}$ ). Nonetheless, it suffered significant changes in size during and since the last deglaciation and has thus made important contributions to global sea level change. A chronology of post-LGM ice sheet extent is important to our understanding of Greenland's contribution to global sea level changes and provides a target against which ice sheet models can be tested (e.g., Tarasov and Peltier, 2002; Fleming and Lambeck, 2004). A long-term

record of Greenland Ice Sheet extent also establishes a baseline for comparison with modern changes, thus yielding insights into the response of the ice sheet over various timescales. Here, we present a brief summary of Greenland Ice Sheet extent during the LGM, deglaciation and the Holocene, highlighting recent research and indicating where data are lacking.

\section{The Greenland Ice Sheet during the LGM and last deglaciation}

During the LGM, in most locations the Greenland Ice Sheet extended offshore, at least onto the continental shelf (Funder,

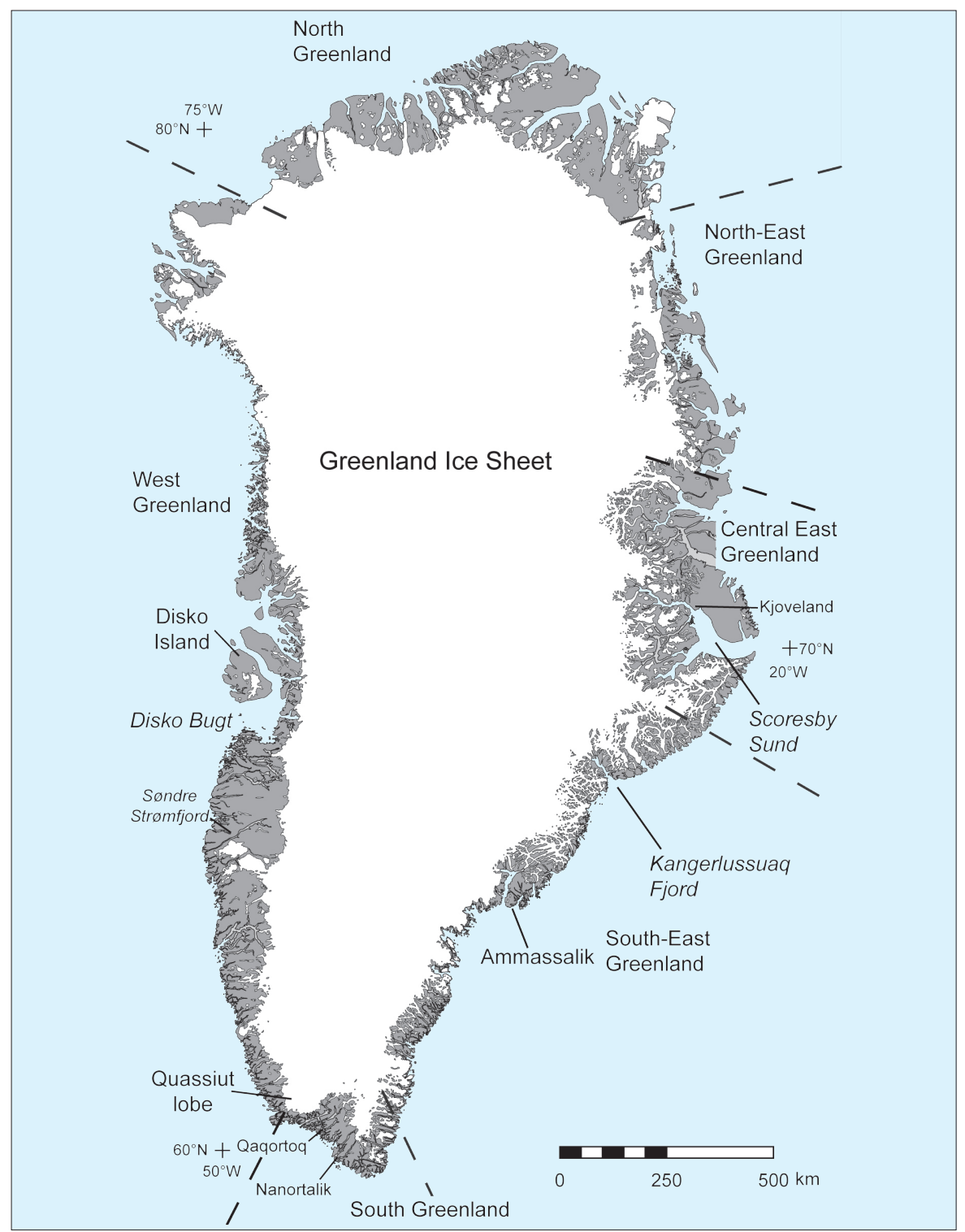

Figure 1: Map of Greenland showing the modern ice sheet extent and locations discussed in the text. Geographical divisions are generally following the Geological Survey of Denmark and Greenland (Dawes and Glendal, 2007). Also shown is Kjoveland, the location of the photo in Figure 2.
1989; Bennike and Björck, 2002). Some debate as to the LGM ice extent exists in locations such as South, Central East and North-East Greenland (e.g., Funder and Hansen, 1996; Bennike and Björck, 2002). However, recent research applying AMS radiocarbon and surface-exposure $\left({ }^{10} \mathrm{Be}\right.$ and ${ }^{26} \mathrm{Al}$ ) dating, as well as ice sheet modeling in South, South-East, Central East and North-East Greenland, indicates that the LGM ice sheet was thick and extended well offshore (Bennike et al., 2002; O'Cofaigh et al., 2004; Roberts et al., 2008; Long et al., 2008; Håkansson et al., 2007a; 2007b).

A few studies register the onset of deglaciation from the LGM extent in offshore areas. For example, radiocarbon ages on foraminifera extracted from sea bed cores from the continental margin off Kangerlussuaq Fjord (South-East Greenland; Fig. 1) show that the ice margin here had begun retreat by $\sim 15$ ka (Meinert et al., 1992). Further data of this type are needed to improve our understanding of the onset of ice margin retreat in other areas, as are surface-exposure ages of ice recession from upper LGM elevations in terrestrial settings (e.g., Rinterknecht et al., 2008). Such data would significantly improve our understanding of the climatic and glaciological conditions that influenced initial deglaciation.

Bennike and Björck (2002) provide a compilation of radiocarbon ages that constrain the timing of ice sheet recession to the present coastline subsequent to the LGM. Most of these radiocarbon ages are on shells from within raised marine deposits and thus afford minimum-limiting ages of local ice margin retreat. Bennike and Björck (2002) suggested that, in all locations except for in South Greenland, ice sheet retreat across the present coastline did not occur until the early Holocene.

Recent terrestrial research in South, South-East and Central East Greenland provides further constraints on the timing of deglaciation to the present coastline. Radiocarbon ages of relative sea level change in the Qaqortoq and Nanortalik areas of South Greenland indicate ice sheet recession by $\sim 11.0 \mathrm{ka}$ and $13.8 \mathrm{ka}$, respectively (Bennike et al., 2002; Sparrenbom et al., 2006a; 2006b). Two recent studies 
using terrestrial data provide the timing of deglaciation in South-East Greenland. Roberts et al. (2008) and Long et al. (2008) report ${ }^{10} \mathrm{Be},{ }^{26} \mathrm{Al}$ and radiocarbon ages from near Ammassalik that date the time of deglaciation in fjords at $\sim 9.9-9.7 \mathrm{ka}$, both at sea level and at higher elevations. Based on the similarity of ages at low and high elevations, the authors suggest that surface ablation controlled rapid deglaciation and ice margin recession. In the Scoresby Sund region (Central East Greenland), radiocarbon and ${ }^{10} \mathrm{Be}$ ages indicate that readvances of Greenland Ice Sheet outlets and mountain glaciers, known as the Milne Land Stages (Funder, 1978), began during late glacial time ( 15-11.5 ka) (Hall et al., 2008a; Kelly et al., 2008). These results imply that at least the outer fjord area of Scoresby Sund was ice free prior to late glacial time.

\section{Late glacial \& early Holocene ice sheet readvances and stand-stills}

There is direct chronologic evidence for late glacial readvances of the Greenland Ice Sheet in only one location; central East Greenland. As mentioned above, ice sheet outlets and mountain glaciers in the Scoresby Sund region readvanced during the Milne Land Stages (Funder, 1978). Although some studies suggest that the Milne Land Stages occurred during Preboreal time ( 11.5-10.2 ka) (e.g., Funder and Hansen, 1996), new AMS radiocarbon and ${ }^{10} \mathrm{Be}$ ages suggest that the outer Milne Land Stage moraines were deposited prior to or during the Younger Dryas ( 12.8 $11.5 \mathrm{ka})$, with the inner Milne Land Stage moraines formed during the Preboreal (Hall et al., 2008a; Kelly et al., 2008). Thus, these moraines constrain the ice sheet extent during the Younger Dryas, likely reflecting a response of the ice sheet margin to the late glacial climatic reversal. Other moraines marking ice sheet readvances have been correlated with the Milne Land

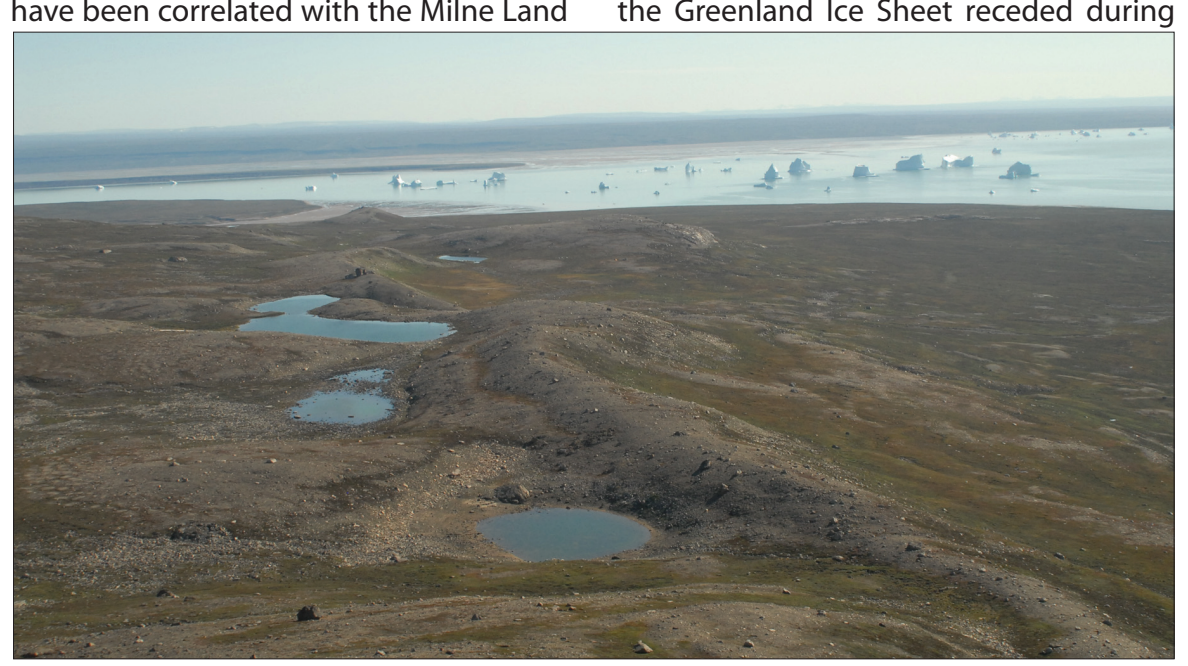

Figure 2: Milne Land stage (left lateral) moraines deposited by a Greenland Ice Sheet outlet glacier prior to or during the Younger Dryas in the Scoresby Sund region of Central East Greenland. View to the east over Kjoveland.

Stage moraines (e.g., in North-East Greenland; Hjort and Björck, 1984), however, no direct ages of these moraines are available. In two other locations, ice margin positions are also suggested to be late glacial in age. A significant moraine on the south coast of Disko Island marks the ice sheet margin during the Godhavn Stade. One radiocarbon age (10.5 ka) of an in situ mollusk shell proximal to the moraine provides a minimum limiting-age for deglaciation from this moraine (Ingólfsson et al., 1990). A readvance of the Qassimiut lobe in South Greenland, termed the Neria Stade, is suggested to have occurred during the Younger Dryas, however no direct ages are available (Weidick et al., 2004).

Early Holocene moraines exist in many locations in West, Central East and North-East Greenland. In most cases, these moraines are thought to mark ice sheet readvances or stand-stills due to local topographic influences. Recent work applying AMS dating of the prominent Fjord Stade moraines (Fig. 2) in the Disko Bugt area of Central West Greenland suggests that these moraines are diachronous (i.e., variable in age) and do not record a single ice-margin response to climate change. Using the age of marine limit as an estimate of the timing of local deglaciation and hence moraine age, Long et al. (2006) demonstrate that the Fjord Stade moraines formed between $\sim 10-8 \mathrm{ka}$ (see also Weidick and Bennike, 2007). Funder (1978) mapped ice sheet outlet stand-stills in the inner fjord areas of Scoresby Sund, known as the Rødefjord Stages, and suggested that these occurred prior to $\sim 7.6 \mathrm{ka}$. In the Søndre Strømfjord region of South-West Greenland, Ten Brink (1975) identified up to seven moraine systems between the outer coast and the present ice sheet margin, most of which are of Holocene age (see also Van Tatenhove et al., 1996; Forman et al., 2008). Thus, in most regions, the Greenland Ice Sheet receded during Bennike, 0. and Björck, S., 2002: Chronology of the last deglaciation of
Greenland, Journal of Quaternary Science, 17: 211-219.

Hall, B.L., Baroni, C., Denton, G.H., Kelly, M.A. and Lowell, T.V., 2008a: Relative sea-level Change, Kjove Land, Scoresby Sund, East Greenland: Implications for seasonality in late-glacial time, Quaternary Science Reviews, 27: 2283-2291.

Kelly, M.A., Lowell, T.V., Hall, B.L., Schaefer, J.M., Goehring, B.M., Alley, R.B. and Denton, G.H., 2008: A ${ }^{10}$ Be chronology of late-glacial and Holocene mountain glaciation in the Scoresby Sund region, east Greenland: Implications for seasonality during late-glacial time, Quaternary Science Reviews, 27: 2273-2282

Long, A.J., Roberts, D.H., Simpson, M.J.R., Dawson, S., Milne, G.A. and Huybrechts, P., 2008: Late Weichselian relative sea-level changes and ice sheet history in southeast Greenland, Earth and Planetary Science Letters, 272: 8-18.

Roberts D.H., Long, A.J., Schnabel, C., Freeman, S. and Simpson, M.J.R., 2008: The deglacial history of the southeast sector of the Greenland Ice Sheet during the Last Glacial Maximum, Quaternary Science Reviews, 27: 1505-1516. 


\title{
Extending the uranium-series dating of fossil coral reefs back to marine isotope stage 15
}

Claudine H. Stirling and Morten B. Andersen ${ }^{2}$

'Department of Chemistry, University of Otago, New Zealand; cstirling@chemistry.otago.ac.nz

2Department of Earth Sciences, University of Bristol, UK.

\begin{abstract}
Recent advances in U-series isotopic analysis allow absolutely dated records of past sea level change to be extended back through the last $600 \mathrm{ka}$, and offer decadal- to millennial-scale resolution for the last $400 \mathrm{ka}$.
\end{abstract}

The U-series dating of fossil coral reefs has been widely used to provide absolutely dated records of past sea level change and numerous observations now exist for the past 130 ka spanning the last glacial cycle (Edwards et al., 2003). To gain a more complete record of Earth's natural sea level cycles and a clearer understanding of the mechanisms driving climate change, it is important to study additional glacial-interglacial transitions further back in time. Extended, dateable records of past sea level change are also required to identify a suitable analog of the present climate system, in order to project future climate trends.

In general, the details of the sea level curve for the interval prior to $130 \mathrm{ka}$ remain elusive, primarily due to a progressive loss in the resolution of the U-series chronometer as one goes further back in time, coupled to a lack of well-preserved, dateable coral in older fossil reefs. The former issue is discussed in detail below. The latter is a major issue for corals of virtually all ages, due to post-depositional open-system disturbance of the U-series isotopic system leading to inaccurate ages (see Andersen et al., this issue). Efforts to ensure reliable ages involve strict isotopic screening criteria, often leading to the rejection of the majority of dated samples (Gallup et al., 1994) or the application of an open-system U-series model to correct for the altered component (Thompson et al., 2003; Thompson and Goldstein, 2005; Villemant and Feuillet, 2003; Scholz et al., 2004).

\section{Gearing up towards a high- precision chronometer}

The U-series chronometer uses the natural radioactive decay of ${ }^{238} \mathrm{U}$ to its longestlived intermediate daughters, ${ }^{234} \mathrm{U}$ and ${ }^{230} \mathrm{Th}$. In general terms, the $\mathrm{U}$-series age of a sample can be determined from measurements of its ${ }^{234} \mathrm{U} / 238 \mathrm{U}$ and ${ }^{230} \mathrm{Th} /{ }^{238} \mathrm{U}$ compositions (Fig. 1A). The advent of multiplecollector thermal ionization (MC-TIMS), and more recently, inductively coupled plasma mass spectrometry (MC-ICPMS) to U-series dating in the 1980s and 1990s dramatically improved measurement precision compared with earlier techniques.

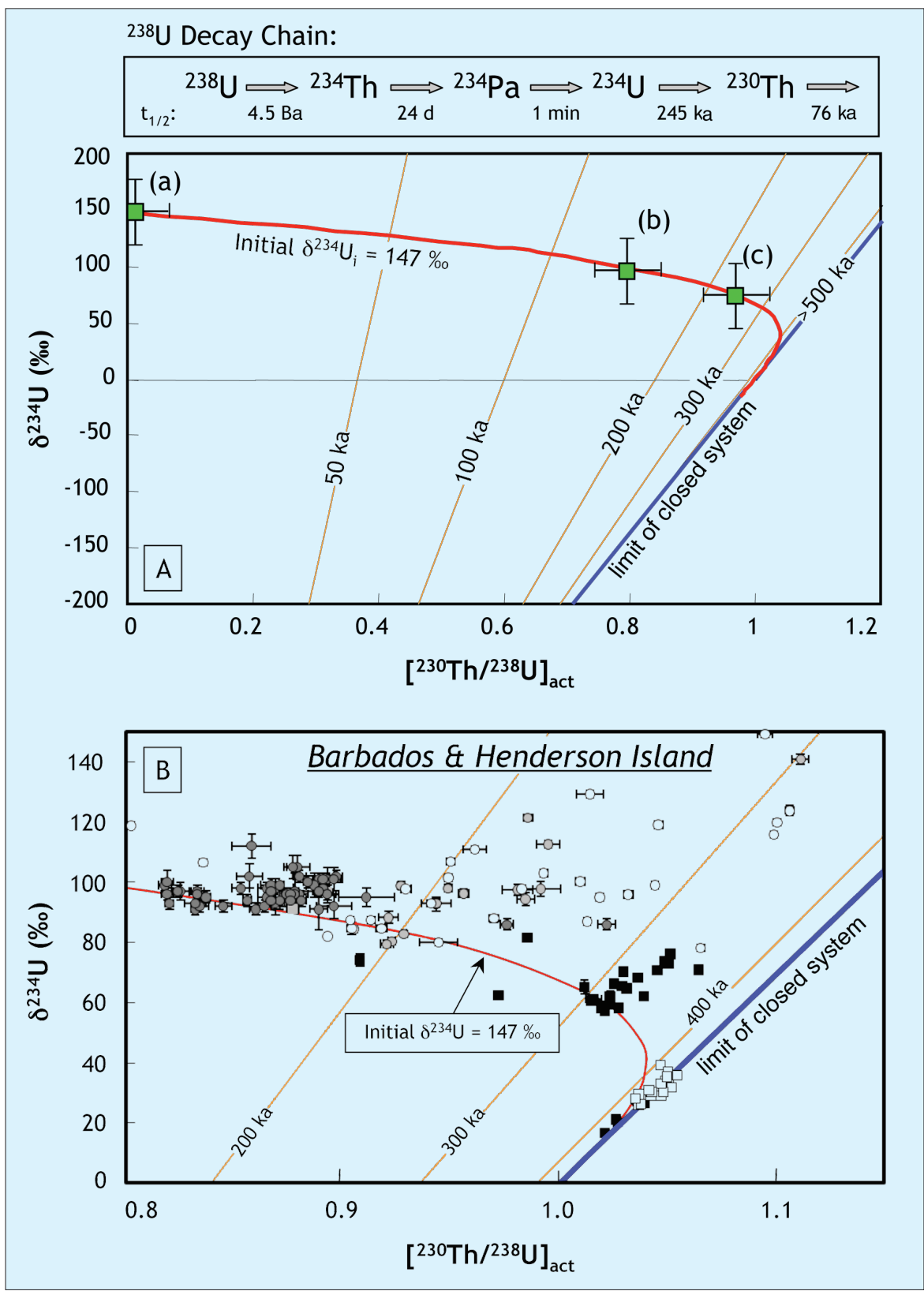

Figure 1: A) Typical representation of $U$-series observations for fossil coral reefs, whereby ${ }^{234} U{ }^{238} \mathrm{U}$ is plotted against ${ }^{230} \mathrm{Th} /{ }^{238} \mathrm{U}$ and contoured in units of $\mathrm{U}$-series age (near vertical lines). ${ }^{234} \mathrm{U} /{ }^{238} \mathrm{U}$ is reformulated into $\delta^{234} \mathrm{U}$-notation as the permil deviation away from radioactive equilibrium, and ${ }^{230} \mathrm{Th} / 238 \mathrm{U}$ is reformulated into the activity ratio $\left.{ }^{230} \mathrm{Th} /{ }^{338} \mathrm{U}\right]$ (e.g., Edwards et al., 2003). For fossil corals, the U-series chronometer is based on the radioactive decay of ${ }^{234} \mathrm{U}$ (half-life $=245 \mathrm{ka}$ ) and radioactive in-growth of ${ }^{230} \mathrm{Th}$ ( $h$ alf-life $=76 \mathrm{ka}$ ) toward radioactive equilibrium with ${ }^{238} \mathrm{U}$. The initial $8^{234} \mathrm{U}=147 \%$ o contour (red line) gives the closed-system evolution path for a coral, assuming a $\delta^{234} \mathrm{U}$ composition of $147 \% 0$ (identical to present-day seawater) and no ${ }^{230}$ Th at the time the coral formed, and no postdepositional loss/gain of ${ }^{238} \mathrm{U},{ }^{234} \mathrm{U}$ and ${ }^{230}$ Th other than by radioactive decay. A living coral would plot at position (a), whereas older $125 \mathrm{ka}$ and $225 \mathrm{ka}$ fossil corals would plot at positions (b) and (c) respectively, as shown by the three data points (green squares). The three data points (measured with identical levels of precision) also demonstrate that the resolution of the U-series chronometer decreases with increasing sample age as the separation between isochrons (orange lines) decreases. If the U-series system becomes open at any time, the isotopic composition of the coral will move away from the closed-system curve and will follow a new decay path, assuming the system remains closed afterward. B) Compilation of published U-series observations pre-dating the last glacial cycle from reef complexes in Barbados (circles) and Henderson Island (squares) displayed as $\delta^{234} \mathrm{U}$ versus [ [230Th/238 $\mathrm{U}$ ]. The initial $\delta^{234} \mathrm{U}=147 \%$ contour denoting the closed-system evolution path for a coral is shown for reference (red line). The majority of data plot above this curve due to open-system exchange of the U-series isotopes during diagenetic alteration and therefore yield "unreliable" U-series ages. The error bars are 20. 


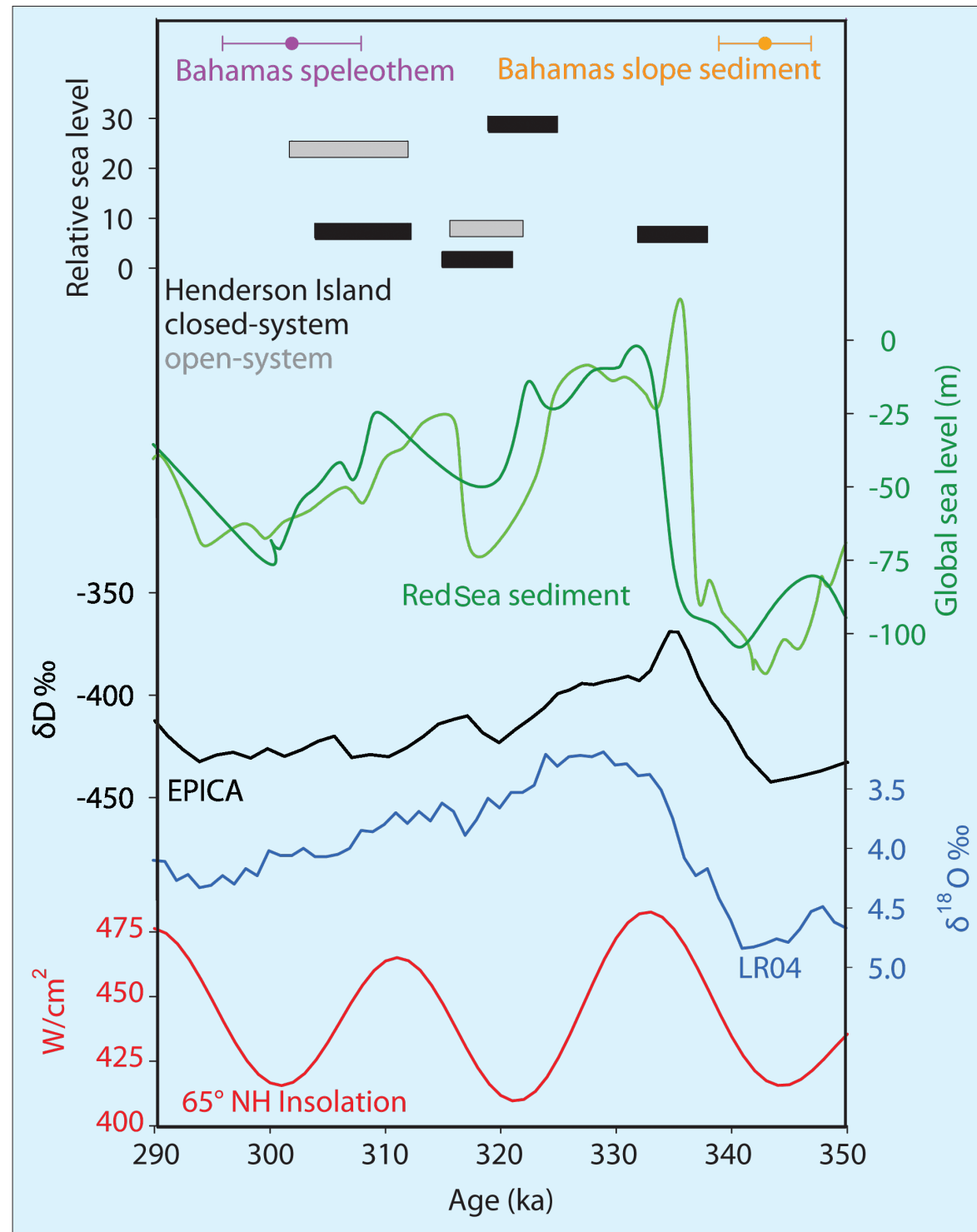

Figure 2: A compilation of sea level and climate records for MIS 9: Summer solar insolation predictions for latitude $65^{\circ} \mathrm{N}$ (red line), which according to the Milankovitch theory of climate change (Milankovitch, 1941), drive Quaternary glacial-interglacial climate variability; LR04 deep-sea sediment $\delta^{18} \mathrm{O}$ record (blue line; Lisiecki and Raymo, 2005), which comprises a stack of 57 globally distributed deep-sea $\delta^{18} O$ records, and provides a combined signal of deep-ocean temperature and global sea level for the past 5.3 Ma. The Pliocene-Pleistocene section of the record has been assigned a chronology based on orbital tuning to Milankovitch insolation predictions; $\delta D$ for the EPICA deep ice core from Dome C, Antarctica (black line; EPICA, 2004), which provides a proxy record of local air temperature for the past $740 \mathrm{ka}$. The chronology for the EPICA record has been derived using ice flow modeling, constrained by radiometric control points based upon Milankovitch orbital forcing theory; high-resolution global sea level reconstructions derived from the $\delta^{18} \mathrm{O}$ signatures of two independent Red Sea sediment cores (dark and light green lines; Siddall et al., 2003). The $\delta^{18} \mathrm{O}$ records were translated into global sea level using a complex hydraulic model for the exchange of water between the Red Sea and the open ocean. A chronology was assigned to the Red Sea records based on a combination of radiometric control points and synchronization with orbitally-tuned Antarctic ice core records; relative sea level observations based on the height-U-series age relationships of fossil corals sampled from Henderson Island's MIS 9 reef complexes but uncorrected for lithospheric flexural uplift and glacio-hydro-isostasy, are shown by the horizontal bars. Conventional U-series ages assessed as "reliable" on the basis of macroscopic and isotopic screening criteria are denoted by the black bars (Stirling et al., 2001); open-system U-series ages for other reef complexes that have been corrected for U-series isotopic shifts caused by diagenetic alteration using the open-system U-series model of Thompson et al. (2003) are represented by the gray bars; U-series observations for speleothems from the Bahamas (purple) constrain the timing of the MIS 8/9 glacial-interglacial transition (Hoffmann et al., 2007); Bahamian aragonitic slope sediments (orange) suggest an early onset for the initiation of MIS 9 (Henderson et al., 2006), which is contrary to the coral reef observations.

Using mass spectrometric techniques, ions generated in the thermal or plasma ionization source are passed through a magnetic field and spatially separated on the basis of their mass-to-charge ratio, then detected simultaneously on an array of Faraday detectors, devices that allow the precise measurement of ion currents. Isotope ratios are then determined on the basis of the ratio of the ion currents. Usually, Faraday detectors, although very stable, mentation over the last decade, conventional U-series measurement precision remains limited to the one-permil level because ion-counting detector systems are inherently unstable and must be frequently cross-calibrated (Goldstein and Stirling, 2003). When propagated through the U-series decay equations, one-permil uncertainties translate to sizeable U-series age errors in older samples of up to $\pm 5 \mathrm{ka}$ in 300 ka samples and $\pm 90 \mathrm{ka}$ in $600 \mathrm{ka}$ samples (Fig. 1). Clearly, age uncertainties of this magnitude are not conducive to sea level reconstruction at the millennial scale, nor do they allow the timing of an interglacial maximum to be resolved from the preceding glacial minimum for the interval prior to MIS 9 ( 350 ka).

New analytical protocols are required to improve the resolution of the $\mathrm{U}$-series chronometer. To address this issue, some recent MC-ICPMS studies have focused on improving measurement precision by a further factor of five to the $0.2 \%$ level by adopting more concentrated solutions and increasing the minor ${ }^{234} \mathrm{U}$ and ${ }^{230} \mathrm{Th}$ ion beam signals to intensities that are sufficiently large for measurement on stable Faraday collectors (Andersen et al., 2004; 2007; 2008; Potter et al., 2005; Stirling et al., 2007; Cheng et al., 2008). MultipleFaraday protocols have also been applied to low-concentration thorium samples by overcoming the Faraday detector noise limitations (Esat, 1995; Stirling et al., 2001). There are several technical challenges that must be overcome to perform $\mathrm{U}$-series isotopic measurements entirely using Faraday collectors. However, these challenges are offset by the fact that $0.2 \%$ levels of precision allow 300 and 600 ka samples to be measured with $2 \sigma$ age uncertainties of \pm 0.8 and $\pm 14 \mathrm{ka}$, respectively. This represents a four-fold or better improvement in precision compared with previous techniques, and at the same time, extends the upper limit of the $\mathrm{U}$-series chronometer further back in time to $\sim 800 \mathrm{ka}$. Thus, multiple-Faraday techniques offer the potential to resolve the finer details of sea level and climate change during and beyond the last four glacial-interglacial cycles, especially when sample size is not restricted.

This enhanced analytical precision must be coupled with accuracy through continued refinement of the $\mathrm{U}$-series half-life determinations to further reduce their contribution to the $\mathrm{U}$-series age error (Cheng et al., 2008). There is also a pressing need for all U-series laboratories to participate in a rigorous inter-laboratory comparison exercise, particularly given and ${ }^{238} \mathrm{U} /{ }^{230} \mathrm{Th} \sim 10^{5}$, it is therefore usual to measure the minor ${ }^{234} \mathrm{U}$ and ${ }^{230} \mathrm{Th}$ isotopes on a low-background ion counting detector system, a device for accommodating low-level ion currents. However, despite ongoing design improvements in instru- 
the rapid evolution of the $\mathrm{U}$-series field over the last decade.

\section{Sea level records pre-dating the last glacial cycle}

Prior to the last glacial cycle, the most extensive compilation of $\mathrm{U}$-series observations for fossil coral reefs exists for MIS 7 (Gallup et al., 1994; 2002; Scholz et al., 2006; Thompson and Goldstein, 2005; Dutton et al., this issue), extending from 245-193 ka. Sea level records for MIS 7 are discussed in detail by Dutton et al. (this issue). Furthermore there are a few isolated data points for MIS 6-5 (e.g., Esat et al., 1999; Thomas et al., 2008). Pre-dating MIS 7, the most extensive suite of coral reef U-series observations have been acquired for unusually well-preserved reef complexes formed during MIS 9 (339-303 ka) and MIS 15 (620-570 ka) on Henderson Island, South Pacific Ocean (Stirling et al., 2001; Andersen et al., 2008). Conventional U-series dating of Henderson Island's MIS 9 fossil corals (Fig. 2) indicate that sea levels during MIS 9.3 approached peak interglacial values near $324 \pm 3 \mathrm{ka}$ (Stirling et al., 2001). High sea levels appear to have persisted for a further $8 \mathrm{ka}$, before falling towards glacial values near $318 \pm 3 \mathrm{ka}$ (Stirling et al., 2001). Conventional U-series ages for a single coral tentatively indicate subsequent MIS 9.1 reef growth at $307 \pm$ 4 ka (Stirling et al., 2001). There are also a growing number of high-precision $\mathrm{U}$ series observations for Henderson Island's MIS 15 fossil corals and the results to date indicate peak interglacial sea levels at 600 \pm 15 ka (Andersen et al., 2008). Additional efforts are underway to continue to refine these MIS 9 and 15 sea level chronologies for Henderson Island (e.g., Stirling and Andersen, 2008). Furthermore, Henderson Island is believed to have undergone systematic but non-linear uplift ( 30 m) caused by lithospheric flexure arising from the volcanic emplacement of nearby Pitcairn Island. A combination of flexural uplift and glacio-hydro-isostatic rebound modeling is required to convert the relative sea level observations for Henderson Island into global constraints of eustatic sea level. To date, there is a complete absence of reliable $\mathrm{U}$-series observations for other glacial-interglacial periods. In particular, effort should be expended to identify MIS 11 in the fossil coral record. MIS 11 has been identified as an exceptionally warm and long interglacial in the climate record, characterized by orbital parameters that are similar to those of the today and of the next few millennia (EPICA, 2004), and could represent the most appropriate analog of the present climate system.

Efforts to pursue robust sea level records from fossil corals further back in time should focus on enhancing the precision and accuracy of the U-series chronometer.
Furthermore, an improved understanding of the mechanisms involved in the opensystem loss/gain of the U-series isotopes during the post-depositional diagenetic alteration of fossil reef systems (see Andersen et al., this issue) is critical to ensure the reliability of $\mathrm{U}$-series ages dated both conventionally and via the implementation of open-system methods. Moreover, it is important to augment the fossil coral records with U-series observations for complementary archives of past sea level change, particularly submerged speleothems (Bard et al., 2002; Dutton et al., this issue) and aragonitic slope sediments (Henderson et al., 2006).

\section{References}

Andersen, M.B., Stirling, C.H., Potter, E.K., Halliday, A.N., Blake, S.G., McCulloch, M.T., Ayling, B.F. and O'Leary, M., 2008: High-precision U-series measurements of more than 500,000 year old fossil corals, Earth and Planetary Science Letters, 265: 229-245.

Edwards, R.L., Cutler, K.B., Cheng, H. and Gallup, C.D., 2003: Geochemical Evidence for Quaternary Sea-level Changes. In: Turekian, K.K. and Holland, H.D. (Eds) Treatise on Geochemistry, Elsevier, 6.13 343-364.

Goldstein, S.J. and Stirling, C.H., 2003: Techniques for measuring uranium-series nuclides: 1992-2002. In: Bourdon, B. et al., (Eds) Reviews in Mineralogy and Geochemistry, Geochemical Society, 52: 23-57.

Stirling, C.H., Esat, T.M., Lambeck, K., McCulloch, M.T., Blake, S.G., Lee, D.-C. and Halliday, A.N., 2001: Orbital forcing of the Marine Isotope Stage 9 interglacial, Science, 291: 290-293.

Thompson, W.G. and Goldstein, S.L., 2005: Open-system coral ages reveal persistent suborbital sea-level cycles, Science, 308: 401 404.

\section{Ice sheet retreat and sea level rise during the last deglaciation}

Peter U. Clark

Department of Geosciences, Oregon State University, Corvallis, USA; clarkp@onid.orst.edu

\section{The terrestrial record of deglaciation provides important constraints on the relative contribution of individual ice sheets to global sea level rise, thus improving our ability to estimate sea level sensitivity to climate change.}

The Last Glacial Maximum (LGM) is conventionally defined as the most recent interval in Earth's history when global ice sheets reached their maximum integrated volume. Documenting the rate of retreat of the global ice sheets following the LGM provides important insights towards understanding the sensitivity of ice sheet retreat and associated sea level rise to climate forcing. Additionally, a number of feedbacks associated with ice sheet retreat, including changes in albedo, orography, and freshwater fluxes to sites of deepwater formation, significantly influenced the trajectory and rate of deglaciation at regional to global scales.
The record of global sea level rise during the last deglaciation is best constrained from geomorphic and biological indicators of sea level at sites far from glaciated areas (far-field sites). Because sea level is an integrated signal, however, it does not distinguish between the relative contributions of individual ice sheets to the global signal, including growth of an ice sheet during the global deglaciation. Moreover, although the rate of sea level rise reveals changes in the total freshwater flux to the ocean associated with melting, it does not indicate how changes in the distribution of that flux to different regions of the ocean may have occurred solely from the rerouting of runoff, which may be just as important in influencing density-driven changes in ocean circulation as changes in the total flux.

Combining the terrestrial record of ice sheet retreat with the sea level record during the last deglaciation provides a complimentary strategy to address important aspects of ice sheet-climate interactions. Radiocarbon and cosmogenic surface exposure ages allow the position of retreating ice sheet margins to be mapped through the deglaciation, thus constraining rates of retreat (or readvance) for individual ice sheets as well as the opening (or closing) of outlets that route subcon- 

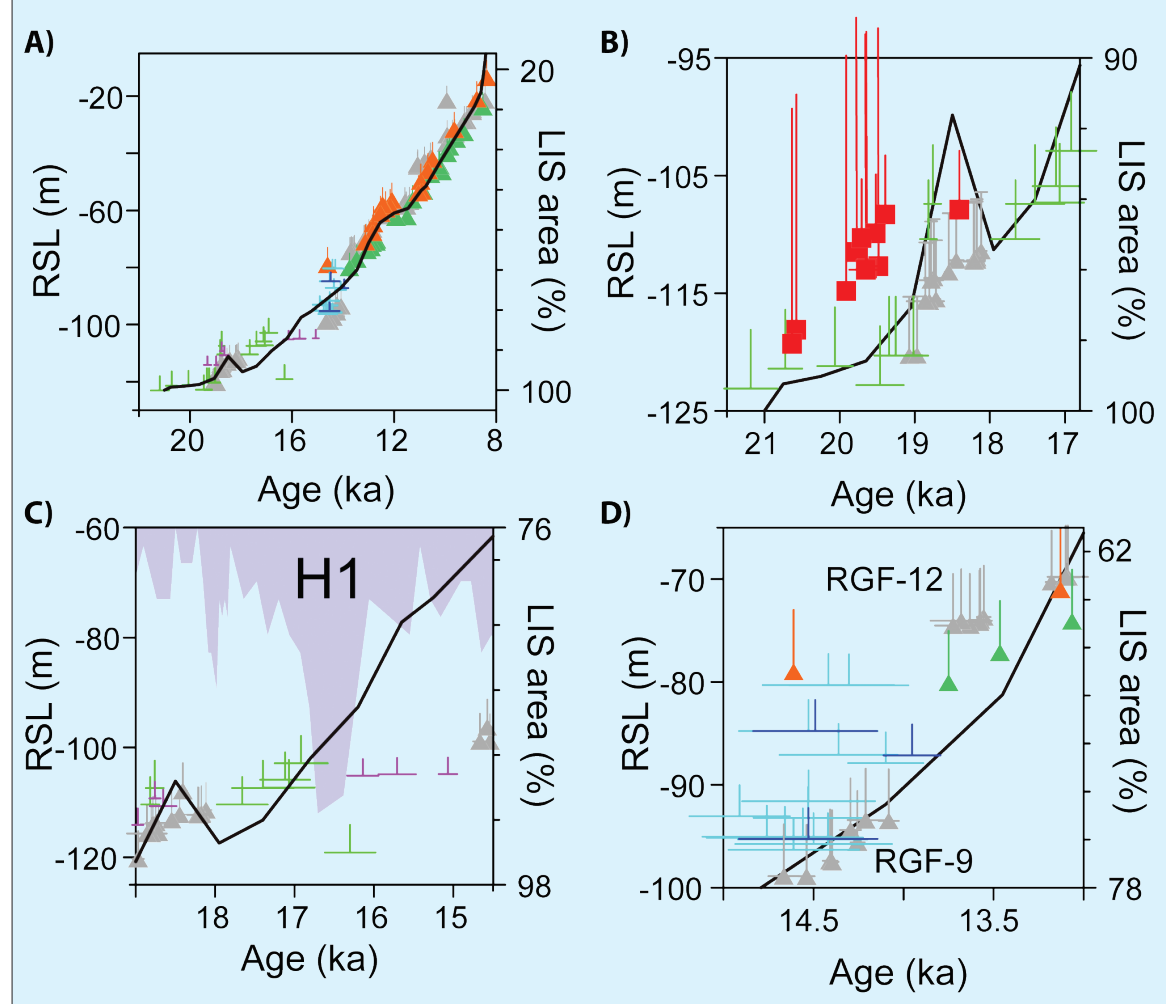

Figure 1: $\boldsymbol{A})$ The last deglaciation relative sea level record (RSL) reconstructed from geomorphic and biological indicators at sites far from the former large ice sheets and compared to the retreat of the Laurentide Ice Sheet (LIS; black line) (Dyke, 2004). Symbols are coded to individual sites as follows: Green lines are Bonaparte Gulf calibrated ${ }^{14} \mathrm{C}$ ages (Yokoyama et al., 2000) showing age and depth uncertainty, Gray diamonds are U/Th ages on Barbados corals from core RGF-9 (Bard et al., 1993; Peltier and Fairbanks, 2006). Sunda Shelf calibrated ${ }^{14} \mathrm{C}$ ages are shown as pink lines (non-mangrove organics), light blue lines (mangrove remains, not in situ), and dark blue lines (mangrove remains in situ) (Hanebuth et al., 2000), Orange triangles are U/Th ages on corals from New Guinea (Edwards et al., 1993: ( Cutler et al., 2003), Light green triangles are U/Th ages on corals from Tahiti (Bard et al., 1996). B) Detail of sea level history and LIS deglaciation between $21.5 \mathrm{ka}$ and $16.8 \mathrm{ka}$, using same symbols as in A). Also shown are Barbados corals from core RGF-15 (red squares), including the species Montastrea annularis (Peltier and Fairbanks, 2006). C) Detail of sea level history and LIS deglaciation between $19 \mathrm{ka}$ and $14.5 \mathrm{ka}$ using same symbols as in A). Also shown is the $\mathrm{CaCO}_{3}$ component of ice-rafted debris, showing a peak at the time of Heinrich event 1 ( $\mathrm{H} 1$; Bond et al., 1999). D) Detail of sea level history and LIS deglaciation between $15 \mathrm{ka}$ and $13 \mathrm{ka} \mathrm{using} \mathrm{same} \mathrm{symbols} \mathrm{as} \mathrm{in}$ A). The Barbados coral samples from cores RGF-9 and RGF-12 are identified.

tinental drainage basins from one river to another. Although the detailed retreat history of some ice sheets remains poorly known, there is sufficient information to identify the first-order aspects of their retreat that are important to the sea level record, such as their contributions to the termination of the LGM lowstand or subsequent episodes of rapid sea level rise (Clark et al., submitted). An important caveat in using the land record to constrain sea level is that it only represents area, not volume, but to first-order, modern relationships suggest that ice sheet extent scales with volume (Paterson, 1994).

Here, I use this complementary strategy to infer the primary ice sheet contributions to the first-order structure of global sea level rise during the last deglaciation. In particular, I focus on the interval between 21 and $13 \mathrm{ka}$, during which time a large fraction of sea level rise occurred in two relatively brief steps (Fig. 1a). The first step is identified from data from Bonaparte Gulf (Yokoyama et al., 2000) and the Irish Sea basin (Clark et al., 2004), which suggest that the LGM lowstand other Northern Hemisphere ice sheets also started to retreat between 19-20 ka (Clark et al., submitted), further supporting the younger age for this event, and identifying the Northern Hemisphere ice sheets as its primary source.

Between 19 and $\sim 14.5 \mathrm{ka}$, rates of sea level rise decreased substantially $(<3.5 \mathrm{~mm}$ $\mathrm{a}^{-1}$ ) (Fig. 1c). The LIS and the Scandinavian
Ice Sheet, however, continued to retreat throughout this interval (Rinterknecht et al., 2006; Clark et al., submitted), and Heinrich event $1(\mathrm{H} 1)$ also occurred at $\sim 17$ ka (Fig. 1c), all suggesting some sea level rise. The fact that existing data indicate little sea level rise thus suggests that one or more other ice sheets must have grown at a rate that nearly balanced the mass loss from these two ice sheets. The southern margin of the Cordilleran Ice Sheet ( $\mathrm{N}$ America) advanced to its maximum extent between $19 \mathrm{ka}$ and $17.5 \mathrm{ka}$ (Porter and Swanson, 1998) but its growth likely represented a small contribution to sea level. The Barents-Kara Ice Sheet had largely collapsed by 19 ka (Svendsen et al., 2004). Accordingly, the only remaining large ice sheets that could offset the sea level rise associated with retreat of the two largest Northern Hemisphere ice sheets were the Antarctic Ice Sheets but there are currently insufficient geochronologic constraints to test this hypothesis.

Sea level subsequently rose rapidly again during meltwater pulse $1 \mathrm{~A}$ (mwp$1 A)$, when as much as $20 \mathrm{~m}$ of rise occurred in less than 500 years (Fig. 1d). Two aspects of this event have been widely discussed: its age, and thus relation to climate change, and its source. With respect to the former, Stanford et al. (2006) argued that it occurred between the youngest dated coral in Barbados core RGF-9 (14.1 ka) and the oldest coral in core RGF-12 (13.6 ka), and dismissed the Sunda Shelf ${ }^{14} \mathrm{C}$ ages that suggest an older age for mwp-1A (Fig. 1d) because of uncertainties in correcting for variable ${ }^{14} \mathrm{C}$ reservoir ages. The key Sunda Shelf ${ }^{14} \mathrm{C}$ ages that constrain the timing of mwp-1A, however, are on fragments of mangrove trees, which are not subject to reservoir age corrections. Moreover, the older age for mwp-1A is supported by a U/ Th age on a coral from New Guinea (Fig. 1d) (Cutler et al., 2003). One explanation for this discrepancy in timing is that the shallow-water corals sampled in core RGF9 were unable to "keep up" with the rapid sea level rise of mwp-1A, and eventually "gave up" (Neumann and Mcintyre, 1985), with the establishment of a new shallowwater coral reef, sampled by core RGF-12, only after sea level rise had sufficiently slowed.

Possible sources of mwp-1A have been widely discussed (e.g., Bassett et al., 2005; Clark et al., 1996; 2002; Peltier, 2005). There are several key reasons why a significant contribution from the Northern Hemisphere is unlikely: (1) Peltier (1994; 2005) argued for a significant contribution from the LIS but there is no acceleration in its rate of retreat during $\mathrm{mwp}-1 \mathrm{~A}$ relative 
to before and after (Fig. 1a, 1d). (2) Peltier (2005) argued that the Barents-Kara Ice Sheet also contributed to the event but this ice sheet had largely deglaciated by 19 ka (Svendsen et al., 2004). (3) Ocean models consistently demonstrate that the freshwater flux to the North Atlantic from a Northern Hemisphere source would have shut down the Atlantic meridional overturning circulation (AMOC), which did not occur (McManus et al., 2004). Aharon (2006) argued that benthic $\delta^{18} \mathrm{O}$ records from the Gulf of Mexico support a substantial contribution from the LIS with minimal effect on the AMOC but Carlson (2009) showed that aspects of the model used by Aharon (2006) were incorrect.

In contrast, a substantial contribution from Antarctica explains why there is no significant reduction in the $\mathrm{AMOC}$, and instead may explain why the AMOC abruptly resumed at this time (Weaver et al., 2003; Pahnke et al., 2008). In addition, an Antarctic source explains the geographic variation in far-field sea level records associated with the processes of glacial isostatic adjustment (Clark et al., 2002; Bassett et al., 2005).

In summary, the terrestrial record of past changes in global ice sheets places important constraints in identifying their contributions to the sea level rise of the last deglaciation. In particular, multiple ice sheets represent multiple reservoirs, each potentially behaving independently of each other in response to regional or hemispheric climate change. As is the case for modern ice sheets and future sea level change, disentangling these contributions is critical to fully decipher the sensitivity of sea level to climate change.

\section{References}

Bassett, S.E., Milne, G.A., Mitrovica, J.X. and Clark, P.U., 2005: Ice sheet and solid earth influences on far-field sea level histories, Science, 309: 925-928.

Clark, P.U., Mitrovica, J.X., Milne, G.A. and Tamisiea, M., 2002: Sea level fingerprinting as a direct test for the source of global meltwater pulse IA, Science, 295: 2438-2441.

Clark, P.U., McCabe, A.M., Mix, A.C. and Weaver, A.J., 2004: The 19-kyr B.P. meltwater pulse and its global implications, Science, 304: 1141-1144.

Dyke, A.S., 2004: An outline of North American Deglaciation with emphasis on central and northern Canada, In: Ehlers, J. and Gibbard, P.L. (Eds), Quaternary Glaciations: Extent and Chronology, Elsevier, 373-424.

Milne, G.A. and Mitrovica, J.X., 2008: Searching for eustasy in deglacia sea level histories, Quaternary Science Reviews, 27: 2292-2302.

For full references please consult:

www.pages-igbp.org/products/newsletters/ref2009_2.html

\section{A new chronology of sea level highstands for the penultimate interglacial}

Andrea Dutton', F. Antonioli² and E. Bard ${ }^{3}$

${ }^{1}$ Research School of Earth Sciences, Australian National University, Canberra; andrea.dutton@anu.edu.au

2Italian National Agency for New Technologies, Energy and Environment, Rome, Italy; ${ }^{3}$ European Center for Research and Teaching of Geosciences and the Environment, National Center of Scientific Research and Aix-Marseille University, College de France, Aix-en-Provence, France

\section{A suite of submerged Italian speleothems constrain the timing of sea level highstands across the entirety of marine isotope stage 7 ( 190-245 ka) indicating that sea level highstands were broadly in phase with insolation forcing.}

Understanding the precise phase relationships of changes in sea level, temperature, and greenhouse gas concentrations during previous interglacials provides us with critical knowledge to evaluate the future response of the climate system to anthropogenic forcing. Absolutely dated sea level archives that document the response of ice sheets to changes in temperature and atmospheric $\mathrm{CO}_{2}$ become increasingly rare as we look beyond the last interglacial (ca. $130 \mathrm{ka}$ ) due to the combined effects of alteration of suitable archives, physical superposition of multiple sea level oscillations, and challenges related to temporal limitations of geochronometers. This leads us to rely upon sea level reconstructions that are derived from deep-sea cores and models, which both lack direct age control. Because we seek to understand the phasing of orbital forcing and climate records relative to more continuous records of sea level change that are available from these models and deep-sea cores, we must first calibrate these against absolutely dated records of sea level response.

We have studied a suite of submerged stalagmites from Argentarola Cave (central west coast of Italy) collected across a depth range of -18 to $-21 \mathrm{~m}$, with the aim

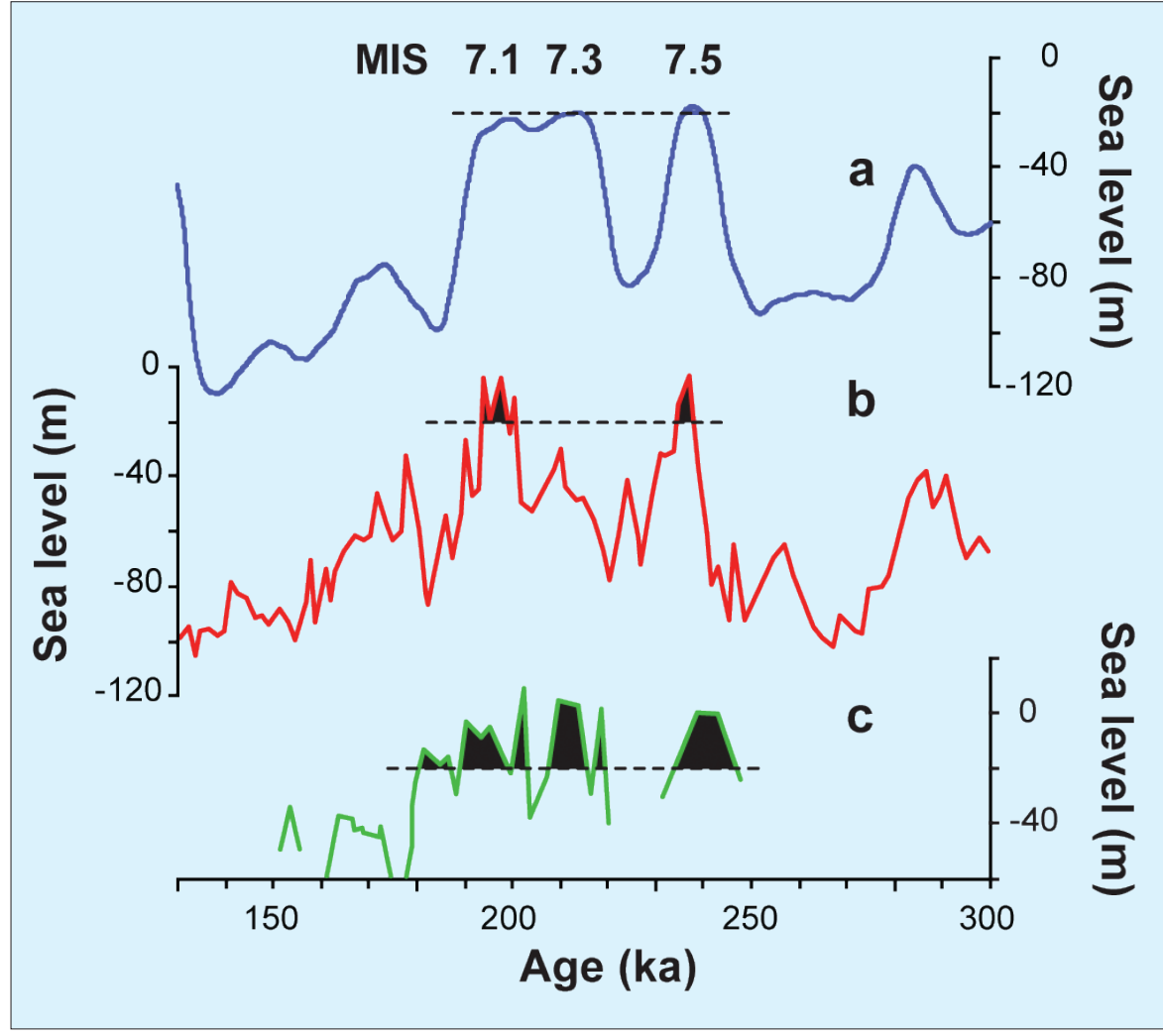

Figure 1: Sea level curves shown for MIS 7, derived using three different methods: (a) model (Bintanja et al., 2008) driven by benthic oxygen isotope $\left(\delta^{18} \mathrm{O}\right)$ stack, (b) reconstruction of Red Sea seawater $\delta^{18} \mathrm{O}$ (Siddall et al., 2003), (c) open system U-Th ages of corals (Thompson and Goldstein, 2005). Shading indicates periods of time that sea level rose above-20 m (dashed lines), the approx. depth of Argentarola Cave stalagmites. Note differences in the number of highstands predicted to exceed $-20 \mathrm{~m}$ and the difference in elevation predicted for MIS 7.3 in particular. Figure modified from Dutton et al., 2009. 
of improving the absolute chronology of several sea level highstands during MIS 7 (190 to $245 \mathrm{ka}$ ), also referred to as the penultimate interglacial (Dutton et al., 2009). Our investigation provides benchmarks of the precise timing of sea level highstands during the penultimate interglacial that help to reconcile existing reconstructions of sea level across this time interval (Fig. 1). As previously reported, the spectacular feature of speleothems recovered from Argentarola Cave is the occurrence of alternating layers of biogenic calcite and inorganically precipitated spelean calcite that result from multiple sea level oscillations in the past (Bard et al., 2002; Antonioli et al., 2004). The biogenic layers are composed of serpulid worm calcite secretions that encase the speleothems during seawater submergence, while the spelean calcite growth only occurs when the cave is emergent, or above sea level. We have used U-series dating techniques to determine the precise timing of speleothem growth that brackets each serpulid calcite layer to ascribe a chronology to the sea level highstands. The combined record from three stalagmites, including one previously studied by Bard et al. (2002), captures the timing of sea level rise and fall past the cave during three successive peaks in sea level during MIS 7 (Fig. 2).

The timing of sea level highstands at Argentarola Cave accurately represents the timing of eustatic sea level oscillations because the time difference between local sea level reaching -18 $\mathrm{m}$ at Argentarola and the calculated timing of $-18 \mathrm{~m}$ eustatic sea level (ice-equivalent volume) is very small (estimated at $<0.1 \mathrm{ka}$ ) relative to the precision of the $\mathrm{U}$-Th ages (1.5 to 3.0 ka) (Dutton et al., 2009). It is also important to recognize that these data provide maximum estimates for the duration of the highstand above the elevation of the cave because the U-Th ages are measured on samples of spelean calcite that grew before and after the sea level highstand.

In a broad sense, the overall timing of these highstands encompasses, and in some cases is almost centered on, the timing of maximum Northern Hemisphere insolation (Fig. 3). We note that the absolute chronology of the Argentarola record is also in good agreement with other absolutely dated archives of sea level and interglacial conditions during MIS 7. However, a closer look at some of the more subtle differences in timing may reveal critical insight to the timing and nature of ice sheet response to insolation forcing. For instance, if we compare the timing of sea level rise past $-18 \mathrm{~m}$ at Argentarola to the timing of maxima in Northern Hemisphere insolation, we see that during MIS 7.5 and 7.1 , speleothem growth at -18 to -18.5 m terminates a few thousand years before insolation maxima are reached. In contrast, during the onset of the MIS 7.3 highstand there is no difference, within our analytical error, between the timing of sea level rise past $-21 \mathrm{~m}$ and the insolation maximum. So this intervening highstand, MIS 7.3, is delayed in a relative sense when compared to the timing observed for the other two highstands.

Before exploring the reason for the different behavior of the MIS 7.3 highstand, we first turn to an unexpected finding made during this study regarding the

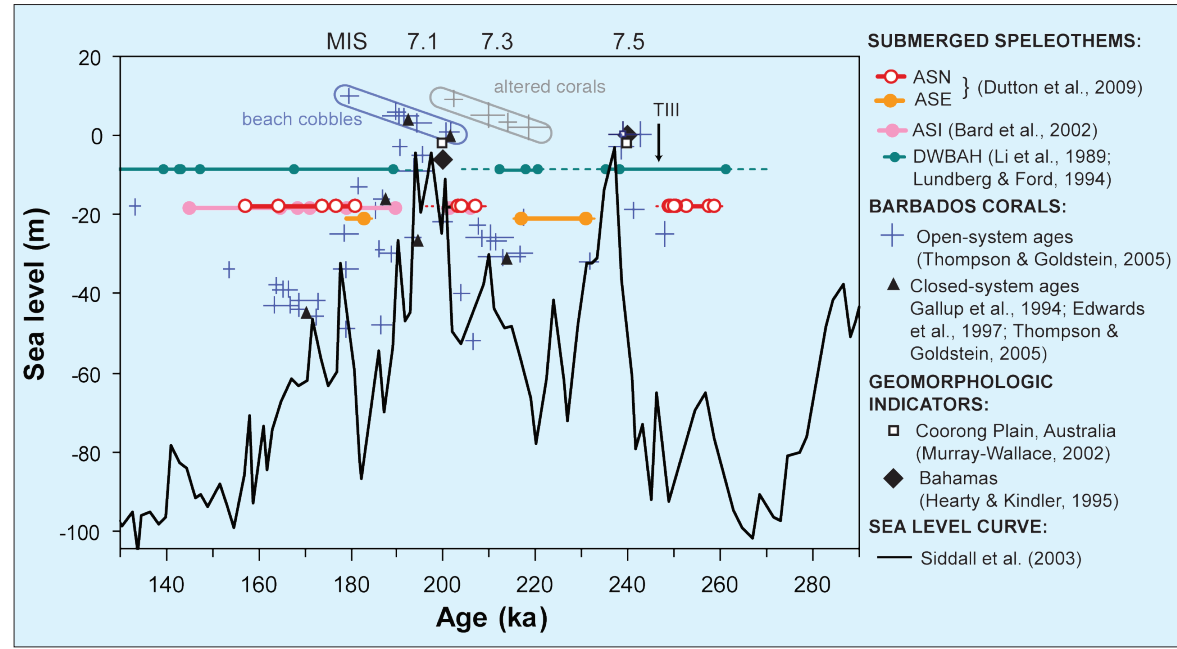

Figure 2: Comparison of Argentarola submerged stalagmite data (Agentarola stalagmite N, E, and I: ASN, ASE, ASI) with other relative sea level records across MIS 7. Speleothem U-Th data represent growth periods and should be above the sea level curve, whereas coral data should be just below the curve; Solid lines connecting these U-Th ages represent periods of uninterrupted growth. Error bars for samples next to hiatuses are shown as dashed lines. PeakMIS 7.5 coral data were assumed to sit at modern sea level (Thompson and Goldstein, 2005). The remainder of the Barbados coral elevations are calculated assuming constant uplift rates, which introduces some error into the elevation estimates. Gray data points are heavily altered corals $\left(\delta^{234} U_{\text {initial }}>330 \%\right)$; blue data points in circle are beach cobbles. Closed-system ages are shown for corals with $\delta^{234} U_{\text {inital }}$ within $2 \% 0$ of seawater. TIII = Termination III. Figure modified from Dutton et al., 2009. relative elevation of these highstands. Due to differences in the number of serpulid calcite layers preserved in stalagmites from different depths and evidence of dissolution that occurred in the halocline, we were able to determine that the elevation of sea level peaked at approx. $-18 \mathrm{~m}$ during the MIS 7.3 highstand and was between -18.5 and -21.0 m during the MIS 7.2 lowstand. In contrast, peak sea level during MIS 7.5 and 7.1 was somewhere above our highest reference point in the cave (-18 m). Our observation of lower peak sea level during MIS 7.3 relative to MIS 7.5 and 7.1 is in agreement with sea level reconstructions of Lea et al. (2002) and Siddall et al. (2003) that are based on seawater $\delta^{18} \mathrm{O}$ determinations but are not in keeping with reconstructions that are based in whole or in part on benthic $\delta^{18} \mathrm{O}$ records (e.g., Waelbroeck et al., 2002; Bintanja et al., 2005) that imply similar peak elevations for all three highstands. This finding suggests that the benthic $\delta^{18} \mathrm{O}$ record may be biased by temperature influence during the MIS 7.3 highstand, possibly as a consequence of strong peaks in insolation in both the Northern and Southern Hemispheres during this time interval (Fig. 3).

Having noted the unusual nature of the MIS 7.3 highstand with respect to both timing and elevation, we now return to the issue of understanding the delayed timing of sea level rise past Argentarola cave relative to the two other highstands. The preceding sea level lowstand, MIS 7.4, has been associated with cold temperatures and ice volumes that approach the full glacial conditions of MIS 8 (e.g., Roucoux et al., 2006; Jouzel et al., 2007; Martrat et al., 2007). The transition from MIS 7.4 to MIS 7.3 has even been likened to a full glacial termination (Huybers and Wunsch, 2005). Both the delayed timing and dampened amplitude of MIS 7.3 may be a consequence of MIS 7.4 glaciation that was extensive but according to Bintanja et al. (2008) was not enough to cause coalescence of the two Cordilleran and Laurentide Ice Sheets in North America. The merging of these two ice sheets has been postulated as a key factor in initiating rapid retreat of the ice sheets during termination events (e.g., Bintanja et al., 2008).

Our chronology of sea level highstands during the penultimate interglacial from Argentarola Cave provides precise and accurate ages that are critical benchmarks in determining the phasing of insolation forcing and climate relative to sea level response. The findings summarized here and more fully developed in Dutton et al. (2009) also underpin the importance of cryosphere state as a critical factor de- 


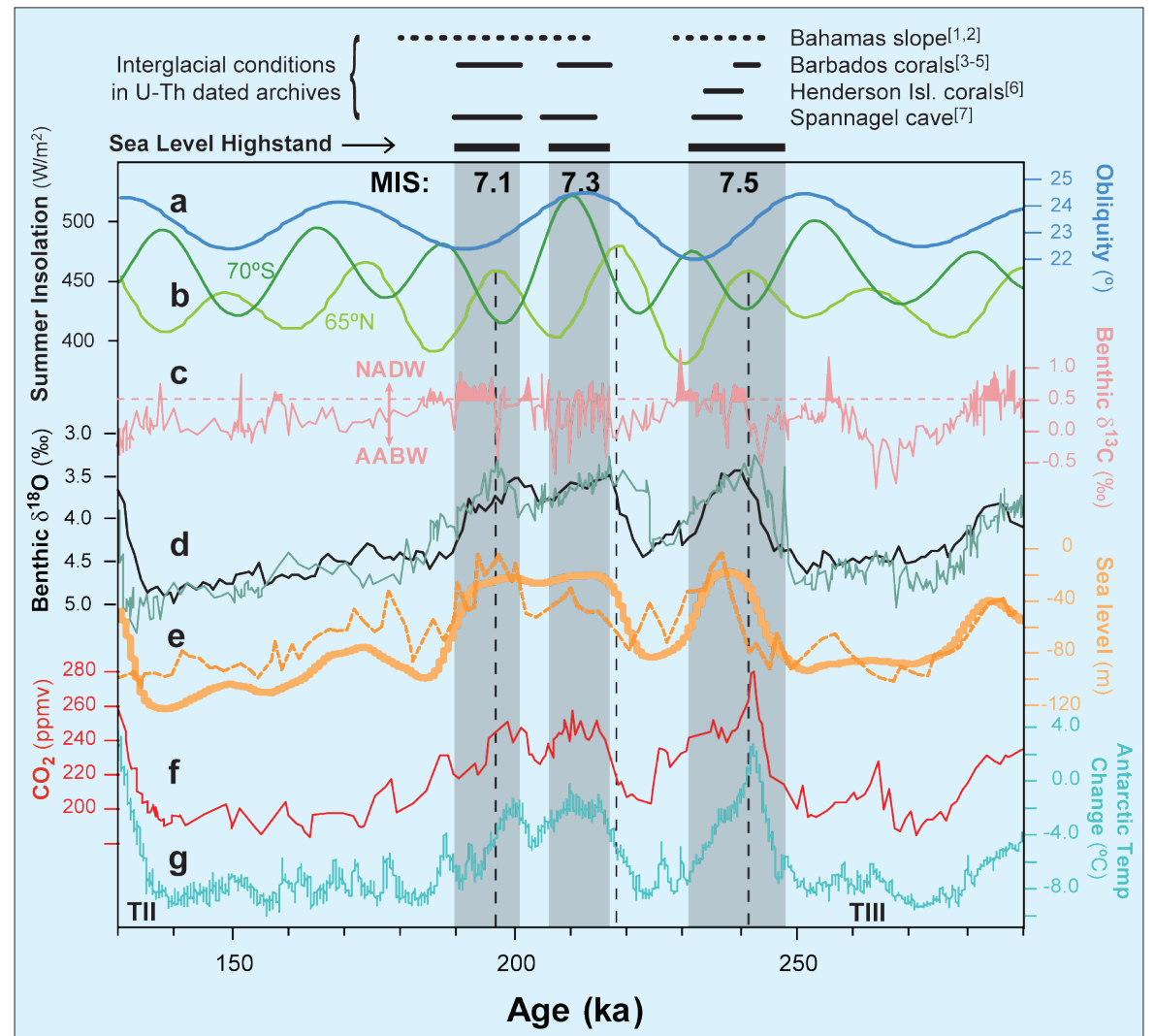

Figure 3: Sea level and climate reconstructions during MIS 7. Sea level highstands at Argentarola denoted by vertical gray bars. (a) Obliquity, and (b) summer insolation curves at $65^{\circ} \mathrm{N}(\mathrm{JJA})$ (maxima shown by dotted lines in MIS 7) and $70^{\circ} \mathrm{S}$ (DJF) (Laskar, 1990), (c) Iberian Margin benthic carbon isotope ( $\delta^{13} \mathrm{C}$ ) data (Martrat et al., 2007) highlights the unusual nature of MIS 7.3, (d) benthic $\delta^{18} \mathrm{O}$ stack (Lisiecki and Raymo, 2005: black) and benthic $\delta^{18} \mathrm{O}$ from the Iberian Margin (Martrat et al., 2007: blue), (e) sea level reconstructions (Siddall et al., 2003; Bintanja et al., 2008: dashed and solid orange lines, respectively), (f) compiled Antarctic ice core CO (Lüthi et al., 2008), (g) EPICA Dome C temperature change (Jouzel et al., 2007). TII and TIII = Terminations. Data sources as follows: [1] Henderson et al., 2006; [2] Robinson et al., 2002; [3] Gallup et al., 1994; [4] Edwards et al., 1997; [5] Thompson and Goldstein, 2005; [6] Andersen, 2006; [7] Spötl et al., 2008; [8] Dutton et al., 2009. Figure modified from Dutton et al., 2009. past, and also to inform us about the interplay of these variables as we head into the future.

\section{Acknowledgements}

We would like to thank T. Esat, K. Lambeck and M. McCulloch for their contributions to the work discussed here, and also J. Desmarchelier, L. Kinsley and G. Mortimer for analytical assistance.

\section{Data Information}

Data are available in online supplemental material associated with Dutton et al. (2009) Nature Geoscience, at http://dx.doi.org/10.1038/ NGEO470

\section{References}

Antonioli, F., Bard, E., Potter, E.-K., Silenzi, S. and Improta, S., 2004: 215 ka History of sea level oscillations from marine and continental layers in Argentarola cave speleothems (Italy), Global and Planetary Change, 43: 57-78.

Bard, E., Antonioli, F and Silenzi, S., 2002: Sea level during the penultimate interglacial period based on a submerged stalagmite from Argentarola Cave (Italy), Earth and Planetary Science Letters, 196: $135-146$.

Dutton, A., Bard, E., Antonioli, F., Esat, T.M., Lambeck, K. and McCulloch, M.T., 2009: The phasing and amplitude of climate and sea level during the penultimate interglacial, Nature Geoscience, doi:10.1038/NGE0470.

Lea, D.W., Martin, P.A., Pak, D.K. and Spero, H.J., 2002: Reconstructing a 350 ky history of sea level using planktonic $\mathrm{Mg} / \mathrm{Ca}$ and oxygen isotope records from a Cocos Ridge core, Quaternary Science Reviews, 21: 283-293

Siddall, M., Rohling, EJ Almogi-Labin, A Hemleben, C, Meischner, D., Schmelzer, I. and Smeed, D.A., 2003: Sea level fluctuations during the last glacial cycle, Nature, 423: 853-858.

For full references please consult:

www.pages-igbp.org/products/newsletters/ref2009_2.htm termining the sensitivity of sea level response to insolation forcing. While records from submerged speleothems such as this are rare, they are archives that have enormous potential to shed light on the dynamics of climate and sea level in the

\section{Tempo of global deglaciation during the early Holocene: A sea level perspective}

SHI-Yong Yu, Y.-X. LI AND T.E. TörnQvist

Department of Earth and Environmental Sciences, Tulane University, New Orleans, USA; syu2@tulane.edu

\section{High-resolution early Holocene sea level records are essential to aid predictions of future sea level change. However, our current understanding about the nonlinear response of sea level to rapid climate changes during this critical time interval is still in its infancy.}

Sea level change is the result of complex interactions among the Earth's lithosphere, hydrosphere, atmosphere and cryosphere as a function of time. Geophysically, this change is defined as the vertical shift of the geoid, an equipotential surface of the Earth's gravitational field that coincides with the ocean surface, due primarily to variations in ocean mass and volume (Farrell and Clark, 1976; Mitrovica and Milne, 2003). This in turn leads to a complex spatio-temporal sea level response (Lambeck and Chappell, 2001). Therefore, studying past sea level changes from different time intervals and geologic settings can not only provide direct information about the dynamics of global ice volume (e.g., Peltier, 2004), but also about the physics of the Earth's interior that cannot be inferred seismologically (e.g., Kaufmann and Lambeck, 2002).

High-resolution sea level records also constitute an important knowledge base for predicting the behavior of future sea level, given the threat that global warming poses to low-lying coastal communities in terms of accelerated sea level rise. However, the predicted magnitude of sea level rise by the end of the $21^{\text {st }}$ century (e.g., 0.26-0.59 m (IPCC, 2007) and 0.5-1.4 $\mathrm{m}$ (Rahmstorf, 2007)) remains highly uncertain. This uncertainty lies primarily in our poor understanding of the dynamic response of ice flow to climate change (AIley et al., 2005; Oppenheimer et al., 2007). For example, transient processes that may lead to non-linear sea level responses were not considered in the IPCC Fourth Assessment Report (IPCC, 2007), and the model of Rahmstorf (2007) includes neither ice sheet physics nor makes use of any longer sea level records. Such longer, high-resolution sea level records have the potential to address these issues. Rather than giving answers, here we raise some key questions that may help guide the next wave of investigations. 
Conventional wisdom and current knowledge gap

Dating the vertical accretion of coral reefs in tropical oceans deepens our insight into the melting history of continental ice sheets since the Last Glacial Maximum (Fairbanks, 1989; Chappell and Polach, 1991; Bard et al., 1996). A compelling feature revealed by these data sets is not only the progressive rise of global sea level that started about $19 \mathrm{cal}$ ka BP and ceased by about $7 \mathrm{cal}$ ka BP but also the occurrence of episodic sea level jumps at about 19, 14.2 , and $11.3 \mathrm{cal} \mathrm{ka} \mathrm{BP.} \mathrm{Unlike} \mathrm{the} \mathrm{second}$ event, the occurrence of the first and last remains a matter of debate. To further address the rapidity of sea level rise during these time windows, other types of sea level records with smaller vertical errors, notably organic-rich sedimentary records from continental shelves (e.g., Hanebuth et al., 2000), preferably in microtidal settings, are required.

The existing coral records also indicate that the rate of sea level rise slowed from 11-8 cal ka $\mathrm{BP}$, mainly reflecting the reduced contribution from Antarctica (Nakada and Lambeck, 1988), and particularly the Laurentide Ice Sheet (LIS) during the final stage of its life cycle (Carlson et al., 2008). This can provide an analog to the present-day Greenland Ice Sheet (GIS), which might be a significant contributor to ongoing and future sea level rise. Recently, Carlson et al. (2007; 2008) reported evidence for episodically rapid ablation of the LIS around 9 and $7.6 \mathrm{cal} \mathrm{ka}$ BP, likely due to summer warming in the Hudson Bay area. This suggests that landbased ice sheets may be more sensitive to rapid climate change than previously thought, thus highlighting the potential threat of accelerated melting of the GIS to sea level rise within the context of global warming. However, the time series of LIS disintegration as documented by Carlson et al. (2008) is partly incompatible with sea level records that contain sufficient detail for (part of) this time interval (e.g., Van de Plassche, 1982; Törnqvist et al., 2006). For example, the Mississippi Delta sea level record shows an acceleration at about 8.2 cal ka BP (Törnqvist et al., 2004), while the data of Carlson et al. (2008) indicate a slow-down.

\section{High-resolution (centennial) sea} level records: A key to the future Given the broadly similar climatic conditions, sea level change during the early Holocene may be regarded as an analog for future sea level rise. Therefore, predictions of sea level rise using either empirical or numerical methods should make full use of these longer records. However, sea level changes during this time span are also dominated by an isostatic component. The late Pleistocene glaciation in high latitudes not only lowered global sea level but also depressed the underlying lithosphere, resulting in a peripheral bulge in large regions surrounding the area of glaciation. As ice sheets melted following glaciation, the deformed crust was restored to its original state. This process is commonly known as glacial isostatic adjustment (GIA), which in turn leads to spatially variable postglacial sea level changes. This spatial variability of sea level is illustrated in Figure 1. The Baltic Sea record (Fig. 1) represents a near-field (i.e., an area within a glaciated region) response of sea level, which is marked by a monotonic fall after about 7 cal ka BP, revealing the slow rebound of the crust well after the demise of the Fennoscandian Ice Sheet. The Mississippi Delta record (Fig. 1) is an expression of sea level history in the intermediate field. Sea level in such regions has experienced a progressive rise throughout the past $7 \mathrm{ka}$ as the result of collapse of the broad peripheral bulge around the LIS. The Malay-Thai Peninsula record (Fig. 1) is an example of far-field sea level response to meltwater addition to the oceans, as characterized by an apparent highstand at about 7 cal ka BP that was then followed by a continuous fall, due primarily to hydro-isostatic effects, the downwarping of ocean basins and associated uplift of continental margins caused by water loading as sea level rises.

A pattern shared by these records is the progressive rise of local sea level prior to 7 cal ka BP (Fleming et al., 1998), at least in part related to the rapid disintegration of the LIS (cf. Carlson et al., 2008). Superimposed upon this pattern, episodic sea level jumps at about 8.2 (Törnqvist et al., 2004) and 7.6 (Blanchon and Shaw, 1995; Yu et al., 2007) cal ka BP (Fig. 1) have been proposed. The former (Fig. 2) may well be associated with the catastrophic drainage of glacial lakes Agassiz and Ojibway (e.g.,

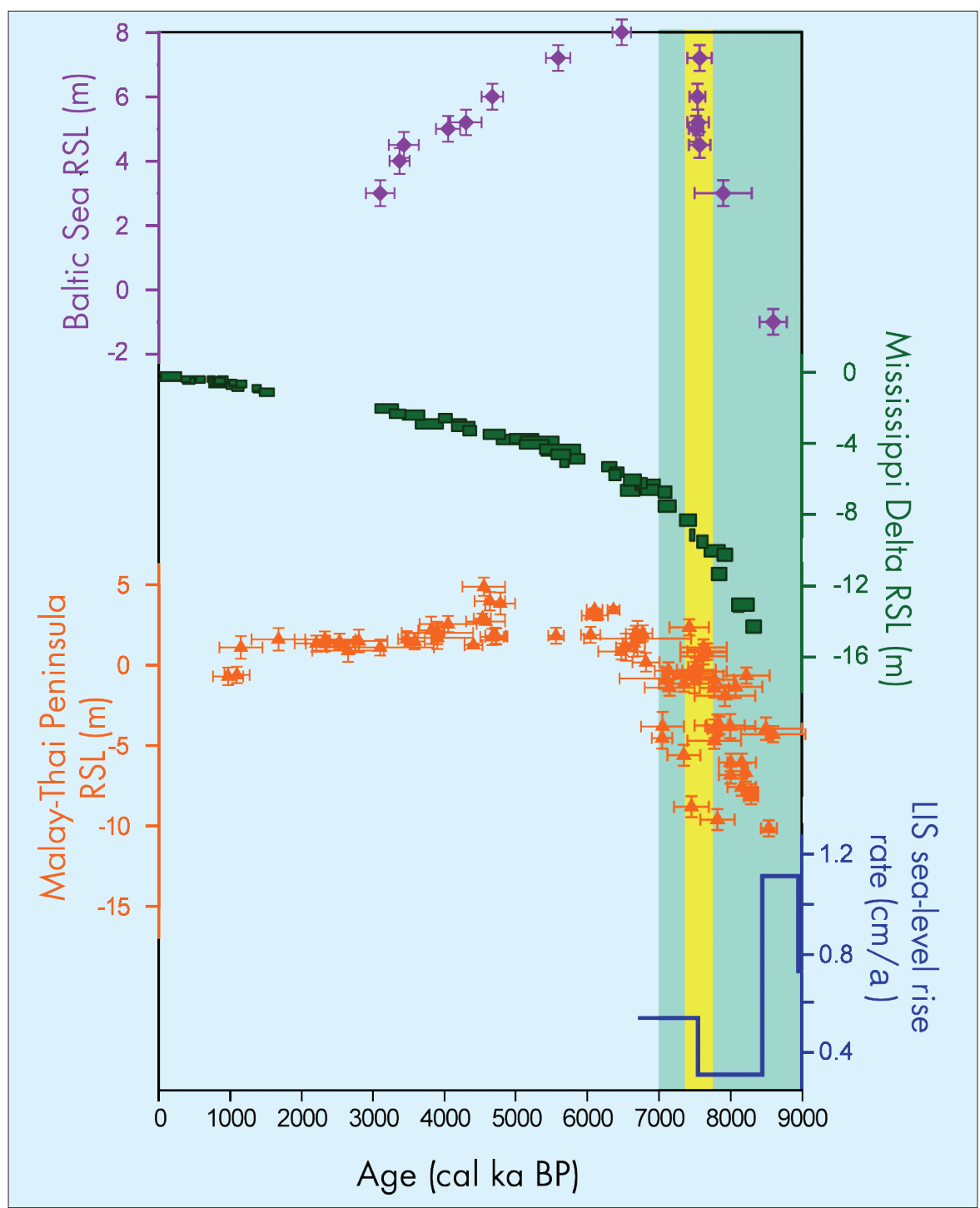

Figure 1: Comparison of Holocene relative sea level (RSL; height of sea level relative to the present-day datum) records from near-field (purple; Yu et al., 2007), intermediate-field (green; Törnqvist et al., 2006; plus unpublished data), and far-field (red; Horton et al., 2005); Blue plot shows rate of sea level rise from the decay of the Laurentide Ice Sheet (LIS; Carlson et al., 2008). Vertical blue bar highlights the period of sea level rise dominated by the ice-volume component; yellow bar highlights a rapid sea level rise event centered on 7.6 cal ka BP in the Baltic Sea record. 
(A)

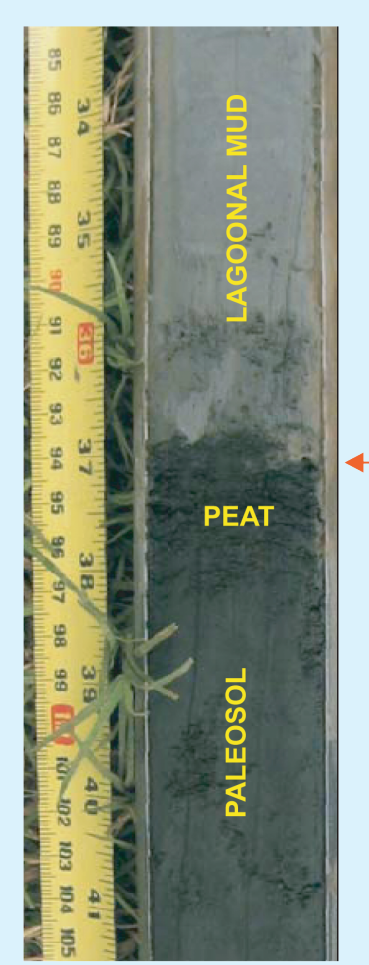

(B) North $\rightarrow$ South
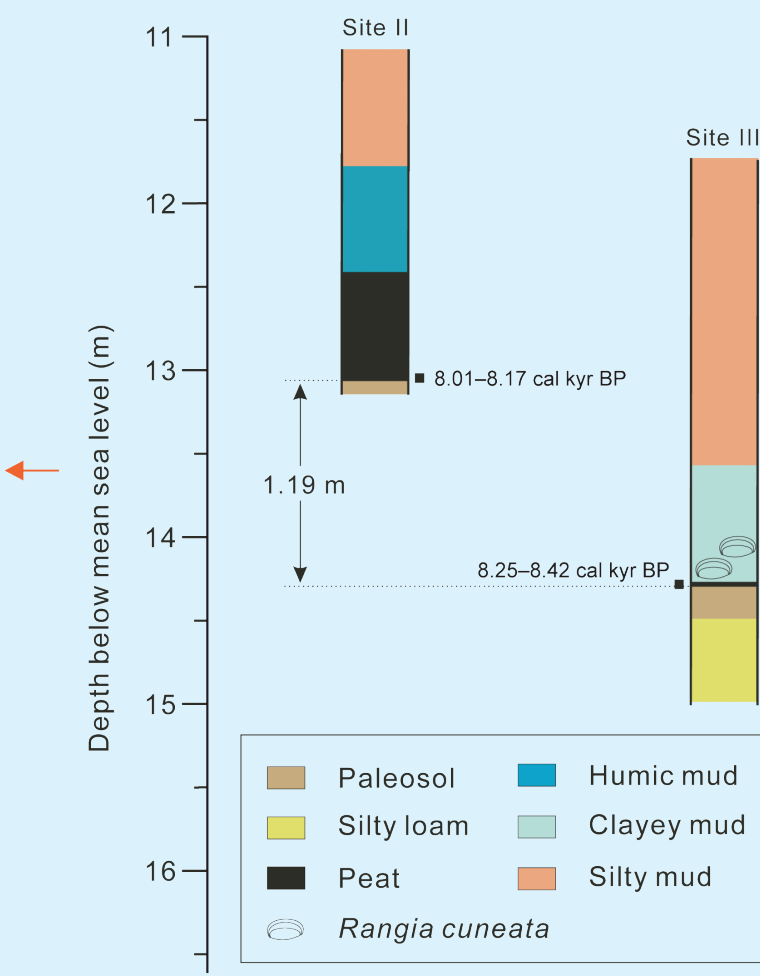

Figure 2: A) A sedimentary sequence including a paleosol (fossil soil) that caps the Pleistocene substrate, basal peat and lagoonal mud from the Mississippi Delta. Note the sharp contact (arrow) between the $\sim 2 \mathrm{~cm}$ thick peat layer and the overlying lagoonal mud, which represents an abrupt sea level rise at ca. 8.2 cal ka BP. B) Stratigraphic signature of the abrupt sea level rise at ca. 8.2 cal ka BP at Bayou Sale, Mississippi Delta (Törnqvist et al., 2004). The occurrence of Rangia cuneata, a brackish water clam characteristic of estuarine and lagoonal environments, is also shown.

Barber et al., 1999). This rapid sea level rise serves as an example of how the amount and source of meltwater can be inferred from sea level records by the fingerprinting method; a technique that capitalizes on the distinct spatial pattern of the global sea surface due to the gravitational attraction of large ice and/or water masses (Mitrovica et al., 2001; Clark et al., 2002;
Kendall et al., 2008). However, more detailed records are required to refine the estimate of the water volume impounded in these glacial lakes. To this end, our ongoing high-resolution sea level work in the Mississippi Delta aims to refine the timing and amplitude of the rapid sea level rise corresponding to the " 8.2 ka event" by detailed stratigraphic studies. With regard to the "7.6 ka event", its extent still remains a matter of debate. Some records suggest a ca. $3 \mathrm{~m}$ rapid rise that occurred at about 7.5 cal ka BP or slightly later (e.g., Siddall et al., 2003; Liu et al., 2004; Bird et al., 2007), while others indicate a smooth rise of sea level during this time window (e.g., Van de Plassche, 1982; Törnqvist et al., 2006). The causes of such spatial contrasts are at present unknown but may in part be related to the location of the associated meltwater sources and their sea level fingerprints. We therefore conclude that our understanding of rapid sea level rise during the early Holocene is still in its infancy. Many more high-resolution sea level records for this critical time interval are needed. Combined with "fingerprint modeling", they could serve to refine the timing, amplitude and origin of such abrupt events.

\section{References}

Carlson, A.E., Legrande, A.N., Oppo, D.W., Came, R.E., Schmidt, G.A., Anslow, F.S., Licciardi, J.M. and Obbink, E.A., 2008: Rapid early Holocene deglaciation of the Laurentide ice sheet, Nature Geoscience, 1: 620-624.

Kendall, R.A., Mitrovica, J.X., Milne, G.A., Törnqvist, T.E. and Li, Y., 2008 The sea level fingerprint of the $8.2 \mathrm{ka}$ climate event, Geology, 36 : $423-426$

Törnqvist, T.E., Bick, S.J., Gonzalez, J.L., van der Borg, K. and de Jong, A.F.M., 2004: Tracking the sea level signature of the $8.2 \mathrm{ka} \mathrm{cool}-$ ing event: New constraints from the Mississippi Delta, Geophysical Research Letters, 31: L23309.

Törnqvist, T.E., Bick, S.J., van der Borg, K. and de Jong, A.F.M., 2006: How stable is the Mississippi Delta? Geology, 34: 697-700.

Yu, S.-Y., Berglund, B.E., Sandgren, P. and Lambeck, K., 2007: Evidence for a rapid sea level rise 7600 yr ago, Geology, 35: 891-894.

For full references please consult:

www.pages-igbp.org/products/newsletters/ref2009_2.html

\section{Coastal vegetation evidence for sea level changes associated with Heinrich Events}

Catalina González and Lydie M. Dupont

MARUM - Centre for Marine Environmental Sciences, Geosciences Department, University of Bremen, Germany; catalina@uni-bremen.de

\section{A Cariaco Basin pollen record shows the development of tropical salt marshes during marine isotope stage 3 and suggests that millennial sea level changes during the periods encompassing Heinrich Events followed Antarctic climate variability.}

The timing of sea level changes during marine isotope stage 3 (MIS 3; 60-25 ka) is a key issue in understanding the role of ice sheets in millennial-scale climate variability. The available reconstructions of sea level changes during this interval greatly rely on oxygen isotope records from deep-sea cores (since coral-based data are sparse and chronologies less precise), and consistently show four cycles of similar amplitude of sea level change in the order of 20-30 m (Siddall et al., 2008 and references therein). However, there is little agreement on the exact timing of these changes or on the relative roles of the Southern and Northern Hemisphere ice sheets in global sea level scenarios.

The ecological response of sensitive terrestrial ecosystems can provide independent information that complements the almost exclusively marine body of evidence of millennial sea level change. For this purpose, intertidal tropical ecosystems can be particularly useful, since they are very sensitive to environmental gradients in the sea-continent interface.
In tidal salt marsh plant communities, species composition varies with elevation, usually in a banded pattern parallel to the shore. Its variation often reflects environmental gradients that result from the interaction between tidal regime, local topography, freshwater input, and biota. It has been proposed that the zonation is a spatial expression of successional changes over time and has potential to be reconstructed for the past by pollen analysis. If patterns of pollen deposition follow zonation and succession patterns, these can be 
reconstructed back in time by establishing a time-depth relationship with the fossil evidence, this then enables past sea level to be reconstructed. Here, we present new palynological evidence from the marine core MD03-2622 collected from the Cariaco Basin that reconstructs the history of intertidal plant communities during intervals associated with Heinrich Events (HEs), linking them to the well-constrained North Atlantic signal of millennial- to submillennial-variability.

The Cariaco Basin is located on the northern shelf of Venezuela and is particularly sensitive to the seasonal shifts of the Intertropical Convergence Zone (ITCZ), which deeply influence the hydrology and oceanographic features of the basin. During MIS 3, the Cariaco Basin record displays a clear North Atlantic climatic variability, shifting from dry conditions during cold stadials to wet conditions and increased river runoff during warm interstadials. This hydrological pattern is reflected by variations in the input of terrestrial materials and has been explained by the latitudinal migration of the ITCZ (Peterson et al., 2000; Peterson and Haug, 2006; González et al., 2008). The chronology used in this study was established by linking similar features of sediment reflectance profile of Cariaco site MD03-2622 with that of the nearby ODP Site 1002D, which has an extremely high-resolution age model for the past 60 ka (Hughen et al., 2004; 2006).

\section{Tropical salt marsh response to millennial climate and sea level changes}

During glacial periods, when sea level was 80-120 m lower than today, a broad shallow shelf became exposed south of the Cariaco Basin. Periods of extremely dry atmospheric conditions might, therefore, have resulted in hypersaline coastal environments (Medina et al., 1989). These extreme conditions could have been tolerated only by a limited number of plant species. Chenopodiaceae, Poaceae and Cyperaceae belong to the most common representatives of salt tolerant plants in tropical and subtropical wetlands (Adam, 2002) (Fig. 1).

\section{The pollen record}

Five high-amplitude vegetation shifts were recorded in the pollen record during MIS 3 (60-25 ka), indicating rapid oscillations of environmental conditions in northernmost South America. Recurrent salttolerant vegetation expansions (i.e., the development of salt marshes) were shown to correlate with HEs 3-6. Within single HE

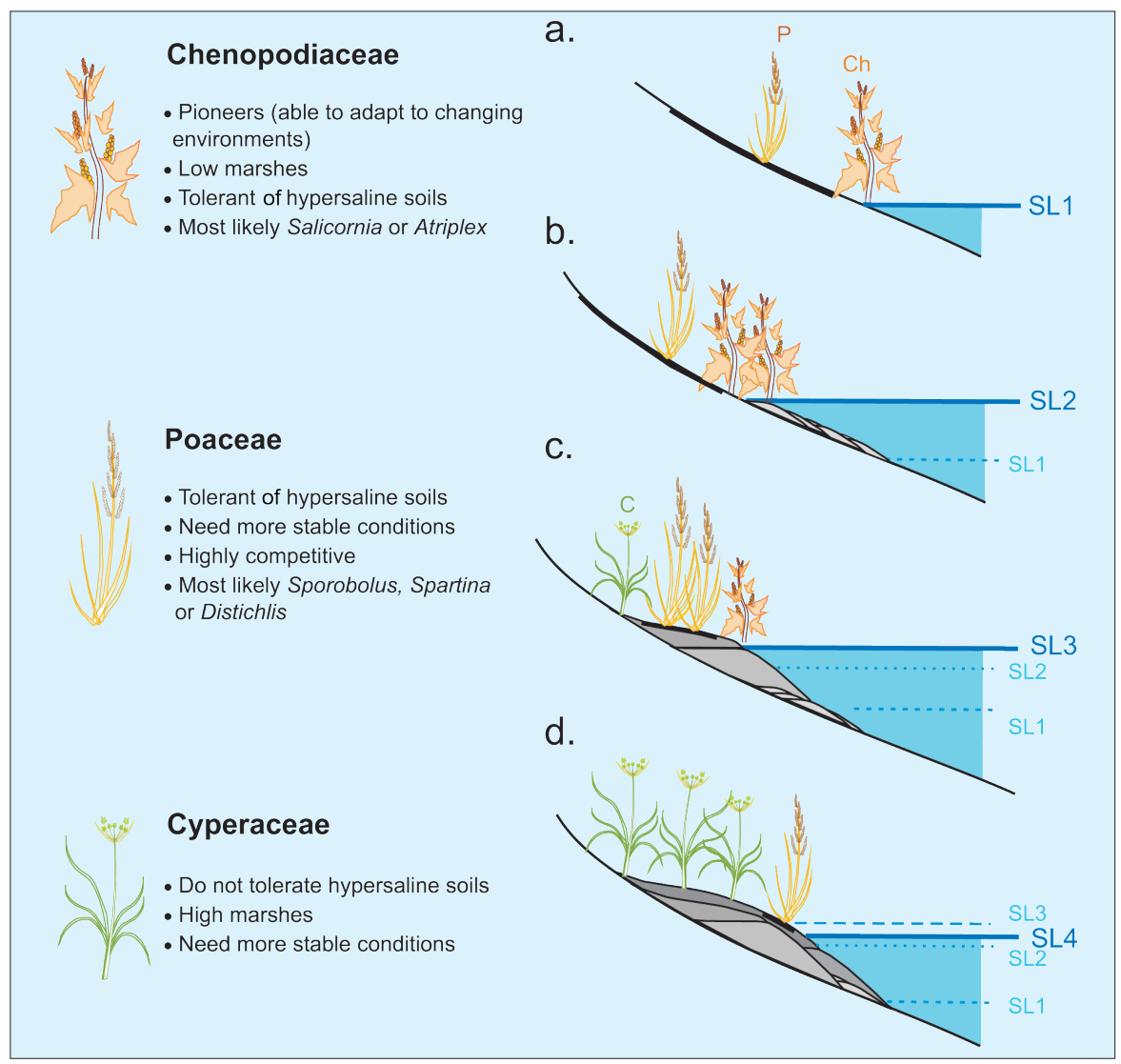

Figure 1: Left - main ecological preferences of 3 salt marsh taxa. Right - schematic representation of salt marsh community dynamics in a changing sea level environment according to the Cariaco Basin pollen record (González and Dupont, 2009). Thicker black lines indicate areas of soil hypersalinity. SL 1 to SL4 denote different sea levels reconstructed from the pollen record and correspond with phases indicated in Fig. 2. a) Establishment of salt marshes when arid condition s promote extensive hypersaline environments; $\boldsymbol{b}$ ) rapid sea level rise causes erosion; only pioneer species tolerate the change; $\boldsymbol{c}$ ) sea level rise decelerates, and accretion of sediments and autochthonous organic material takes place; more competitive species take advantage offavorable conditions; $\boldsymbol{d}$ ) sea level drops, sediment accumulation constrains the tidal influence to the seaward edge.

intervals, a recurrent and directional succession of pollen taxa was observed in the following order: Abrupt increases in saltbush (Chenopodiaceae) followed by a dominance of grasses (Poaceae), which in turn were replaced by sedge (Cyperaceae) (Fig. 2). Once interstadial conditions returned, salt marshes were replaced by mangroves and other arboreal species.

In this sequence, salt marshes started to develop under extremely arid stadial conditions (Peterson and Haug, 2006; González et al., 2008) when intertidal habitats became hypersaline due to extended periods of strong evaporation and reduced rainfall. The salt marshes were most likely restricted to narrow intertidal areas because under strongly seasonal conditions they are usually fringed on the landward side by extensive bare salt pans (Fig. 1a, b; Adam, 2002). Early colonizing species of salt marshes, like the annual Atriplex and Salicornia (Chenopodiaceae), first colonize bare zones of lower and middle marsh areas, with a high incidence of waves and prolonged inundation regimes (Ranwell, 1972). Thus, intervals of maximum pollen representation of Chenopodiaceae are interpreted as periods of direct tidal influence and sediment relocation. Frequent tidal flooding under accelerated sea level rise would result in flooding of the marsh surface, transforming it into a new seafloor, with the later landward accretion of new, low marsh sediments (Fig. 1b).

By comparing our high-resolution pollen data with sea level reconstructions from the Red Sea (Arz et al., 2007; Siddall et al., 2008 and references therein) and the independently dated fossil corals from the Huon Peninsula (Thompson and Goldstein, 2006) for the period between 40.5-38 $\mathrm{ka}$, we found that the phase dominated by Chenopodiaceae corresponds closely with an interval of accelerated sea level rise (Fig. 2). This confirms that only early successional plants, with high colonizing abilities (e.g., rapid growth, annuals or short-lived perennials) were capable of surviving the stressful high rates of change (Fig. 1a). Moreover, the erosion of low marsh sediments would wash out and transport the pollen produced in situ (Fig. 1b).

As soon as sea level rise decelerated (ca. 1 ka after the Chenopodiaceae peak), some vegetation was able to establish permanently. In low marsh areas, sediment accretion greatly depends on vegetation cover, which limits erosion, and enhances sediment and organic matter trapping. Thus, areas covered with vegetation experienced higher marsh heights. The 
build-up of middle and high marsh environments favored the expansion of more competitive perennial grasses (Poaceae), thus replacing Chenopodiaceae pioneer species (Figs. 1c, d and 2). In contrast, the presence of Cyperaceae indicates less saline conditions, since sedges do not tolerate salinity excess. Thus, since there is no evidence of increased freshwater input during HEs, Cyperaceae pollen maxima might reflect an expansion of elevated marsh areas (Fig. 1c, d).

Once interstadial conditions resumed and the average position of the ITCZ shifted northwards, the increased availability of freshwater might have alleviated salinity stress on soils, allowing a more complex plant community to develop on the shelf, and pushing the upper borders of the salt marsh seawards. Simultaneous increases in mangrove pollen (González and Dupont, 2009) confirm that coastal environments became less saline and increasingly suitable for the establishment of forests during stadial-interstadial transitions. In addition to freshening, decelerated sea level rise (or sea level fall) would be required to allow the establishment of mangroves, since mangroves do not survive if sea level rise occurs too rapidly (Ellison, 1993; Woodroffe, 1999).

\section{Comparison}

The Cariaco Basin pollen record also shows a similar relation between salt-marsh expansion and sea level rise during HEs 3, 5, $5 \mathrm{a}$ and 6 , in spite of dating uncertainties and poorer resolution of the vegetation data (González and Dupont, 2009). In all five cycles, maximum values of Chenopodiaceae pollen coincide with the onset of HE stadials in the North Atlantic, and with warming phases in Antarctica. According to our palynological evidence, sea level started to rise before the ice sheet collapse that caused Heinrich layers in the North Atlantic, being in agreement with both Red Sea sea level reconstructions during the HE 4 (Fig. 2; Siddall et al., 2008; Arz et al., 2007) and with fossil coral data from the Huon Peninsula (Thompson and Goldstein, 2006). However, a subsequent decelerated rise or fall of sea level is needed to reconcile with the expansion of Poaceae. In this case, our data supports the timing of central Red Sea reconstruction (Siddall et al., 2003; 2008; Rohling et al., 2008), the independently dated corals from the Huon Peninsula, and models, which suggest that melting in Antarctica might have accounted for a rise in sea level of about 20 m (Rohling et al., 2004; 2008; Flückiger et al., 2006).

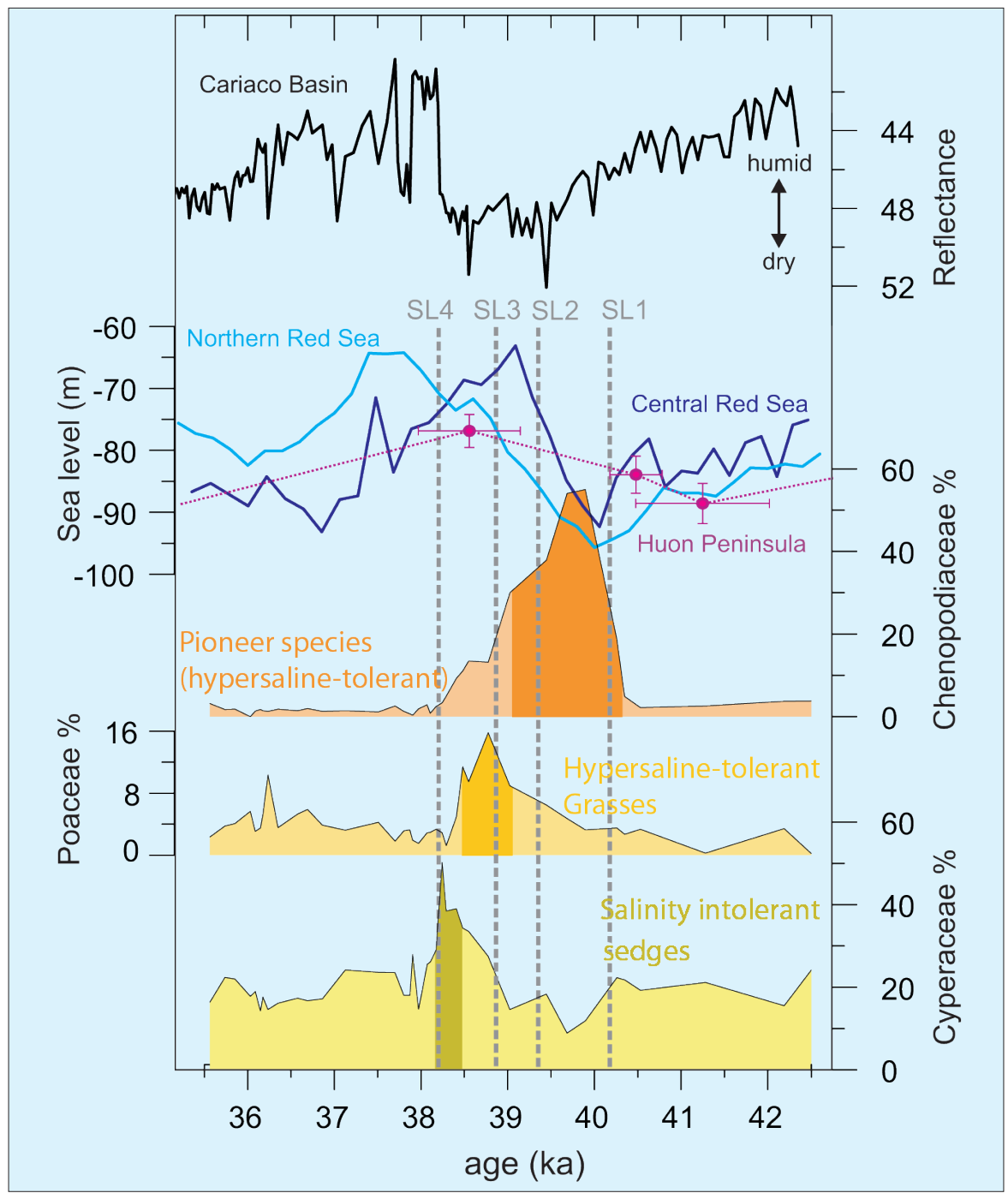

Figure 2: Comparison of the high-resolution palynological record from core MD03-2622 (Cariaco Basin) with sea level reconstructions from Red Sea marine sediment cores and Huon Peninsula (Papua New Guinea) fossil corals during HE 4 (González and Dupont, 2009). Top to bottom: Reflectance data from core MD03-2622 (Laj, 2004). Sea level data; dark blue line - central Red Sea (Siddall et al., 2003; 2008), light blue line-northern Red Sea (Arz et al., 2007), and dotted pink line- Huon Peninsula (Thompson and Goldstein, 2006). Pollen \% of Chenopodiaceae, Poaceae, and Cyperaceae indicating the directional alternation of salt marsh species during HE4. Dotted gray lines SL 1 to SL4 denote different sea levels reconstructed from the Cariaco Basin pollen record, which correspond to phases explained in Figure 1.

\section{Conclusions}

Through the palynological reconstruction of intertidal vegetation in core MD03-2622 we provided indirect evidence of rapid sea level change during MIS 3. Five intervals of expanded salt marsh vegetation corresponded to the onset of HEs of the northern high latitudes and suggest periods of accelerated sea level rise in the tropical Atlantic. The close relationship between sea level rise and community dynamics is consistent with a resource-based mechanism of succession, where soil development and salinity gradients are the main factors determining the vegetation dynamics of coastal marshes. In this context, the Cariaco Basin palynological record is especially informative on the timing of sea level changes during MIS 3 and their connection with HEs, supporting the idea that sea level fluctuations followed Antarctica climate variability.

\section{Acknowledgements}

This work was supported by the Programme Alßan -the European Union Programme of High Level Scholarships for Latin America (Scholarship E04D047330CO) - and the Deutsche Akademische Austausch Dienst (DAAD)-Colfuturo Program. Data will be available in PANGAEA (www.pangaea.de).

\section{References}

Adam, P., 2002: Saltmarshes in a time of change, Environmental Conservation, 29: 39-61

Arz, H.W., Lamy, F., Ganopolski, A., Nowaczyk, N. and Pätzold, J., 2007 Dominant Northern Hemisphere climate control over millennialscale glacial sea-level variability, Quaternary Science Reviews, 26: 312-321.

González, C. and Dupont, L.M., 2009: Tropical salt marsh succession as sea-level indicator during Heinrich events, Quaternary Science Reviews, 28: doi: 10.1016/j.quascirev.2008.12.023.

Siddall, M., Rohling EJ., Thompson, W.G. and Waelbroeck, C., 2008: Marine isotope stage 3 sea level fluctuations: Data synthesis and new outlook, Reviews of Geophysics, 46: RG4003, doi: 10.1029/2007RG00226.

Thompson, W.G. and Goldstein, S.L., 2006: A radiometric calibration of the SPECMAP timescale, Quaternary Science Reviews, 25: 32073215 . 


\section{Ice sheet-climate interactions during the ice age cycle}

Ayako Abe-Ouchi ${ }^{1}$ and Bette Otto-Bliesner ${ }^{2}$

1University of Tokyo, Japan; abeouchi@ccsr.u-tokyo.ac.jp; ${ }^{2}$ National Center for Atmospheric Research, Boulder, USA; ottobli@ucar.edu

\section{The impact of ice sheet size and geometry on both climate and the ice sheet itself is investigated with general circulation models. This information is used to simulate the observed change of ice sheet and sea level throughout the ice age cycle.}

Large ice sheets influence climate through changes in surface albedo, land and ocean temperature, atmosphere and ocean circulation, and other feedbacks in the climate system. The climate in turn drives ice sheet growth or retreat and thus drives changes in sea level. To estimate ice sheet and sea level change, it is crucial to evaluate these ice sheet-climate interactions (Clark et al., 1999). To simulate ice sheet evolution, past climateforcings are needed, and to simulate climate, an ice sheet shape (topographical distribution) is needed as a boundary condition. Future climate and sea level changes are being estimated using a combina- tion of general circulation models (GCMs) and ice sheet models. It is important to evaluate the ability of these models by performing paleoclimate experiments and validating them with paleoclimate data. It is, however, not an easy task because both the data and models are still far from perfect and contain many uncertainties. Moreover, computation of long timescales (tens of thousands of years or more) is not easy with a GCM. So far, two types of modeling efforts exist that are aimed at understanding the ice sheet-climate coupling process. Here, we discuss progress in these two approaches. One is the study of the response

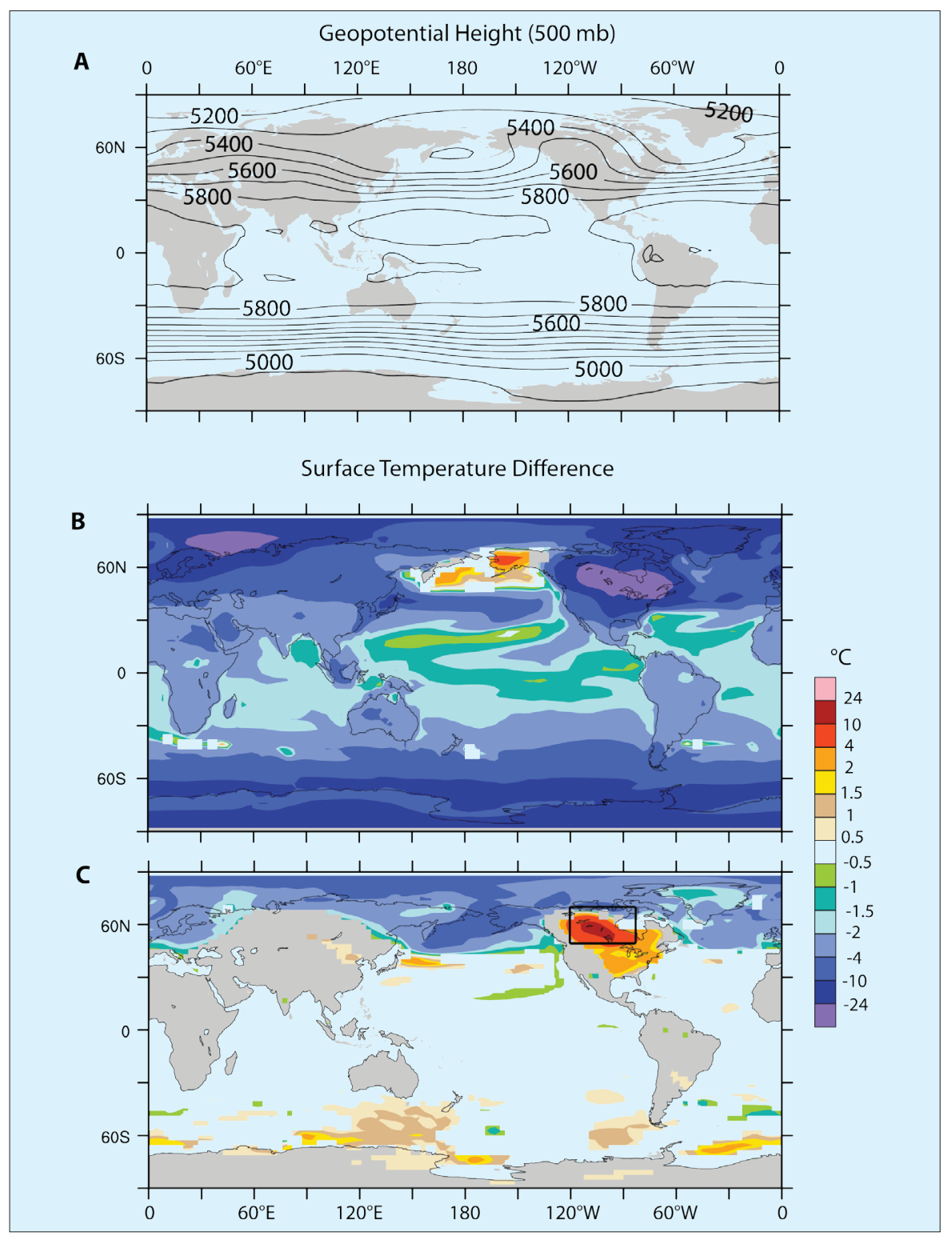

Figure 1: $\boldsymbol{A})$ Mean annual 500-mb geopotential height $(m)$ for the LGM simulation with ICE5G reconstruction; B) Annual surface temperature difference $\left({ }^{\circ} \mathrm{C}\right)$ for the LGM simulation with ICE5G reconstruction compared to a preindustrial simulation; C) Annual surface temperature difference $\left({ }^{\circ} \mathrm{C}\right)$ of $L G M$ simulations with reduced ice sheet topography (blackbox) minus regular (ICE5G) LGM simulation; only differences significant at 95\% are shown (Figure modified from Otto-Bliesner et al., 2006). of climate to a fixed ice sheet boundary condition, and the other is the study of the ice sheet evolution under climate forcing driven by information obtained from GCM experiments.

\section{Climate response to ice sheets}

The GCMs used for future projections have also been applied to the Last Glacial Maximum (LGM, ca. $21 \mathrm{ka}$ ), when the most recent large-scale ice sheets existed. These GCMs typically use a spatial resolution of $3-5^{\circ}$ in latitude and longitude to allow a number of sensitivity studies, although higher resolution GCMs with about 1 deg resolution in latitude and longitude are also being used for focused experiments to resolve the topographical and geographical boundary conditions of realistic ice sheets (Yamagishi et al., 2005; Jost et al., 2005; Abe-Ouchi et al., 2007). The most common experimental design for LGM experiments is to incorporate the boundary conditions different from present day for: 1) orbital parameters (Berger, 1978), 2) atmospheric greenhouse gas content (e.g., $\mathrm{CO}_{2}$ from ice cores), and 3) reconstructed global ice sheet topography (PMIP; Paleoclimate Modelling Intercomparison Project, Bracconot et al., 2007). Fortunately, the geographical distributions of the ice sheets are well documented for the maximum extent at the LGM and for the deglaciation phase (21-0 ka), while the thickness must be estimated by modeling. In the 1980s, the ice sheet reconstruction by the CLIMAP project assumed a parabolic ice sheet shape (CLIMAP, 1981), and for the last 15 years, global ice sheets were reconstructed using the geodynamical models ICE4G (Peltier, 1994) and ICE5G (Peltier, 2004). The ICE4G and ICE5G reconstructions differ in the spatial extent, height and volume of the ice sheets at the LGM. In ICE5G, the Laurentide Ice Sheet over North America contains significantly more volume than ICE4G, with the Keewatin Dome west of Hudson Bay 2-3 km higher over a broad area of central Canada. Further, in ICE5G the Fennoscandian Ice Sheet does not extend as far eastward into northwestern Siberia as it did in ICE4G.

Atmospheric GCM experiments have been performed with and without LGM ice sheets as a boundary condition. It has been shown that ice sheets at the LGM 
play a big role in modifying the westerly wind and surface pressure distribution, and in cooling the climate in the Northern Hemisphere, especially in mid- to high -latitudes (Rind, 1987; Manabe and Broccoli, 1985; Broccoli and Manabe, 1987; Felzer et al., 1996). The impact of ice sheets on atmospheric circulation is characterized by a stronger anticyclone over the ice sheet, a stronger trough and cold air over the east side of North America, a sharper storm track in the North Atlantic, and more precipitation in the southern periphery of the Laurentide Ice Sheet. Moreover, the impact is shown to be important not only in the North Atlantic but also in the North Pacific. The height of the Laurentide Ice Sheet has been shown to be important in these responses. The results of a sensitivity experiment replacing the high dome of the ICE5G Laurentide Ice Sheet with ICE4G heights from $50-70^{\circ} \mathrm{N}$, and $85-120^{\circ} \mathrm{W}$ and keeping the ICE5G heights elsewhere are shown in Figure 1 (Otto-Bliesner et al., 2006). Lowering of the high dome leads to less upper-air ridging and significant cooling both upstream and downstream of North America.

\section{Ice sheet evolution under climate forcing}

Ice sheet models can provide the time sequence of ice sheet shapes (area and topography) using ice sheet flow and thermo-mechanical coupling, as well as sliding and basal deformation (Marshall, 2005). For the climatic forcing to drive these ice sheet models, most models interpolate the monthly mean temperatures estimated from GCM simulations for LGM and pre-industrial time slices, and are weighted by the time sequence of isotopic temperature derived from Greenland ice cores (Charbit et al., 2007; Zweck and Huybrechts, 2005; Marshall and Clark, 2002; Tarasov and Peltier, 2004). These temperature and precipitation fields, together with the altitude effect according to a certain lapse rate (the temperature change per given altitude change), are given as the "forcing" to the ice sheet model. However, with this method the impact of astronomical forcing upon the change of seasonal insolation, which is key for ice age cycles in the Milankovitch theory (Milankovitch, 1930), is not taken into account. In these studies, the gravitational load of a thickening ice sheet in an LGM-run indirectly forces the fast spread of the ice, and results in formation of a flat ice sheet before it can reach the size of an IGE5G LGM ice sheet. On the other hand, the model setup limits the expansion of the ice sheets to the reconstructed LGM ice sheet extent.

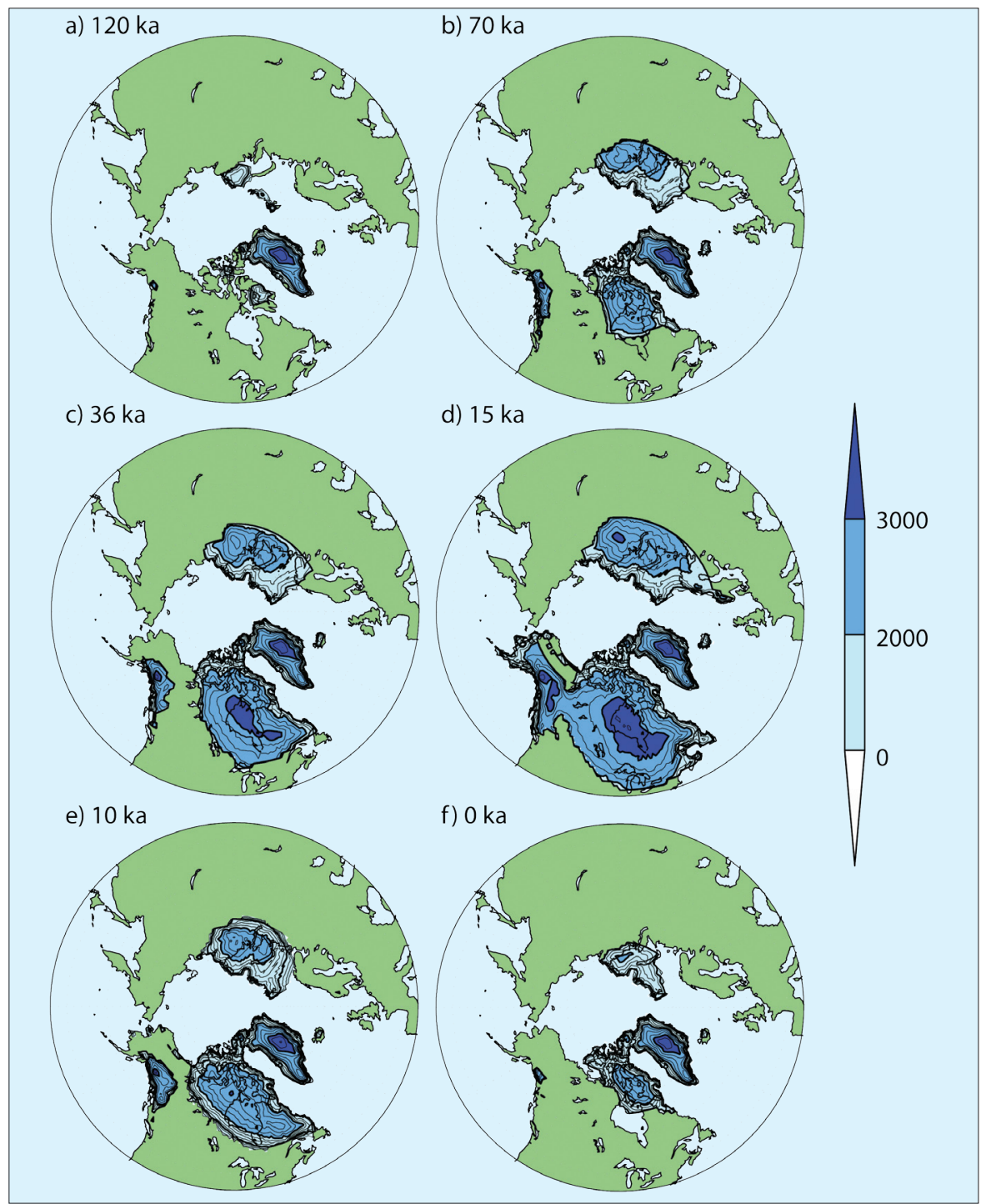

Figure 2: Simulated N. Hemisphere ice sheet distribution at different time slices. Contour intervals are $250 \mathrm{~m}$ (thin lines) and $1000 \mathrm{~m}$ (thick lines, blue shading). The approx. volume of each ice sheet in terms of sea level contribution is a) $-6 m, b)-52 m, c)-90 m, d)-138 m, e)-77 m, f)-27 m$. Figure modified from Abe-Ouchi et al. (2007).

To overcome this problem, an alternative method of forcing the ice sheet model has been proposed (Abe-Ouchi et al., 2007). Initially, several GCM experiments with different $\mathrm{CO}_{2}$ levels, orbital forcing and ice sheet size and height are carried out, to include the effects for driving ice sheets separately. In addition, the lapse rate for the ice sheet evolution can be estimated from these simulations, and it is found to be a smaller value than in many studies but is consistent with a study on the Antarctic Ice Sheet (Krinner and Genthon, 1999). When this information is used to drive a dynamical ice sheet model with the time series of $\mathrm{CO}_{2}$ from ice cores (Petit et al., 1999) and the insolation of Berger (1978), the ice sheet expansion and retreat are successfully simulated throughout the ice age cycle, as in Figure 2. The thickest part of the Laurentide Ice Sheet is in the eastern part of Canada near Hudson Bay and an ice-free part appears in Alaska, which is consistent with observations. Studies are on-going to improve model representation of basal processes and ice shelf/ice stream processes to obtain a thinner ice sheet over Eurasia.

Once the model successfully simulates ice sheet expansion and retreat, the causes and mechanisms of ice age cycles will be investigated in more detail with many sensitivity studies. Moreover, modeling is expected to enable studies linking past change to projections for the future.

\section{References}

Abe-Ouchi, A., Segawa, S. and Saito, F., 2007: Climatic Conditions for modelling the Northern Hemisphere ice sheets throughout the ice age cycle, Climate of the Past, 3: 423-438.

Braconnot, P. et al., 2007: Results of PMIP2 coupled simulations of the mid-Holocene and Last Glacial Maximum Part 1: experiments and large-scale features, Climate of the Past, 3: 261-277.

Marshall, S.J., 2005: Recent advances in understanding ice sheet dynamics, Earth and Planetary Science Letters, 240: 191-204.

Otto-Bliesner, B.L, Brady, E.C., Clauzet, G., Tomas, R., Levis, S. and Kothavala, Z., 2006: Last Glacial Maximum and Holocene Climate in CCSM3, Journal of Climate, 19: 2526-2544.

Yamagishi, T., Abe-Ouchi, A., Saito, F., Segawa, T. and Nishimura, T., 2005 Re-evaluation of paleo-accumulation parameterization over Northern Hemisphere ice sheets during the ice age examined with a high-resolution AGCM and a 3-D ice-sheet model, Annals of Glaciology, 42: 433-440.

For full references please consult:

www.pages-igbp.org/products/newsletters/ref2009_2.html 


\section{ADOM - Atmospheric circulation dynamics during the last glacial cycle: Observations and modeling}

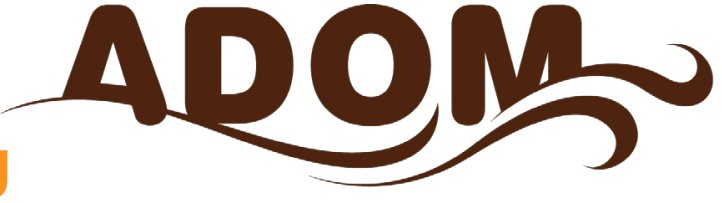

Denis-Didier Rousseau' ${ }^{1}$, C. Hatte ${ }^{2}$ and I. Tegen ${ }^{3}$

'Lab. de Meteorologie Dynamique and CERES-ERTI, Paris, France; denis.rousseau@Imd.ens.fr

2UMR CEA-CNRS-UVSQ, Gif-sur-Yvette, France; ${ }^{3}$ Leibniz Institute for Tropospheric Research, Germany

Atmospheric circulation is responsible for rapid distribution of heat and moisture across the earth and hence determines our weather and regional climate, today and in the past. Records from eolian deposits consistently suggest that atmospheric dynamics were highly variable during the last glacial cycle, resulting in alternating periods of extremely dusty and non-dusty conditions, on timescales of millennia and shorter (Andersen et al., 2006; GRIP members, 1993; Petit et al., 1999; Porter and An, 1995; Rousseau et al., 2007; Steffensen et al., 2008; Tada et al., 1999). Yet records differ considerably from different regions, archives and proxies. The strong atmospheric variations during the last glacial interval provide particularly good test-cases for how well we understand atmospheric circulation on all levels of conceptual and numerical modeling. However, this requires good knowledge of the patterns of prevailing atmospheric paleocirculation on various regional scales, as well as timing of atmospheric variability relative to other parameters of climatic and environmental change.

The PAGES Working Group ADOM aims to combine eolian-based circulation reconstructions from terrestrial, marine and ice records-in addition to model simulations of past and present atmospheric circulation-to produce detailed knowledge of the processes driving atmospheric dynamics at the regional to hemispheric scale. This knowledge can eventually be upscaled to understand global atmospheric teleconnections.

ADOM will be officially launched at the first of four workshops in November 2009 (www.pages-igbp.org/science/ adom/adom-north.html). Titled "High-mid latitude northern atmospheric circulation changes during the last climate cycle", this workshop will focus on the mid- to high-latitude circulation in the Northern Hemisphere where loess records from North America, Europe and Asia, and dust records from Greenland, the North Atlantic and the North Pacific provide a comprehensive database. The workshop will explore strategies to derive quantitative and physically consistent synoptic reconstructions by integration of dust records,

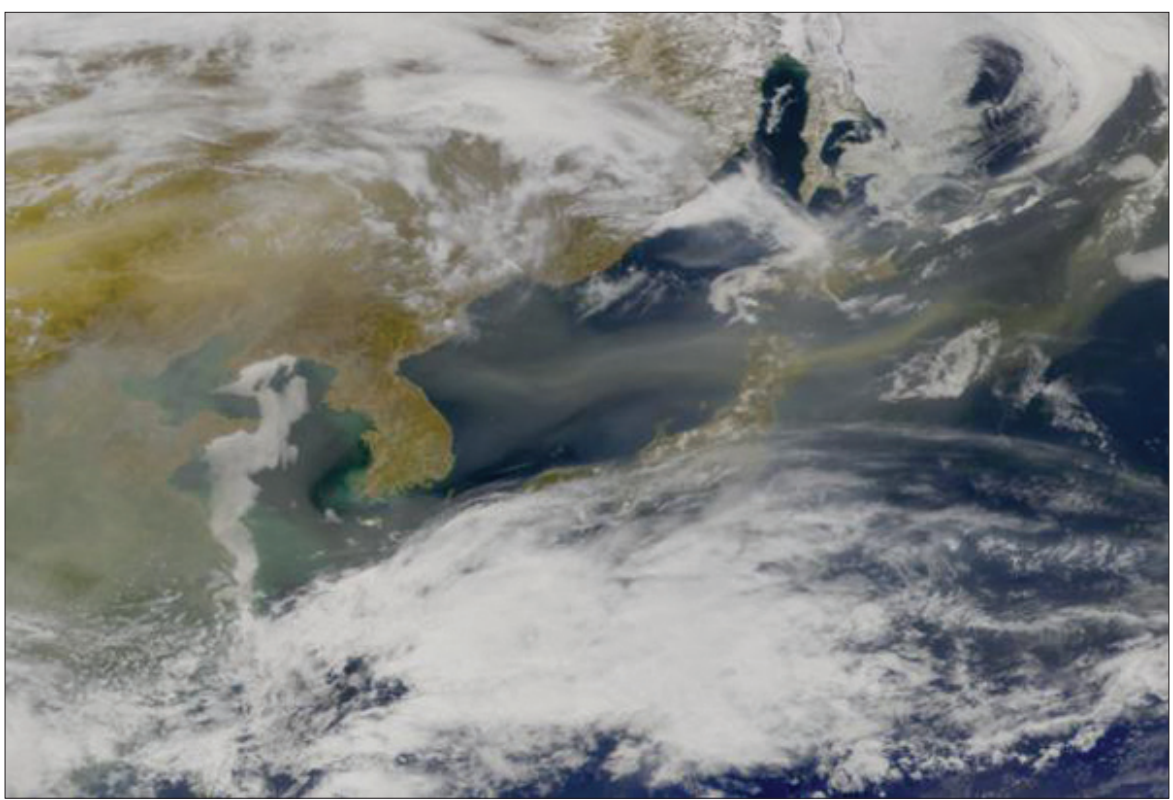

Figure 1: Satellite picture (SeaWifs) of an Asian dust event (Source: NASA, 2001).

climate observations and model simulations. The specific objectives of this meeting will be to:

- Review datasets and model results relevant to atmospheric paleocirculation Define commonalities and differences between regions, archives and proxies - Identify links between dust deposition and abrupt climatic and environmental change

- Summarize the current knowledge on past atmospheric dynamics

- Compare data records with modeling results

- Identify the critical gaps in knowledge and data for reconstructions and modeling

\section{- Outline group papers}

The second and third workshops will similarly address the atmospheric circulation

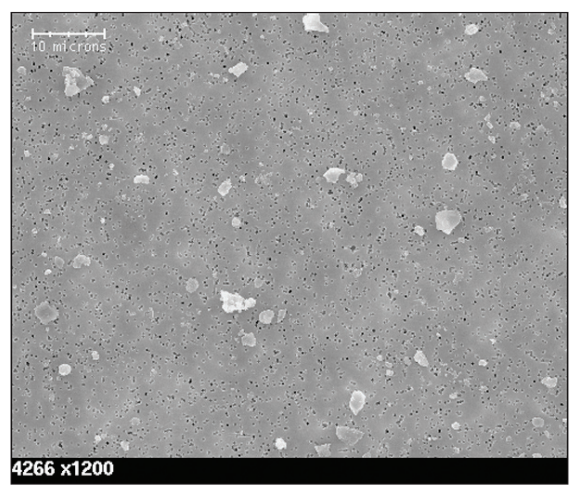

Figure 2: Dust particles filtered from Antarcticice (EPICA, Photo: J-R Petit) changes during the last climate cycle but will focus on the low-latitudes and the Southern Hemisphere, respectively. The final workshop will synthesise results on a global scale.

Beyond publication of results in the peer-reviewed literature, ADOM also aims to provide database access to data and model simulations, and contribute to quantifying the past climate forcing from mineral dust aerosols (with PAGES Focus 1 and QUEST-Dust).

\section{Note}

For more information on ADOM, please see www.pages-igbp.org/science/adom/

\section{References}

Andersen, K.K. et al., 2006: The Greenland Ice Core Chronology 2005 15-42 ka, Part 1: constructing the time scale, Quaternary Science Reviews, 25: 3246-3257.

GRIP members, 1993: Climate instability during the last interglacial period recorded in the GRIP ice core, Nature, 364: 203-207.

Petit, J.R. et al., 1999: Climate and atmospheric history of the past 420,000 years from the Vostok ice core, Antarctica, Nature, 399 : 429-436

Porter, S.C. and An, Z.S., 1995: Correlation between climate events in the North Atlantic and China during the last glaciation, Nature, 375: 305-308

Rousseau, D.D., Sima, A., Antoine, P., Hatté, C., Lang, A. and Zoeller, L, 2007: Link between European and North Atlantic abrupt climatic changes over the last glaciation, Geophysical Research Letters, 34: doi:10.1029/2007GL031716.

For full references please consult:

www.pages-igbp.org/products/newsletters/ref2009_2.html 


\title{
Termination of the Medieval Warm Period: Linking sub- polar and tropical N Atlantic circulation changes to ENSO
}

Antoon Kuijpers' ${ }^{1}$, B.A. Malmgren², M.-S. Seidenkrantz ${ }^{3}$

'Geological Survey of Denmark and Greenland, Copenhagen, Denmark; aku@geus.dk 2Norrtälje, Sweden; ${ }^{3}$ Department of Earth Sciences, University of Aarhus, Denmark

\begin{abstract}
Paleoceanographic evidence from the N Atlantic subpolar gyre and NE Caribbean indicates a major, longterm change in ocean-atmosphere circulation modes around AD 1230, indicating that the termination of the Medieval Warm Period prevailing circulation mode occurred prior to the Wolf Solar Minimum, apparently without an obvious external trigger.
\end{abstract}

\section{Medieval warming and Little Ice Age climate anomalies}

Historical records and proxy climate data from the Northern Hemisphere have provided evidence for higher average temperatures in the period between ca. $A D$ 800 and $A D$ 1200. The existence of this Medieval Warm Period (MWP) is not only demonstrated by climate data from northern Europe but is also found elsewhere in the Northern Hemisphere. Significant temporal and regional differences did exist however, and the case for a global MWP is more inconclusive than indicated by global records for the following colder era, termed the Little Ice Age (LIA), which spanned the period from ca. AD 1350 to 1850 (Broecker, 2001).

Several theories have been proposed to explain the possible cause of the climate anomalies experienced during the MWP and LIA. Shindell et al. (2001) explained these anomalies by long-term solar variations that modulate the atmospheric circulation. Other mechanisms, such as sulfate aerosols ejected into the atmosphere by volcanic eruptions and changes in large-scale ocean circulation, are also proposed to have played an important role (Broecker, 2000; Crowley, 2000). It has often been reported that variations in sea ice can influence thermohaline circulation (e.g., Mauritzen and Häkkinen, 1997). Such variations in sea ice and polar water (PW) advection have occurred on widely different timescales with periodicities of decades, centuries and millennia, and have had major impacts on North Atlantic climate (e.g., Bond et al., 1997; Andrews et al., 2003). Increased fluxes of low salinity PW may reduce or even shut down deepwater formation in the Nordic Seas, leading to regional cooling. At the same time, however, it may result in significant warm anomalies in thermocline waters of the tropical Atlantic (Dahl et al., 2005). With marine sediment-core data presented below, we underline possible linkages between subpolar and tropical North Atlantic circulation changes associated with the termination of the MWP. This information contributes to a better understanding of polar-tropical Atlantic teleconnections at the transition from a warmer to a colder climate regime.

\section{West Greenland Current changes and medieval cooling}

A recent study of sediment cores collected from West Greenland fjord and shelf environments (Figs. 1, 2A) showed clear evidence for cooling of West Greenland Current water masses at the beginning of the MWP that persisted into the following centuries (Seidenkrantz et al., 2007; 2008). This regional early cooling is also reflected in reduced melt-water production from the West Greenland inland ice margin, as indicated by decreased amounts of the land-derived elements $\mathrm{Ti}, \mathrm{K}$, and Fe measured by XRF-scanning of sediment cores (Møller et al., 2006). Notably, during the same period between ca. AD 730 and AD 1100 , the climate of the eastern Greenland Nansen Fjord region was warmer

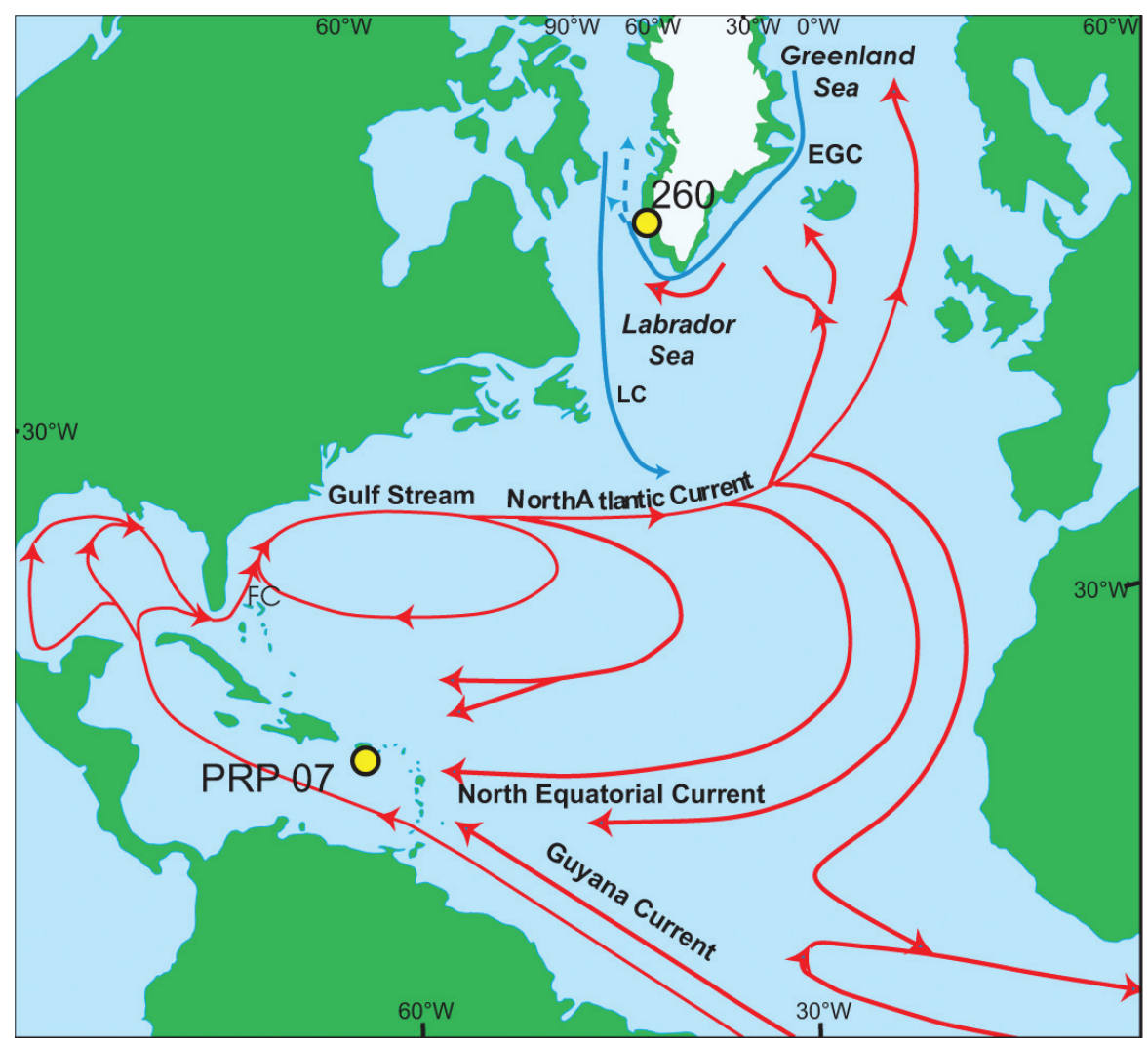

Figure 1: Map of the North Atlantic with location of gravity core 248-260-2 from Ameralik Fjord, SW Greenland and the NE Caribbean study of core PRP-07 (box core and piston core). Blue lines indicate cold Polar Water transport pathways ( $E G C=$ East Greenland Current, $L C=$ Labrador Current); red lines and arrows show the main warm water transport pathways of the North and Equatorial Atlantic. and more stable than today (Jennings and Weiner, 1996), and the GISP2 Greenland ice core record indicates warmer climate conditions than in the following LIA (Stuiver et al., 1995). In comparison, from present climate variability we know that although global average temperature has been rising over the past decades, during the late $20^{\text {th }}$ century, a well-documented cooling prevailed in the Hudson Strait region (Kasper and Allard, 2001). Cooling during the late $20^{\text {th }}$ century has also been reported from coastal southern Greenland and the adjacent Labrador Sea (Hanna and Cappelen, 2003). Immediately after AD 1200 , the sediment core record indicates enhanced subsurface transport of warmer Irminger Sea Water advected by the West Greenland Current (Fig. 2A). Other paleoceanographic evidence of increased subsurface advection of Atlantic water masses elsewhere in South Greenland fjords (Lassen et al., 2004) confirms this LIA feature 
Core 248260

Ameralik Fjord

SW Greenland

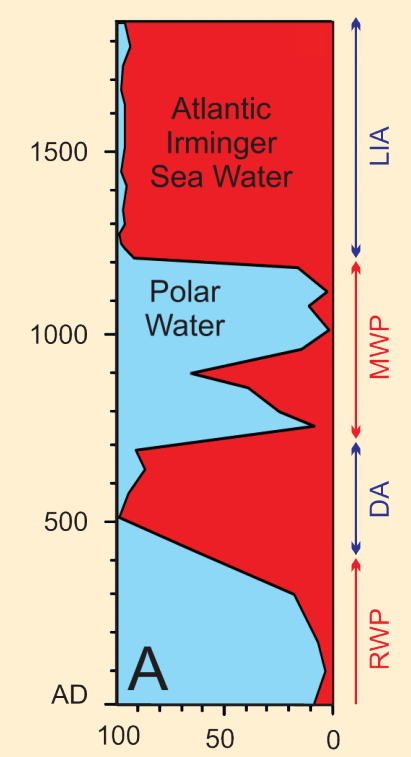

$\%$ calcareous vs.

agglutinated foraminifera strength of ISW advection

Figure 2: A) Variations in the strength of Irminger Sea Water (ISW) transport by the West Greenland Current based on benthic foraminiferal studies of a core from AmeralikFjord, SW Greenland (Seidenkrantz et al., 2007). Note increased ISW transport during colder European (winter) climate of the Dark Ages and Little Ice Age. B) Cold (winter) season (CS) and warm season (WS) SST variations over the southern Puerto Rico insular slope since AD 800 reconstructed for core PRP-07 by the Artificial Neural Networks (ANN) method (Malmgren et al., 2001). RWP= Roman Warm Period, $D A=$ (European) Dark Ages, MWP = Medieval Warm Period, LIA = Little Ice Age, MW = Modern Warming.

to be typically associated with North (East) Atlantic cooling. For the recent climate, it can be shown that warming of the subpolar gyre during the 1950s and most of the 1960s (Levitus et al., 1994) coincided with a generally colder European winter and a more frequent negative North Atlantic Oscillation (NAO). Thus, shortly after AD 1200, Irminger Current water mass transport into the northern Labrador Sea apparently intensified, while sediment diatom records from the southeast Greenland shelf (Jensen, 2003) show a decreased influence of Irminger Sea water for this time.

\section{Northeast Caribbean SST since AD 800}

A 2.70-m-long piston core PRP-07 was retrieved from the southern insular slope of Puerto Rico at $17^{\circ} 52.82^{\prime} \mathrm{N} 66^{\circ} 35.90^{\prime} \mathrm{W}$ (Fig. 1), where water depth is $273 \mathrm{~m}$. At the same site, a 0.20-long box core was collected. Surface-water flow in the region is controlled by interannual and seasonal variability of the North Equatorial Current and Guyana Current. Upper water masses are Caribbean Surface Water and Tropical Atlantic Central Water (TACW; Metcalf, 1976; Wüst, 1964). The inflow of warm, saline TACW into the eastern Caribbean is at a maximum during winter, when the Intertropical Convergence Zone (ITCZ) is far-
Core PRP 07

Puerto Rico, Caribbean

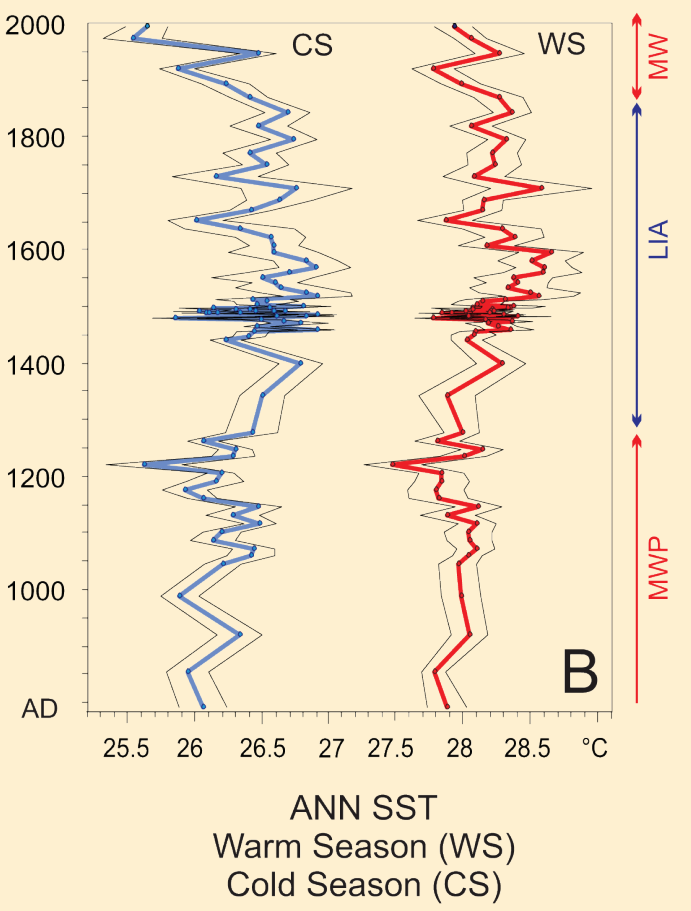

the ITCZ and North Atlantic cyclone belt. Warmer NE Caribbean (winter) SST dominating during the LIA may thus be related to a more southerly ITCZ favoring stronger advection of warm TACW into the area, and favored additionally by positive SST anomalies prevailing east of the Caribbean under a more negative NAO mode.

\section{Subpolar - tropical and ENSO linkage}

Actual ENSO teleconnections imply, amongst other things, colder winter climate over NE Canada and a cooler NE Caribbean during La Niña years. Our sediment core data for the MWP indicate cooling offshore West Greenland and lower NE Caribbean SST prior to ca. AD 1230, suggesting more frequent La Niña years and a positive NAO mode associated with a more northerly ITCZ during the MWP. This supports the study by Mohtadi et al. (2007), who reported southern high-latitude cooling and reduced ENSO activity during the MWP with a sustained northward shift of Southern Hemisphere zonal systems between 1300 and $750 \mathrm{yr}$ BP. After AD 1230, southward movement of the ITCZ favored a more frequent negative NAO mode leading to higher NE Caribbean SST and colder NE Atlantic climate, which can thus be linked to Southern Hemisphere climate changes. As the above changes occurred prior to the Wolf Solar Minimum, ocean-atmosphere circulation modes appear to have the potential of a significant shift without an obvious external trigger, possibly due to non-linear response of the system after surpassing critical boundary conditions.

\section{References}

Bakke, J., Lie, Ø., Dahl, S.O., Nesje, A. and A.E. Bjune, 2008: Strength and spatial patterns of the Holocene wintertime westerlies in the NE Atlantic region, Global and Planetary Change, 60: 28-41.

Broecker, W.S., 2001: Was the Medieval Warm Period global? Science, 291: 1497-1499.

Malmgren, B.A., Winter, A. and D. Chen, 1998: El Nino-Southern Oscillation and North Atlantic Oscillation control of climate in Puerto Rico, American Meteorological Society Notes and Correspondence, October 1998: 2713-2717

Mohtadi, M., Romero, 0.E., Kaiser, J. and D. Hebbeln, 2007: Cooling of the southern high latitudes during the Medieval Period and its effect on ENSO, Quaternary Science Reviews, 26(7-8): 1055-1066.

Seidenkrantz, M.-S., Aagaard-Sørensen, S., Sulsbrück, H., Kuijpers, A., Jensen, K.G. and Kunzendorf, H., 2007: Hydrography and climate of the last 4400 years in a SW Greenland fjord: implications for Labrador Sea palaeoceanography, The Holocene, 17(3): 387401. values between AD 1400 and AD 1850 (LIA). Evidence for a worldwide change in atmospheric circulation change between AD 1200 and AD 1250 is found both in the Southern Hemisphere (Mohtadi et al., 2007) and at northern high latitudes (Lassen et al., 2004; Bakke et al., 2008). This change involves a change in El NiñoSouthern Oscillation (ENSO) boundary conditions, and (southward) migration of
For full references please consult: www.pages-igbp.org/products/newsletters/ref2009_2.html 


\section{Reading the first early Cenozoic central Arctic sediment record: A palynological view}

Francesca Sangiorgi ${ }^{1,2}$, A. Sluijs ${ }^{1}$, J. Barke ${ }^{1}$ and H. Brinkhuis ${ }^{1}$

'Laboratory of Palaeobotany and Palynology, Institute of Environmental Biology, Utrecht University, Netherlands; f.sangiorgi@uu.nl

2 Department of Marine Biogeochemistry and Toxicology, Royal Netherlands Institute for Sea Research, Texel, Netherlands

Palynological analyses performed on long sedimentary records from the crest of the Lomonosov Ridge (Arctic Ocean) indicates that the Arctic developed from a warmer-than-expected, semi-isolated, shallow, freshwater dominated, eutrophic basin during the early Paleogene, to a sea-ice and iceberg dominated ocean during most of the Neogene. During the Eocene, the environmental changes were orbitally paced, with a biological response strongly affected by obliquity.

The Cenozoic history of the Arctic Ocean was largely unknown from direct evidence prior to Integrated Ocean Drilling Program (IODP) Expedition 302 (or ACEX, the Arctic Coring EXpedition) in 2004, when sediments were drilled on the crest of the Lomonosov Ridge (LR), in water depths of $1300 \mathrm{~m}, 250 \mathrm{~km}$ from the North Pole (Fig. 1).

The spliced stratigraphic section of $430 \mathrm{~m}$ (Fig. 1) includes an Upper Cretaceous basement, underlying sediments that were deposited on the LR after its rifting from the Eurasian continental margin $\sim 58 \mathrm{Ma}$ (Glebovsky et al., 2006). An unexpected hiatus from $\sim 44-\sim 18$ Ma separates the Paleogene "Greenhouse" from the Neogene "Icehouse" sections (Moran et al., 2006; Backman et al., 2008; Sangiorgi et al., 2008a). Four years of intensive, multidisciplinary research has resulted in a basic understanding of the Arctic environment, oceanography and climate. The picture obtained, however, represents only snapshots of the Lomonosov Ridge during its migration from the Eurasian continent to its present location, and suggests a basin geographically different from today's during most of the early Cenozoic (Fig. 1). The Arctic developed from a warmer-than-expected, semi-isolated, shallow, freshwater dominated, eutrophic basin during much of the early Palaeogene (e.g., Brinkhuis et al., 2006; Sluijs et al., 2006; Pagani et al., 2006), to a sea-ice and iceberg dominated ocean during most of the Neogene (Moran et al., 2006; Darby et al., 2008; Krylov et al., 2008). Along with providing the most continuous biostratigraphical tool (Backman et al., 2008, Fig. 1), palynology (the study of organic-walled dinoflagellate cysts (dinocysts), pollen, spores and other organic remains) has been pivotal for unraveling the history of the Arctic basin across several intervals of the Cenozoic.

\section{Paleocene-Eocene Greenhouse and "hyperthermals"}

Dinocyst assemblages throughout the latest Paleocene and early Eocene, including the PETM (Paleocene/Eocene Thermal

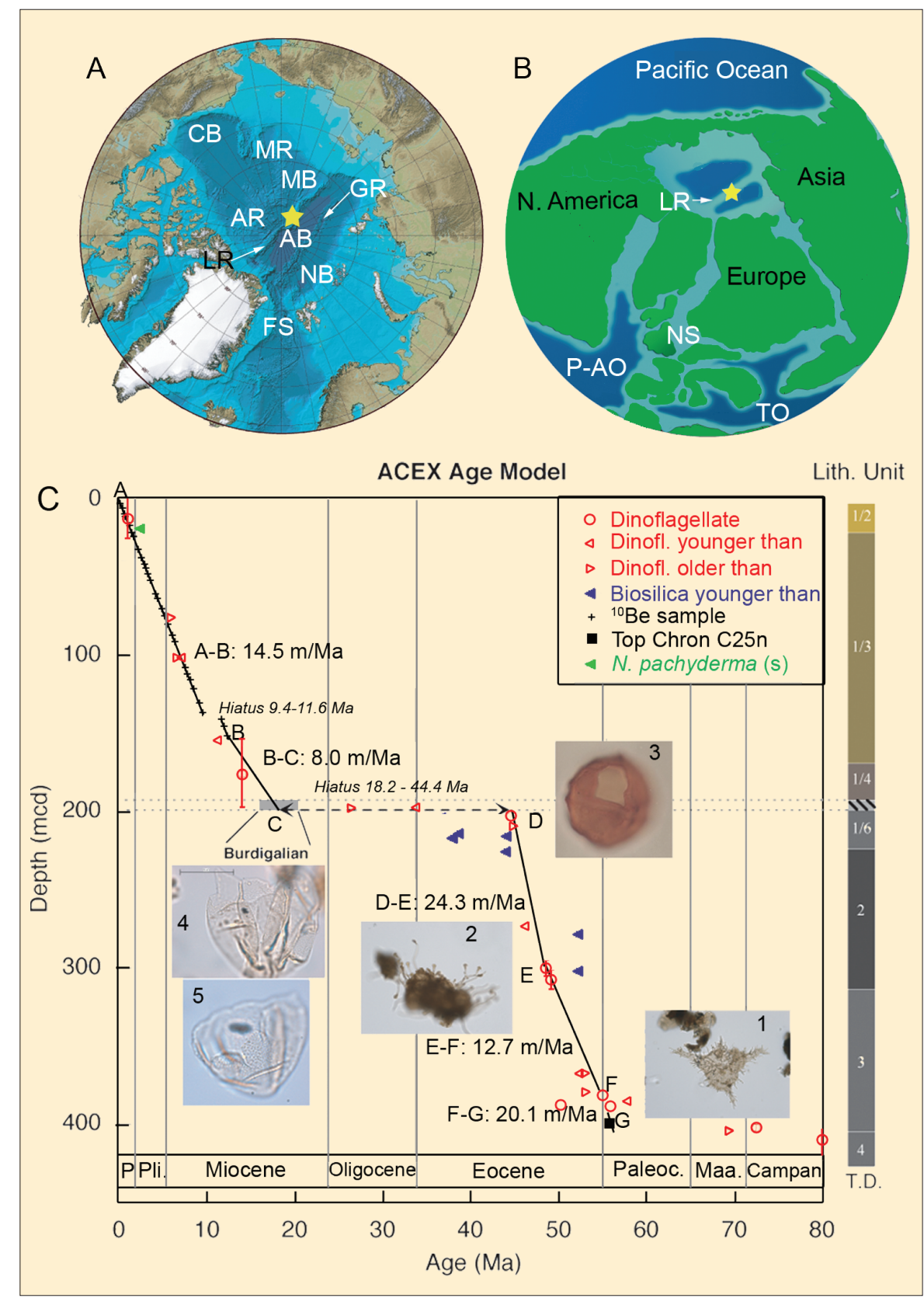

Figure 1: A) Arctic Ocean map (modified from International Bathymetric Chart of the Arctic Ocean, Jakobsson et al., 2000), with indication of the Arctic sub-basins and ridges: AR, Alpha Ridge; FS, Fram Strait; GR, Gakkel Ridge; LR, Lomonosov Ridge; MR, Mendeleev Ridge; MB, Makarov Basin; NB, Nansen Basin; AB, Amundsen Basin; CA, Canada Basin. Star indicates the location of IODP 302 drilling on the LR; B) Location of drilling within the early Eocene paleogeographical reconstruction of the Arctic Ocean (Brinkhuis et al., 2006) TO, Tethyan Ocean; P-AO, Proto-Atlantic Ocean; NS, North Sea; C) ACEX age model (modified from Backman et al., 2008) with indication of the Lithologic Units (Lith. Unit) and sub-units (Expedition 302 Scientists, 2006). Pictures of the dinoflagellate cysts Apectodinium augustum (1), Phthanoperidinium clithridium (3), Arcticacysta backmanii (4), A. moraniae (5) and the remains of Azolla (2) used as biostratigraphical markers are also shown. The palynological events considered in building the age model in the early Cenozoic are: Last Occurrence (LO) of A. augustum (F), LO of Azolla (E), Last Abundant Occurrence of P. clithridium (D) and the mid point of the Burdigalian stage where A. backmanii and A. moraniae occur (C). The oldest identified paleomagnetic chron datum (top of magnetochron C25n, Chron (25n), (G) deepest Berillium-10 samples (B) and top of the section (A) on which the age model is based are also shown. TD: Terminal Depth. Depth scale in meters composite depth (mcd). 


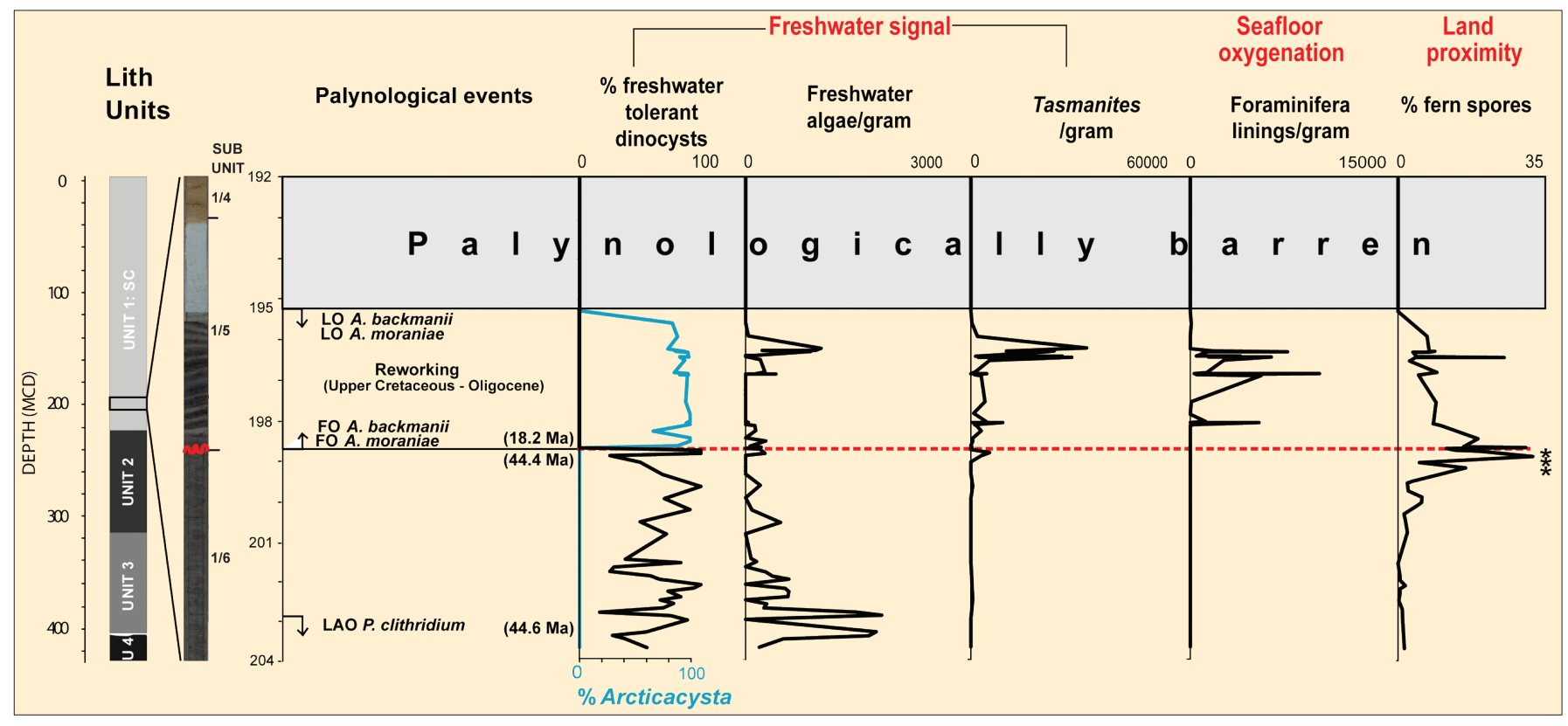

Figure 2: $\boldsymbol{A}$ ) Lithostratigraphic column showing the lithologic units and sub-units recognized in the ACEX section (Expedition 302 Scientists, 2006); $\boldsymbol{B}$ ) image of the core section showing the hiatus (wiggly red line); $\boldsymbol{C}$ ) Dinocyst events used to identify the location and duration of the hiatus, see text for full species names, $L O=$ last occurrence, LAO = last abundant occurrence, $F O=$ First Occurrence; $\boldsymbol{D})$ Selected palynological proxies and their environmental interpretation, hiatus = red dashed line, Asterisks = abundant occurrence of fungal spores (see text). Depth scale in meters composite depth (mcd).

Maximum, $\sim 55 \mathrm{Ma}$ ), point to brackish and productive Arctic surface waters (Sluijs et al., 2008). The influx of Apectodinium spp., which prior to the PETM were characteristic of (sub)tropical regions, suggests a significant warming during the PETM (Sluijs et al., 2006). Consistent with this interpretation is an organic biomarkerbased concomitant sea surface and air warming from an initial temperature value of 18 to $23^{\circ} \mathrm{C}$ (Sluijs et al., 2006; Weijers et al., 2007). Sea level rose, while anoxic and euxinic (i.e., anerobic, waters with restricted circulation) conditions developed in the bottom waters and photic zone, respectively (Sluijs et al., 2006), favored by increased moisture delivery to the Arctic and a strong hydrological cycle and, consequently, an enhanced geological weathering cycle (Pagani et al., 2006; Schouten et al., 2007; Sluijs et al., 2008). Such high temperatures imply unexpectedly small poleequator temperature gradients, far from the expectations based on paleoclimate models (e.g., Huber and Nof, 2006), and require feedback mechanisms other and/ or stronger than those already included in the simulations (Sluijs et al., 2006). Approx. $20 \mathrm{~m}$ above the PETM section, the Eocene Thermal Maximum 2 ( 53.5 Ma) was identified in the core (Stein et al., 2006; Sluijs et al., 2008) and is currently subject to intensive dinocyst and geochemical analyses.

\section{The Arctic "lake" phase: The Azolla event}

Large quantities of remains of the freefloating freshwater fern Azolla were found in the LR core at the onset of the middle Eocene ( 49 Ma). Abundant Azolla remains are characteristic of middle Eocene marine deposits of all Nordic seas (e.g., Bujak and Mudge, 1994). Since Azolla concentrations in the LR core were found to be one order of magnitude higher than elsewhere, the Arctic was likely the source of Azolla transported to the Nordic seas. Azolla and accompanying abundant freshwater organic microfossils indicate episodic, cyclic, orbitally (likely obliquity) driven freshening of Arctic surface waters during an $\sim \mathrm{Ma}$ interval, (Brinkhuis et al., 2006; Speelman et al., in press). The Azolla phase is accompanied by an increase of $\sim 3 \%$ in the total organic carbon from background levels. This increased carbon burial may have influenced the global carbon cycle (Speelman et al., in press), as the termination of the Azolla phase coincides with the beginning of the long-term Cenozoic cooling (e.g., Zachos et al., 2008). The cause(s) for the termination of the Azolla phase are still largely unknown. The Azolla demise coincides with a local sea surface temperature rise from $10^{\circ} \mathrm{C}$ during the Azolla phase to $13^{\circ} \mathrm{C}$ at its demise, pointing to simultaneous increases in salt and heat supply owing to the influx of waters from adjacent oceans (Brinkhuis et al., 2006). On-going (paleo-)ecological, botanical, physiological and geochemical studies, together with growing experiments on the living relative(s) of the fossil Azolla, are being performed at Utrecht and Nijmegen Universities (The Netherlands), in collaboration with international partners, to better constrain the Azolla event (duration, geographical distribution, effect on the carbon cycle, etc.) in the Eocene Arctic. These will shed light on the climatic and oceanographic importance of the Arctic Ocean during warm greenhouse conditions and its implication for global climate. More information on the on-going "Azolla project" is available at www.bio.uu.nl/ palaeo/ Azolla/Azolla.htm

\section{The first sea ice in the mid- Eocene and orbital modulation of environmental changes}

Middle Eocene ( 46 Ma) cores also contain evidence of ice-rafted debris, as indicated by grain texture and composition analyses of terrigenous sand (St. John, 2008). The same sediments have revealed strong cyclicity in the terrigenous sand accumulation, in several geochemical elements, and in biological proxies (dinocysts, pollen and spores, siliceous microfossils) (Sangiorgi et al., 2008b; Spofforth et al., 2008). Freshwater-tolerant dinocysts, pollen of flowering plants and chrysophyte cysts (freshwater siliceous microfossils) cyclically alternate with marine dinocysts, bisaccate pollen and marine diatoms, suggesting paced environmental changes. These results indicate that the biological response is strongly affected by obliquity (growing season length/darkness) at times of seaice formation in the Arctic, whereas the terrigenous components, directly driven by sea ice and/or glacial ice formation and extent, responded more directly to seasonal insolation (precession) (Sangiorgi et al., 2008b).

\section{Hiatus at the greenhouse- icehouse transition}

Biostratigraphical analyses, based mainly on dinocysts, have identified a $\sim 26 \mathrm{Ma}$ hiatus from the late middle Eocene ( 44.4 Ma) 
to the late early Miocene ( 18.2 Ma) (Figs. 1 and 2; Sangiorgi et al., 2008a; 2008c).

The hiatus is marked by a sharp change in sediment color, a few meters above the last abundant occurrence of the middle Eocene marker dinocyst species Phthanoperidinium clithridium. Sediments above the hiatus contain a new dinocyst genus, Arcticacysta, likely of Miocene (Burdigalian) age (Sangiorgi et al., 2008c). The two species found, Arcticacysta backmanii and $A$. moraniae, co-occur and dominate the interval, where sparse reworked dinocysts of Cretaceous to Oligocene age are also found (Fig. 2). Palynological analyses suggest that the hiatus marks the transition from an anoxic environment with a fresh-brackish water lid, to an estuary-like environment, where high freshwater in- put co-occurred with oxygenated bottom waters. When the sediments become palynologically barren (Fig. 2; Sangiorgi et al., 2008a), a fully ventilated oxic marine environment develops, likely as result of the opening and the deepening of the Fram Strait (Jakobsson et al., 2007). High abundance of fern and fungal spores in the sediments around the hiatus indicate that sediment deposition occurred either close to shore or on land, suggesting that unexpectedly, the Lomonosov Ridge remained at or near sea level for the duration of the gap, likely as a consequence of tectonic activity (O'Regan et al., 2008).

\section{Acknowledgements}

We thank the Netherlands Organisation for Scientific Research (NWO) for funding, and the In- tegrated Ocean Drilling Program for providing samples and data. Stefan Schouten, Jaap Sinninghe Damsté, ACEX co-chiefs Jan Backman and Kate Moran, and all the ACEX colleagues are thanked for the fruitful collaboration.

\section{References}

Backman J. et al., 2008: Age Model and Core-Seismic Integration for the Cenozoic ACEX Sediments from the Lomonosov Ridge, Paleoceanography, 23: PA1S03, doi:10.1029/2007PA001476

Brinkhuis, H. et al., 2006: Episodic fresh surface water in the Eocene Arctic Ocean, Nature, 441: 606-609.

Sangiorgi, F. et al., 2008a: A 26 million year gap in the central Arctic record at the Greenhouse-Icehouse transition: Looking for clues, Paleoceanography, 23: PA1504, doi:10.1029/2007PA001477

Sangiorgi, F. et al., 2008b: Cyclicity in the middle Eocene central Arctic Ocean sediment record: orbital forcing and environmental response, Paleoceanography, 23: PA1508, doi:10.1029/2007PA001487

Sluijs A. et al., 2006: Subtropical Arctic Ocean temperatures during the Paleocene/Eocene thermal maximum, Nature, 441: 610-613.

\title{
Potential imprint of changes in multidecadal climate variability on temperature reconstructions of the past millennium
}

\author{
Michael Schulz and Matthias Prange \\ MARUM - Center for Marine Environmental Sciences and Faculty of Geosciences, University of Bremen, Germany; mschulz@uni-bremen.de
}

\section{Model results suggest that the wider spread of individual Northern Hemisphere temperature reconstructions during cold phases of the last millennium may partly reflect enhanced climate variability at multidecadal timescales.}

A wide range of reconstruction techniques and proxy data have been used to infer how mean temperature of the Northern Hemisphere has changed over the past millennium (Jansen et al., 2007). This research is driven by the important question of whether the rate and amplitude of the warming during the past decades is unprecedented in the framework of the last millennium, that is, before humans affected the Earth System at an unparalleled magnitude.

The individual reconstructions (Jansen et al., 2007; Fig. 6.10 therein) agree with respect to the overall evolution of Northern Hemisphere temperature. This evolution comprises a warming towards the Medieval Warm Period (centered on the $11^{\text {th }}$ century $\left.A D\right)$, a subsequent cooling culminating in the Little Ice Age $\left(16^{\text {th }}\right.$ to mid- $19^{\text {th }}$ century $A D$ ), followed by the most recent warming. The reconstructed centennial-scale variability is thought to be mainly driven by changes in total solar irradiance and possibly also by volcanic eruptions (Jansen et al., 2007 and references therein). Upon closer visual inspection, the temperature reconstructions reveal that the widest spread between the reconstructions occurs before and after the Medieval Warm Period (Jansen et al., 2007; Fig. 6.10 therein). That is, the overlap between the individual reconstructions seems to be better for warm than for cold intervals.

Although each reconstruction is based on a proxy calibration in the recent warm

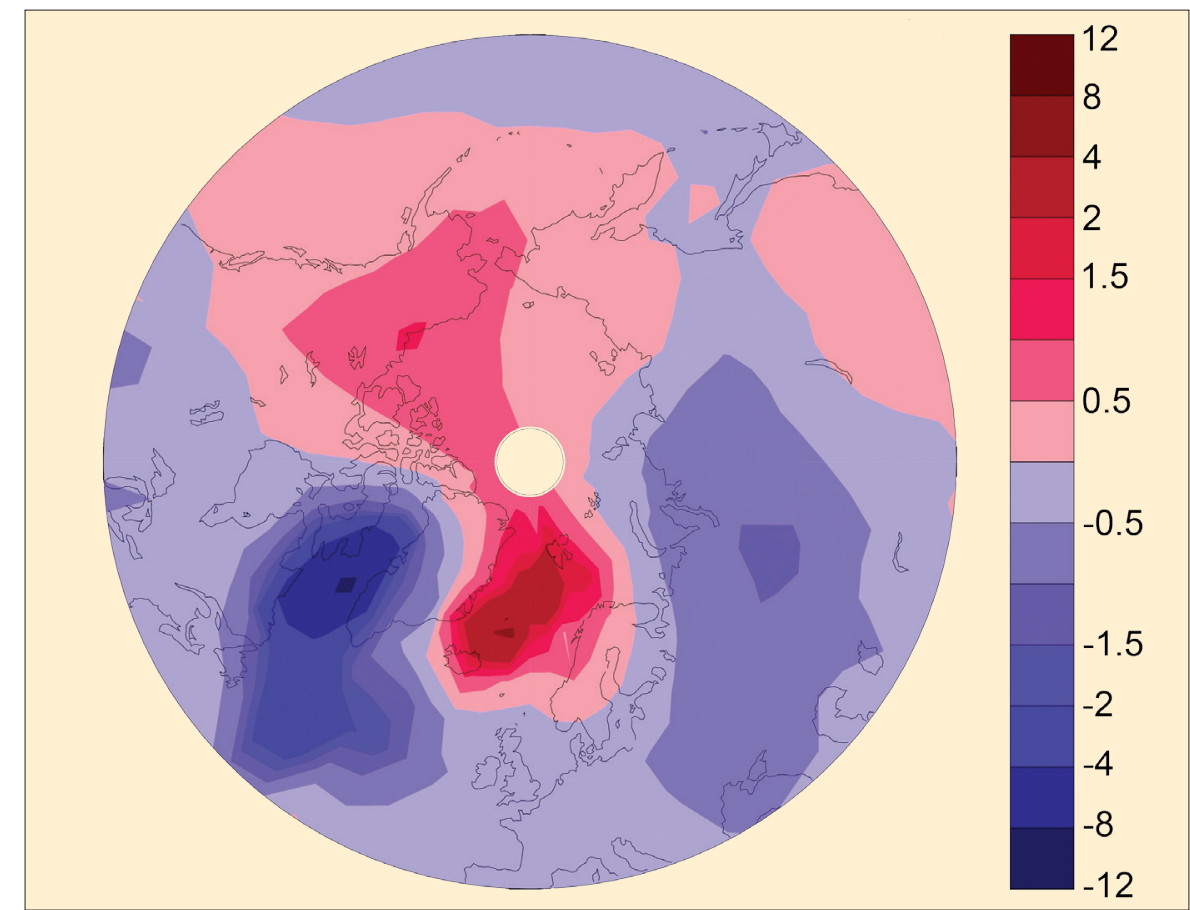

Figure 1: Surface air-temperature difference $\left({ }^{\circ} \mathrm{C}\right)$ between cold and warm mode in the Northern Hemisphere.

period, it appears that the divergence between the individual reconstructions cannot be entirely explained by such a calibration bias (cf., Mann et al., 2008). Another reason for the difference between the reconstructions could be changes in the density of the underlying proxy network, 


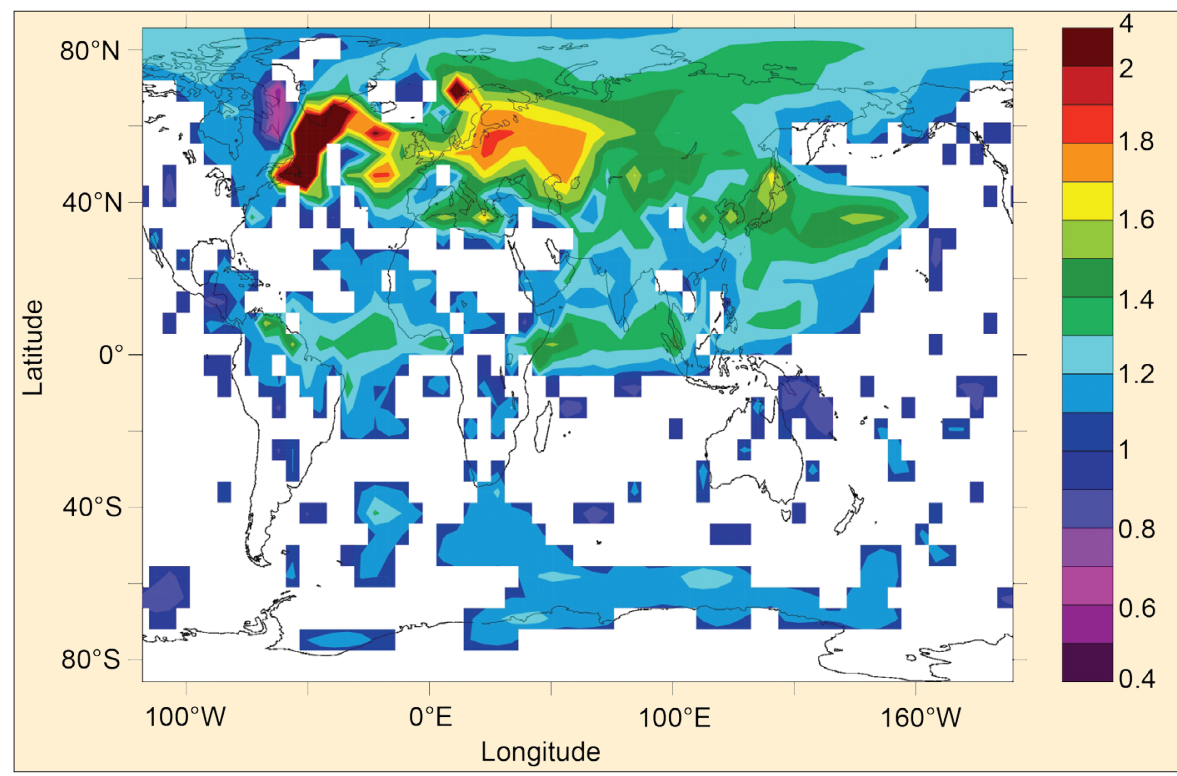

Figure 2: Ratio between surface-temperature standard deviation during the cold and warm modes, respectively. Values larger than unity indicate enhanced temperature variability at multidecadal timescales in the cold mode. Ratios are only depicted if they differ significantly $(a=0.01)$ from unity, taking the autocorrelation of the time series into account

which is relatively sparse prior to $1400 \mathrm{AD}$. However, as the number of proxy records increases with time, changes in the density of the network alone cannot explain the reduced spread of the reconstructions seen during the transition from the warm $11^{\text {th }}$ into the somewhat colder $12-13^{\text {th }}$ century AD. Here we put forward the idea that the larger spread between the reconstructions during colder phases results from sparse sampling of a temperature field with higher temporal variability.

Model results using a 3D Earth System model of intermediate complexity suggest that the meridional overturning circulation of the Atlantic Ocean can exhibit self-sustained oscillations at centennial to millennial timescales for modern boundary conditions (see Schulz et al., 2007 for further details). The oscillations are characterized by phases of active and inactive deepwater formation in the Labrador Sea. In contrast, deepwater formation in the Nordic Seas is active during all phases of the oscillations. The cessation of deepwater formation in the Labrador Sea during one part of an oscillation excites anomalies in surface temperature that amount to several degrees Celsius over large parts of the Northern Hemisphere at mid-latitudes (Fig. 1). While the principal pattern of these temperature anomalies is rather stable, the actual extent of the anomalies may vary from one oscillation to the next. Due to the overall cooling in the eastern sector of North America as well as over most of Europe we will refer to this phase of the oscillation (i.e., without deepwater formation in the Labrador Sea) as the "cold" mode. The corresponding interval with active deepwater formation will be referred to as the "warm" mode. We argued earlier (Jongma tennial to millennial timescales.

To assess the temperature changesfurther, we analyzed separately the variance of the annual mean surface temperature field within the warm and cold phases of the oscillations. For this purpose, we created two composite time series for the warm and cold mode at each model grid point. The variability in the model at century and longer timescales is associated with the transitions between warm and cold mode. Hence, the composite time series capture only variability at interannual to multidecadal scales. Since our main interest is in multidecadal climate variability, the composite time series were smoothed with a 20-year wide boxcar filter. Subsequently the variance of surface temperature was estimated at each grid point for the warm and cold mode. The model results indicate that temperature variability increased up to 1.7-fold over large parts of northeastern Europe and central Asia during the cold mode (Fig. 2). Over most of North America and the Southern Hemisphere, the model suggests no significant change in variability between the two modes. Upon closer inspection, the model data reveal that the larger variability during the cold mode downstream of the northern North Atlantic is associated with a larger variability in sea ice cover during the cold mode compared to the warm mode.

The band of increased temperature variability extending from Europe to Asia coincides to a large extent with the area from which a large number of proxy records have been generated to quantify temperature changes over the last mil- lennium (Mann et al., 2008). Accordingly, our model results suggest that part of the disagreement between the individual proxy reconstructions, particularly prior to the $15^{\text {th }}$ century $A D$ may result from a too-sparse sampling of a temperature field that exhibited enhanced variability at multidecadal timescales during this cold phase. In other words, it is conceivable that the variation in overlap between the various temperature reconstructions during the past millennium is not only due to "averaging a small number of noisy local temperature estimates" (Mann et al., 2008) but also to the fact that the noise level covaried with climate.

\section{References:}

Jansen, E. et al., 2007: Palaeoclimate. In: Solomon, S. et al. (Eds.) Climate Change 2007: The Physical Science Basis. Contribution of Working Group I to the Fourth Assessment Report of the Intergovernmental Panel on Climate Change, Cambridge University Press, Cambridge, United Kingdom and New York, NY, USA.

Jongma, J.I., Prange, M., Renssen, H. and Schulz, M., 2007: Amplification of Holocene multicentennial climate forcing by mode transitions in North Atlantic overturning circulation, Geophysical Research Letters, 34: L15706, doi:15710.11029/12007GL030642

Mann, M.E., Zhang, Z., Hughes, M.K., Bradley, R.S., Miller, S.K., Rutherford, S. and Ni, F., 2008: Proxy-based reconstructions of hemispheric and global surface temperature variations over the past two millennia, Proceedings of the National Academy of Sciences, 105:13252-13257.

Schulz, M., Prange, M. and Klocker, A., 2007: Low-frequency oscillations of the Atlantic Ocean meridional overturning circulation in a coupled climate model, Climate of the Past, 3: 97-107. 


\section{PAGES Global Monsoon Symposium - Shanghai, China, 29-31 October 2008}

Pinxian Wang ${ }^{1}$, Bin Wang ${ }^{2}$ and T. KIefeR ${ }^{3}$

'State Key Laboratory of Marine Geology, Tongji University, Shanghai, China; pxwang@online.sh.cn 2SOEST, University of Hawaii, Honolulu, USA; 3PAGES International Project Office, Bern, Switzerland

Although scientific focus on monsoons can be traced back nearly 350 years, only recently have monsoons been recognized as a global system. With the application of remote sensing and other new techniques, the concept of a "global monsoon" has been introduced as a global-scale seasonal overturning of the atmosphere and the associated seasonal contrast in precipitation. The paleocommunity has not yet responded to this new trend in modern climatology. The paleo-monsoon is still being studied almost exclusively as a regional phenomenon.

To consider global monsoon changes from a geological perspective, 60 scientists from 5 continents gathered at Tongji University in Shanghai for the PAGES Global Monsoon Symposium. It was the first meeting organized by the newly established PAGES Working Group "Global Monsoon and Low-Latitude Processes: Evolution and Variability". The symposium brought together paleo- and modern climatologists, data-producers and modelers to compare monsoon records from various regional monsoon systems, to find out their similarities and differences across a range of timescales from interannual to orbital, and to unravel the mechanisms causing variations in the global monsoon system and regional deviations from the global trend.

Of the 26 oral presentations, 12 were given by modern and 14 by paleo-climatologists. The modern climatologists introduced the current understanding of "global monsoon" and its measurement (Fig. 1), advanced a new concept of "dynamic warm pool", and discussed the variations of the monsoon system over the past decades. A crucial issue that was raised was the discrimination of the global and regional components in monsoon variations. For example, global monsoon precipitation over land has declined over the past half-century (B.Wang and Ding, 2006) but the mechanisms remain elusive. Approached on a regional scale in East Asia, this change may be caused by variations in the snow cover in Tibet. However, taken from a global perspective, it could be ascribed to a global factor, such as enhanced volcanic activity. A compilation of monsoon variations from various continents

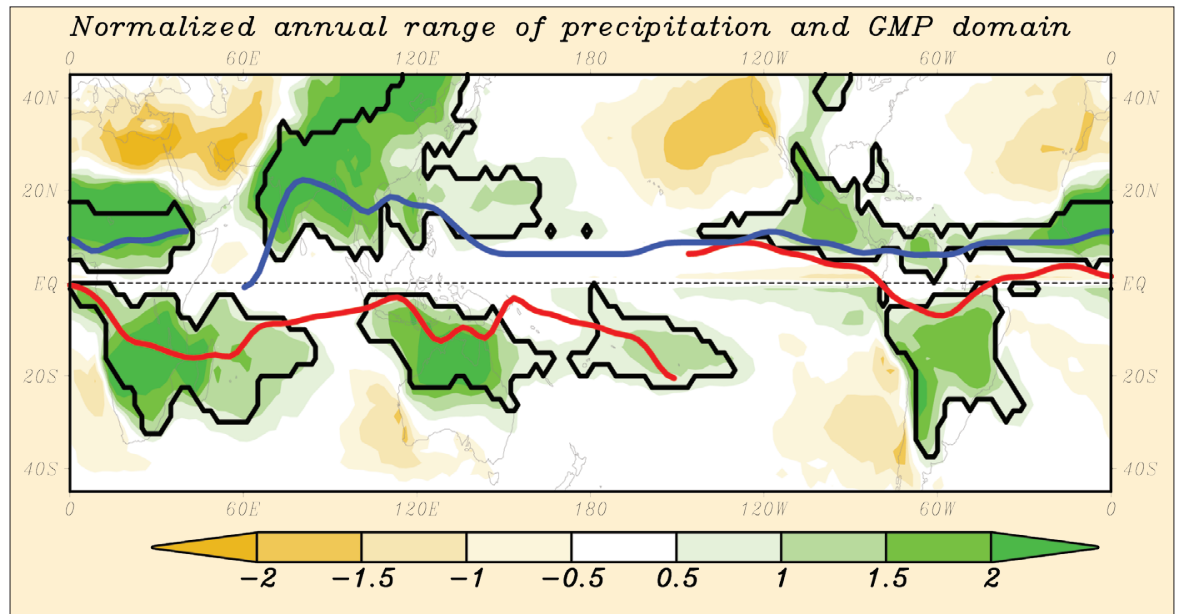

Figure 1: The modern global monsoon precipitation (GMP) domain (outlined by the black curves) based on annual range (local summer minus winter mean) of precipitation normalized by annual mean precipitation (color shading). Red (Blue) line indicates the ITCZ position in Jan-Feb (July-Aug) estimated by maximum precipitation rate (B. Wang and Ding, 2008).

will help to distinguish regional from global features, and shed light on the roles of the external forcing and internal feedback processes in determining monsoon variability on different spatial (regional and global) and temporal scales.

One focus of the symposium was orbital cyclicity of the global monsoon during the late Quaternary. Results of data analyses and numerical modeling were presented to demonstrate the monsoon cycles in the Americas, Asia, Africa and Australia. A common feature is the prevalence of precession pacing of the monsoon variations indicative of their global nature (Fig. 2). On the other hand, the observed deviations from the common trend suggest a role played by regional conditions such as land orography and sea temperature. An outstanding example of precession cycles in monsoon precipitation is the speleothem records from South China (Y. Wang et al., 2008) but a heated debate evolved on the detailed interpretation of oxygen isotopes of speleothems as a monsoon proxy. While new evidence was presented from in situ studies of local precipitation to support the interpretation that the speleothem $\delta^{18} \mathrm{O}$ represents changes in intensity of monsoon precipitation, variation in moisture sources was offered as an alternative interpretation that would be more consistent with other paleoenvironmental records from China. Since the $\delta^{18} \mathrm{O}$ records of speleothems are similar to those of air bubbles in Antarctic ice cores (Y. Wang et al., 2008), the debate extended to the general nature of the oxygen isotope signal of rainwater and its use as a proxy of the global monsoon.

Many presentations were based on high-resolution records from deep sea and lake deposits displaying monsoon variations on sub-orbital timescales. Millennialscale events discovered in monsoon records from Asia, Africa and America have been correlated to those in Greenland and the North Atlantic, yet it remains unclear whether the monsoon responds through teleconnections to high-latitude forcing, or plays a primary role in initiating and amplifying abrupt changes originating from the tropics. Disentangling this requires improved understanding of the teleconnection dynamics associated with the tropical-extratropical interaction. Another challenging issue is the negative correlation between monsoon and ENSO during the last 2 millennia. As shown by deep-sea sequences from the Indian and eastern $\mathrm{Pa}$ cific, the monsoon intensity was weak 1-2 ka ago and enhanced during the last millennium, while the ENSO variability was intense 1-2 ka ago but has weakened since then. Thus, ENSO appears to be sensitive and variable on the same timescales as the monsoon, but to what extent one system is forced by the other, or whether they vary as an interactive system in response to common forcing, remains unclear.

The second Global Monsoon Symposium will be held in 2010, and will explore global monsoon changes across all region- 


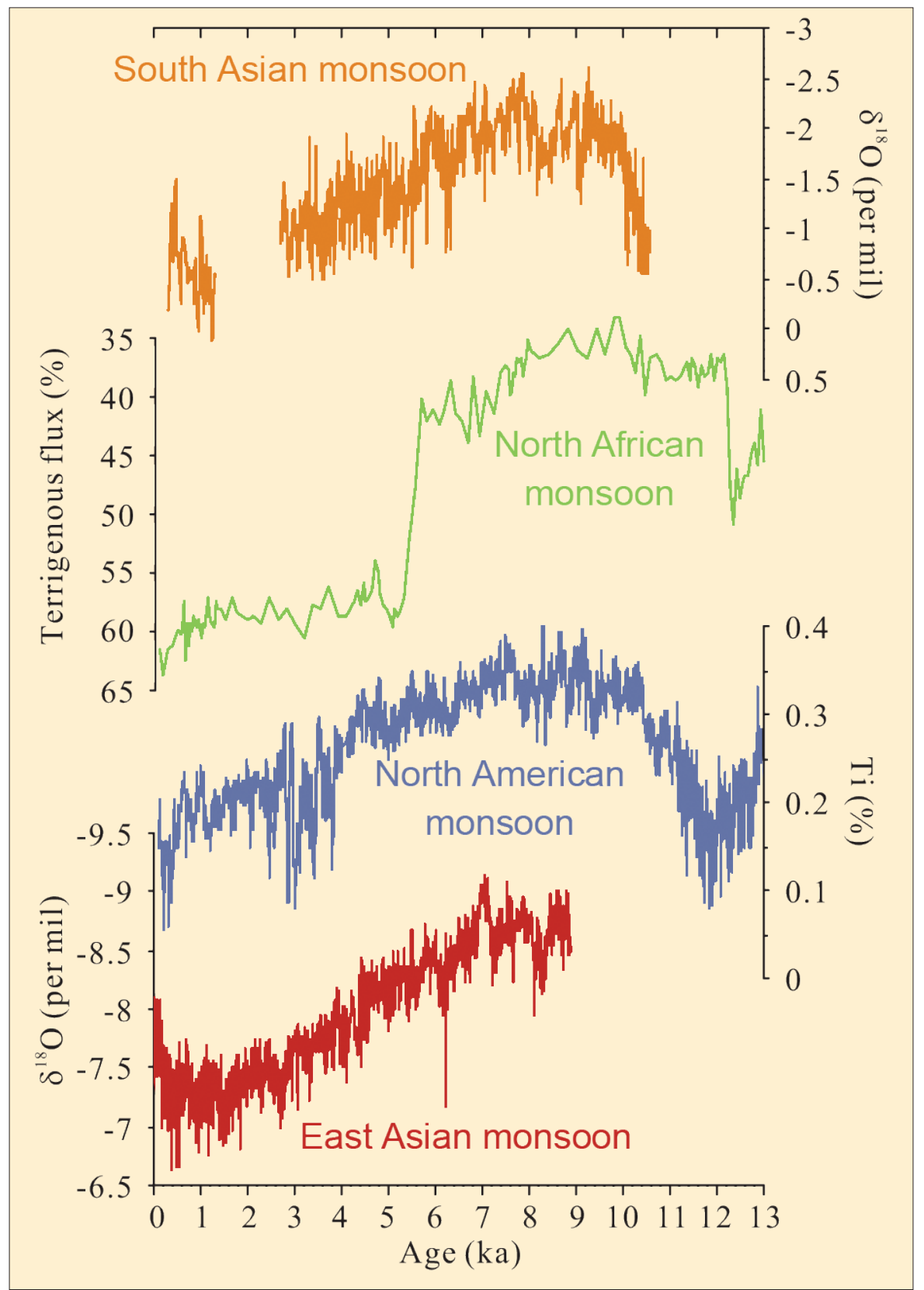

al sub-systems over a range of timescales from interannual to orbital.

\section{References}

deMenocal, P.B., Ortiz, J., Guilderson, T., Adkins, J., Sarnthein, M., Baker, L. and Yarusinski, M., 2000: Abrupt onset and termination of the African Humid Period: Rapid climate response to gradual insolation forcing, Quaternary Science Reviews, 19: 347-361.

Fleitmann, D., Burns, S.J., Mudelsee, M., Neff, U., Kramers, J., Mangini, A. and Matter, A., 2003: Holocene Forcing of the Indian Monsoon recorded in a stalagmite from Southern Oman, Science, 300: 1737-1739.

Wang, B. and Ding, Q., 2006: Changes in global monsoon precipitation over the past 56 years, Geophysical Research Letters, 33: L06711.

Wang, B. and Ding, 0., 2008: Global monsoon: Dominant mode of annual variation in the tropics, Dynamics of Atmospheres and Oceans, 44: 165-183.

Wang, Y. et al., 2008: Millennial- and orbital-scale changes in the East Asian monsoon over the past 224,000 years, Nature, 451: 10901093

For full references please consult:

www.pages-igbp.org/products/newsletters/ref2009_2.htm

Figure 2: Global monsoon in the Holocene: The common trend in monsoon variations in the Northern Hemisphere. A) South Asian monsoon: Stalagmite $\delta^{18} \mathrm{O}$ from Qunf Cave in Southern Oman (Fleitmann et al., 2003); B) North African monsoon: Terrigenous detritus \% from ODP 658, tropical Atlantic off Western Africa (deMenocal et al., 2000); C) North American monsoon: Ti\% in laminated deposits from the Cariaco Basin off Venezuela (Haug et al., 2001); D) East Asian monsoon: Stalagmite $\delta^{18} \mathrm{O}$ from Dongge Cave, South China (Y. Wang et al., 2005).

\section{First international cave monitoring field workshop}

\section{Gibraltar, 26 February - 1 March, 2009}

David MatTeY ${ }^{1}$ and ChRISTOPH SPÖTL $^{2}$

'Department of Earth Sciences, Royal Holloway, University of London, UK; mattey@es.rhul.ac.uk 2Institute for Geology and Paleontology, University of Innsbruck, Austria; christoph.spoetl@uibk.ac.at

Cave deposits (speleothems) are one of the most promising fields in paleoenvironmental research and recent studies have highlighted the potential of this terrestrial archive to provide paleoclimatic information on a range of timescales (e.g., seasonal to orbital) (see PAGES News, 16(3), 2008). While the accuracy and the precision of uranium-thorium chronologies of speleothems are superior to many other climate-proxy dating techniques, much has still to be learned about the way climate signals are being transmitted through the soil zone and karst aquifer to be recorded in growing stalagmites or flowstone. The key to a better process understanding-enabling the eventual calibration of climate-proxy transfer functions-are long-term observations of the relationship between weather and the chain of processes that transmit the climate signal to the speleothem. Setting up and maintaining cave monitoring programs can be a challenge given that caves may be diffi- cult to access or located in remote regions. Several groups have now been involved in cave monitoring over recent years and have acquired considerable expertise but little of this knowledge has found its way into the international literature.

A 4-day workshop held in Gibraltar was convened to bring together for the first time the international researchers who are actively involved in monitoring caves around the world. The aim of this meeting was to share experience and 
discuss technical issues of cave monitoring in order to improve understanding of the local processes affecting speleothem growth and the ways that climate is recorded. The workshop was attended by 30 participants from Great Britain, Germany, Austria, Switzerland, Sweden, Spain, France, the Netherlands, Romania, and the United States, ranging from $\mathrm{PhD}$ students to university professors. The workshop, sponsored by the Gibraltar Ornithological and Natural History Society, also had local support from members of the Gibraltar Cave Science Unit (GCSU) who have been collaborating in a cave monitoring program with Royal Holloway (London) for the last five years. The workshop was held in the historic Garrison Library located at the foot of the world-famous rock, which also hosts a remarkable series of solution cave systems.

The workshop format was designed to be informal and encourage interactive

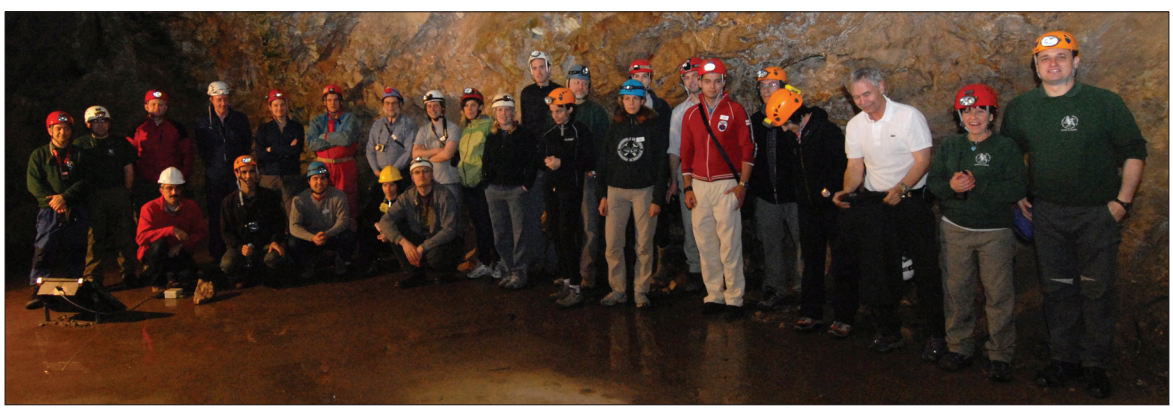

Figure 1: Workshop participants inside the rock of Gibraltar (St. Michaels Cave)

discussion. Participants contributed material for leaders to arrange into four themed sessions: Aquifer processes and climatedripwater relations (led by lan Fairchild and Dominique Genty); Karst $\mathrm{CO}_{2}$ systems and ventilation controls (led by Christoph Spötl and James Baldini); Speleothem selection, growth kinetics and sampling strategies (led by Eric James), and Data logging, automation and telemetry (led by David Mattey and Marc Luetscher). Tim Atkinson presented a stimulating introduc- tory historical perspective on cave monitoring, which was followed by discussion sessions interspersed with field visits to the cave monitoring laboratory in St. Michaels Cave (Fig. 1) and to Ragged Staff Cave, a unique site and the target of a new monitoring campaign by Royal Holloway and the GCSU beginning later this year.

Further information about the workshop and Gibraltar Cave Science can be found at www.gibcaving.net.

\section{Integrated analysis of interglacial climate dynamics - INTERDYNAMIC Status Seminar}

\section{Bremen, Germany, 24-25 February 2009}

Michael Schulz and André Paul

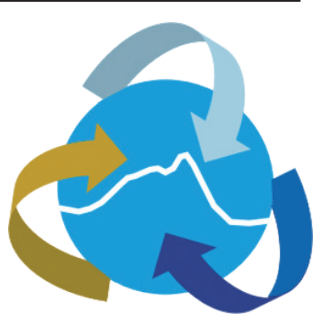

MARUM - Center for Marine Environmental Sciences and Faculty of Geosciences, University of Bremen, Germany; mschulz@uni-bremen.de

The Priority Research Program "Integrated analysis of interglacial climate dynamics" (INTERDYNAMIC), funded by the German Research Foundation (DFG), aims at a better understanding of climate dynamics using quantitative paleoclimate analyses with a view to create more reliable scenarios for future climate change.

INTERDYNAMIC is based on an integrated approach in paleoclimate research in which all available paleoclimate archives (terrestrial and marine, as well as ice cores) are combined in order to yield a comprehensive and quantitative analysis of global environmental variations. Through close linkage between paleoclimate reconstructions and results from Earth System models, detailed insights into the dynamics of climate variations are gained.

The investigations in INTERDYNAMIC focus on the interglacials of the late Quaternary (including their onset and end) and address the following key questions: - What are the amplitudes of natural climate variations on timescales of several years to millennia, and how do patterns of climate variability vary in time and space?

Do abrupt changes in the large-scale circulation of the Atlantic Ocean occur in interglacials?
- Which biogeochemical feedback mechanisms control the natural limits of atmospheric concentrations of greenhouse gases and aerosols?

- What linkages exist between climate and pre-industrial cultures?

INTERDYNAMIC was established in 2007 and has an expected duration of 6 years. The program consists exclusively of collaborative projects, in which at least two of the research fields (e.g., ice cores, marine archives, terrestrial archives and Earth System modeling) are represented. Cur- rently 13 projects are active, supporting 22 doctoral and 8 postdoctoral scientists. Information on the individual projects can be found at www.interdynamik.de

During the annual status seminar, initial results from each project were presented and discussed. Climate changes during the Holocene were addressed with respect to the hydrology of the Arctic Ocean, variation of precipitation, and flood dynamics in central Europe and central Asia. High-frequency intra-Holocene changes in the Caribbean and with respect to dust

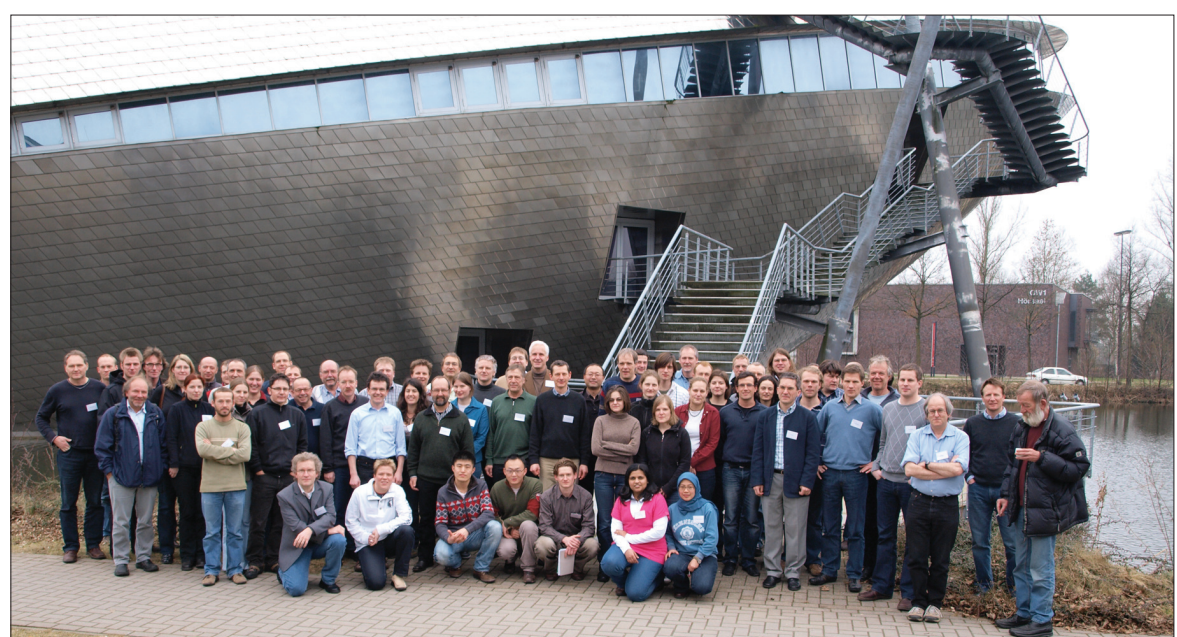

Figure 1: Participants of the INTERDYNAMIC status seminar in Bremen. 
deposition in Antarctica were also presented. Further, the role of solar forcing on climate was discussed, with emphasis on the southern westerlies. Human-climate interactions during the Holocene were discussed for Europe and central Asia, as were large-scale changes in circulation of the Atlantic Ocean for the Holocene and during Terminations I and II. Research into biogeochemical feedbacks to understand the formation of sapropels in the Mediterranean during the Holocene, were also presented. Additionally, previous interglacials were highlighted with regard to carbon cycle dynamics and orbitally induced trends in sea-surface temperature.

The program was complemented with invited presentations by Julian Sachs (on Holocene changes in the position of the Pacific rainbelt), Pinxian Wang (on the global monsoon system and its variability over a range of timescales) and Jürg Luterbacher (on perspectives of high-resolution climate reconstructions for the last millennium).

The next status seminar for the program will be held in spring 2010.

\section{Compiling records of Holocene erosion and sediment transport}

\section{LUCIFS Workshop - Christchurch, New Zealand, 6-10 December 2008}

\section{Nick Preston}

School of Geography, Environment and Earth Sciences, Victoria University of Wellington, New Zealand; Nick.Preston@vuw.ac.nz

A general meeting of the PAGES Focus 4 (PHAROS) Working Group "LUCIFS" took place in Christchurch, New Zealand, on the campus of Canterbury University. Richard Dikau (University of Bonn, Germany) as Chair, and the local organizer, Nick Preston (Victoria University of Wellington, New Zealand), were pleased to welcome 30 participants from 13 countries. The workshop provided an opportunity for presentation of recent research results and for discussion of a range of topical issues.

The workshop followed a joint meeting of the International Association of Hydrological Sciences and the International Commission on Continental Erosion, with many participants attending both meetings. A field trip led by Nick Preston and Nicola Litchfield (GNS Science, New Zealand) provided a break between the meetings. The field trip traveled to Mount Cook at the heart of New Zealand's Southern Alps and followed a source-to-sink route from the headwaters down through the catchment of the Waitaki River, focusing on the relative impacts on sediment flux of anthropogenic modifications and the glacial/post-glacial transition.

The schedule consisted of 18 oral presentations spread over two days. Many presentations highlighted the importance of human land use as the dominant control on erosion and sedimentation in diverse environments, ranging from central Europe to South America and New Zealand. It is therefore important to be able to reconstruct population densities through time, which the prehistoric archeologists from the University of Cologne have been able to do, suggesting that the pronounced human impacts result from lower population densities than have been conventionally estimated. Nevertheless, over longer temporal scales, human impacts must be considered to intensify natural trends, as

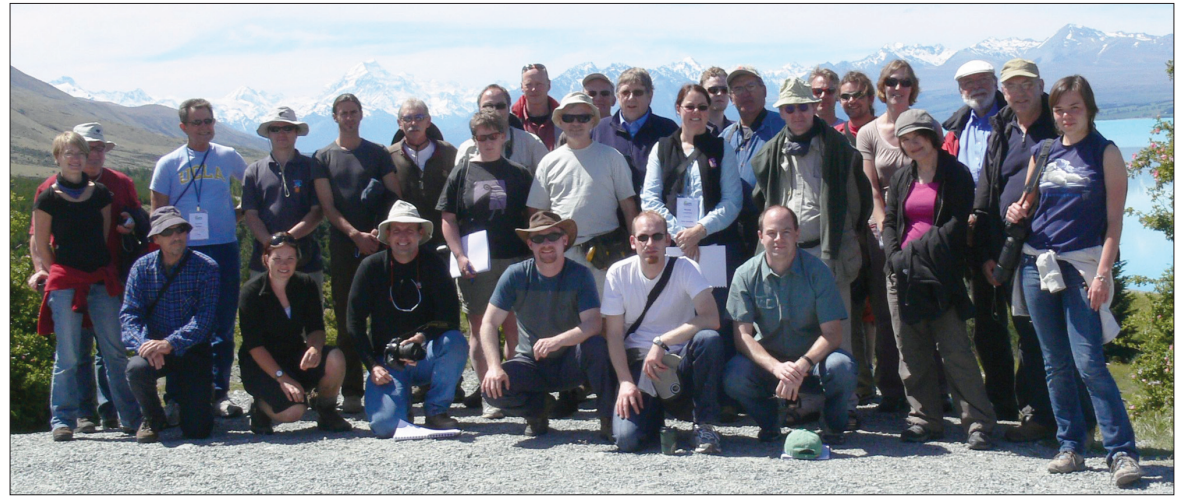

Figure 1: Participants of the LUCIFS general meeting

was shown for Middle East desertification. Similarly, research from the Rhine catchment shows that the behavior of the geomorphic system itself offers a further level of complexity. A number of keynote talks provided the basis for subsequent discussion group sessions. On the second and third days of the workshop, the meeting separated into small working groups to discuss the following issues:

- Defining a "LUCIFS method": Identification and elaboration of the systematic context in which LUCIFS researchers characterize fluvial systems (trajectories of change, spatial and temporal dis/connectivity, scale issues, etc.).

Methodological considerations: Techniques for reconstruction of past landscape behavior using multiple and diverse environmental proxies.

- Development of a LUCIFS database: Structure, metadata, content.

These structured discussions helped to clarify key issues for further research, which were presented to the whole group of participants in a plenary session. White papers will be produced, summarizing the discussions and the issues that they raised, and will initially be published on the LUCIFS website.

A final discussion addressed future LUCIFS research strategies and the group's role within the overarching PHAROS research focus. While LUCIFS research will continue with its emphasis on understanding the behavior of fluvial sediment redistribution systems, particularly as influenced by humans, members of the group will also contribute to the PHAROS "Soil and Sediment" and "Carbon" Themes (see www.pages-igbp.org/science/focus4 .html for more information on these).

Richard Dikau expressed the wish to pass on the leadership of the group, and the gathered membership decided to make a number of changes to the organizational structure. Nick Preston was elected as Chair and Thomas Hoffmann to fill the dual role of Secretary and Co-Chair. They will be joined by a flexible Steering Committee, consisting of Andreas Lang, Gilles Erkens, Jochen Schmidt and Mike Page. Membership of the Committee will change to reflect the nature of the group's activities. In addition, those members who have previously served on the Committee will be invited to continue their input by serving on an Advisory Board.

People interested in LUCIFS activities are invited to visit the LUCIFS website (http://gidimap.gub.uni-bonn.de:9080/ lucifs/) for further information.

\section{(2)}


Elena Xoplaki ${ }^{1,2}$ and Fekri Hassan ${ }^{3}$

${ }^{1}$ Oeschger Centre for Climate Change Research and Institute of Geography, University of Bern, Switzerland; ${ }^{2}$ Energy, Environment and Water Research Center, The Cyprus Institute, Nicosia, Cyprus; exoplaki@oeschger.unibe.ch; ${ }^{3}$ nnstitute of Archaeology, University College London, UK; f.hassan@ucl.ac.uk

Land degradation, over-irrigation and desertification in the Middle East and North Africa (MENA) and other semi-arid areas of the Earth are adding further stresses to regions already under pressure from global environmental change. This workshop, cosponsored by the International GeosphereBiosphere Programme (IGBP) and the Egyptian Academy of Scientific Research and Technology (ASRT), provided a forum for local and international researchers to highlight land- and water-related problems in semi-arid regions, and to propose adaptation and mitigation strategies. The workshop aimed to refine IGBP's scientific agenda for applied Earth System science and sustainability in the MENA region, and to identify where IGBP and MENA researchers can better contribute to addressing mitigation, innovation and adaptation, large-scale pilot projects and institutional networking.

Sessions focused on the main pressures in the area; drought, water use and management, land degradation and desertification, and impacts on humans and ecosystems. Presentations were given by MENA scientists, as well as international experts and leaders of several IGBP projects on land, atmosphere, historical perspectives and modeling.

Countries in the MENA region are confronted with large changes in land use and related stresses on their water supplies. Global environmental changes will strongly affect the region, causing an expected rise in average temperature of $1-4^{\circ} \mathrm{C}$ by 2060, and a decline in annual precipitation by, for example, $10-40 \%$ over much of Egypt by 2100 . Impacts of global change in the area include water scarcity, food shortage, loss of biodiversity, sea level rise and pressures on human health.

In view of such developments, the impact on water resources and ecosystems in the MENA countries require integrated water management strategies emphasizing maximization of water use efficiency and maximum financial return of unit water volume. However, such strategies cannot ignore the social dimensions of water, and its role as an important element in maintaining food security (especially for the poor), social cohesion, and political stability. The transboundary aspect of key water resources in the MENA region, ex-

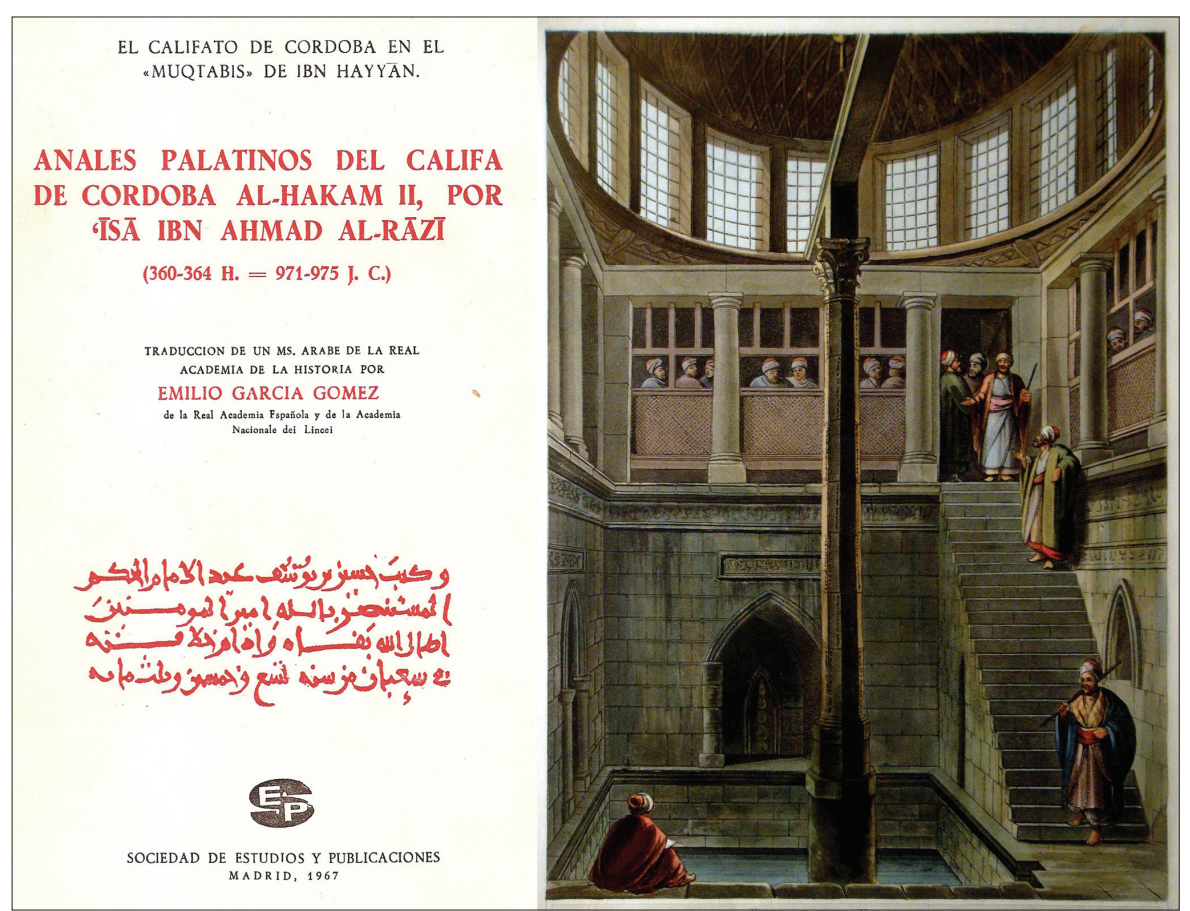

Figure 1: Historical records from the MENA region. Left: Anales Palatinos. Right: View of the Nilometer (Luigi Mayer, R. Brown Historic Gallery, Pall Mall 1802). tending beyond national borders, will also require policies that are trans-regional. The impact of climate change must, therefore, also be discussed in the broader context of social and political stressors, such as inappropriate water management policies or economics. Chronic poverty conditions, unemployment, rapid population increase, accelerating urbanization, land reclamation and industrial development cannot be excluded from the debate on resilience, sustainability and coping strategies.

The workshop included a session on the African Network of Earth System Science (AfricanNESS), an initiative launched at IGBP's Congress in South Africa in May 2008. The goal of AfricanNESS is to develop a network for global environmental change in Africa, with thematic clusters-rainfall, land cover, livelihoods, cities, diseases and pests, Africa and the Earth system, integrated development, and marine.

Participants re-affirmed the importance of the participation of MENA in IGBP research in order to better understand pressing environmental changes and concomitant social responses, to assess vulnerability, and to contribute to the effective mitigation and coping strategies that will have to include, by necessity, social and economical components to achieve the goals of sustainable development. The participants stressed the importance of further research to remedy the current lack of available information from the MENA region and other African countries, to critically assess existing data sets, to integrate climate modeling with climatic and environmental proxies, and to elucidate the social mechanisms in responding and coping with environmental change.

The workshop ended with a session on "Drought and Humans: Learning from the Past". It covered existing evidence of climatic variability and the impact of droughts and other climatic events on water and life-support resources, and social systems during the last $10 \mathrm{ka}$. Key outcomes of the PAGES ESF-MedCLIVAR Symposium "Climate extremes during recent millennia and their impact on Mediterranean societies" (Athens, 2008) were also presented. In 
particular, the need for long-term, highquality and high-resolution data from both instrumental records and historic archives, and the benefits of a multiproxy approach, were stressed. Further, it was recognized that in order to bridge the communication gap between various research communities, future research should focus on developing stronger integration and exchange between paleodata researchers and modelers. The importance of continuous caution and re-evaluation of possible human impact on the proxy recording process and resultant signal was also emphasized.

The current changes in the Earth System, which are strongly associated with the coupled human-environment system, make the integration of cultural and Earth processes and dynamics a priority for developing future coping strategies.

The MENA region is one of the most vulnerable spots on the globe (World Bank, 2007). It is also of paramount geopolitical significance. This places the MENA region as a priority for international and trans-regional collaborative research by scientists from complimentary disciplines, with the main objective of sustaining development, food security and political stability. Information gained from the MENA region will, in addition, contribute to a better understanding of the global changes in the Earth
System. The exceptional historical records from the region (Fig. 1) are also bound to provide well-documented case studies of how social systems responded and coped with environmental change.

\section{Note}

Sections of this article were extracted from the IGBP Secretariat Press Release see www.igbp. net/page.php?pid $=444$

\section{References}

World Bank, 2007: The World Bank Middle East and North Africa Region (MENA) Sustainable Development Sector Department (MNSSD) Regional Business Strategy to Address Climate Change. Available at: http://siteresources.worldbank.org/INTCLIMATECHANGE Resources/MENA_CC_Business_Strategy_Nov_2007_Revised. $\mathrm{pd}$

\section{New on the PAGES bookshelf \\ Philosophical Transactions of the Royal Society The Pliocene: a vision of Earth in the late $21^{\text {st }}$ century?}

\section{Alan M. Haywood, Harry, J. Dowsett and Paul J. Valdes \\ Royal Society Publishing, ISBN: 978-0-85403-727-8}

This volume summarizes current knowledge regarding climate and environments during warm intervals of the Pliocene, and assesses how similar certain aspects of the Pliocene Earth System are to predictions of Earth at the end of the $21^{\text {st }}$ century.

\section{Summary of contents:}

- Introduction: Pliocene climate, processes and problems

- Obituary: Prof. Bruce William Sellwood

- Pliocene palaeoceanography of the Arctic Ocean and subarctic seas

- The Arctic cryosphere in the mid-Pliocene and the future

- Surface temperatures of the mid-Pliocene North Atlantic Ocean

- Pliocene climate and seasonality in North Atlantic shelf seas

- Mid-Pliocene equatorial Pacific sea surface temperature reconstruction

- El Niño Southern Oscillation, Pliocene climate and equifinality

- Mid-Pliocene sea level and continental ice volume

- Constraints on the amplitude of mid-Pliocene eustatic sea level fluctuations

- Comparing mid-Pliocene vegetation with predicted biome distributions for the $21^{\text {st }}$ century
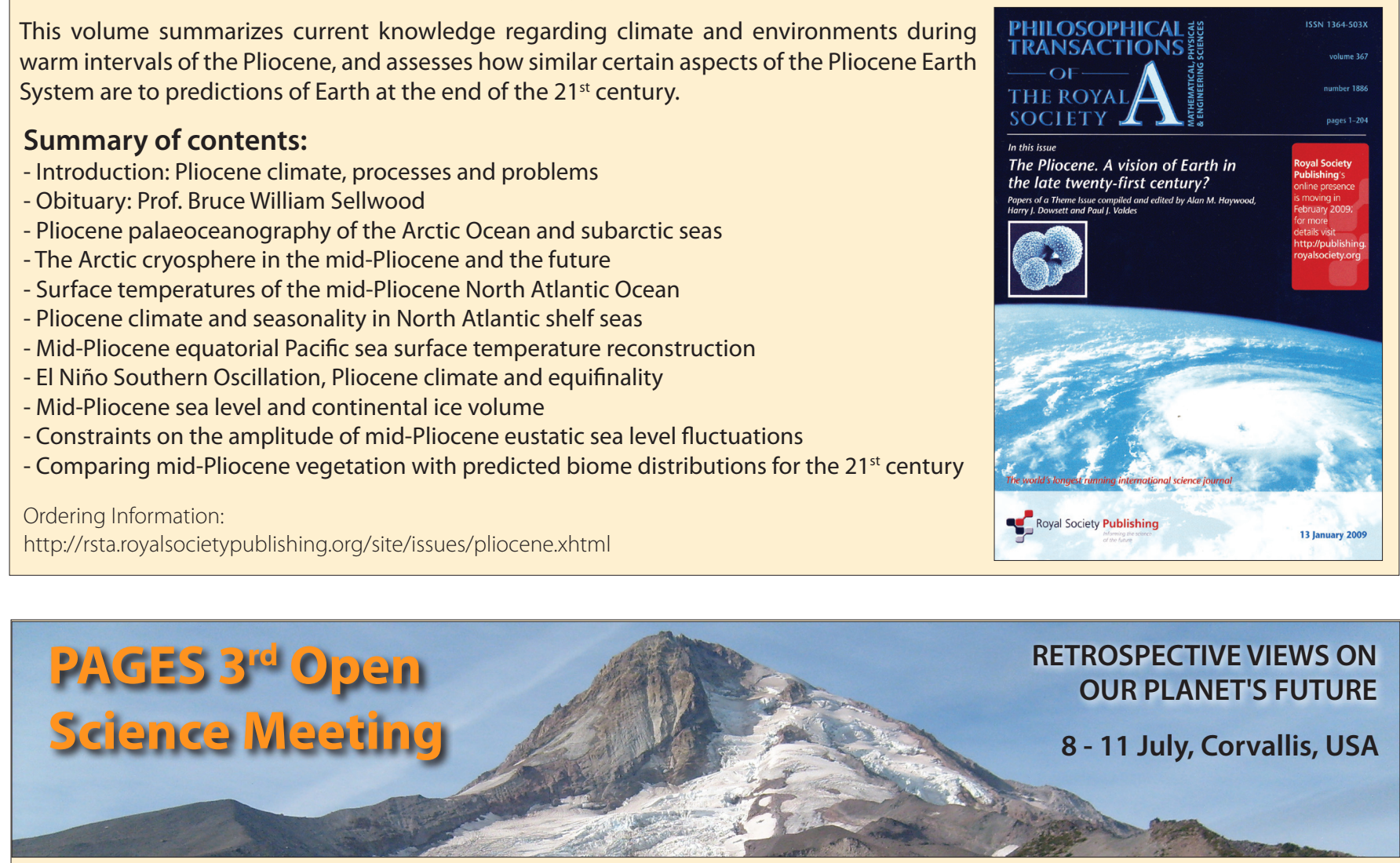

POST-CONFERENCE FIELD TRIPS AT PAGES $3^{\text {RD }}$ OPEN SCIENCE MEETING

Information is now available on a number of post-meeting field trips to be held on Sunday, 12 July. These include visits to the Oregon coast, Oregon wine country and Mt. Hood. See www.pages-osm.org/osm/fieldtrips for more details.

\section{UNABLE TO MAKE IT TO THE PAGES OSM?}

PAGES is excited to announce that talks at the Open Science Meeting will be recorded and made available online. For those with limited download capacity, PAGES will also be making these presentations available on DVD soon after completion of the meeting.

\section{www.pages-osm.org/}


PAGES International Project Office

- New on the PAGES Bookshelf

\section{Special Section: Understanding sea level: Ways forward from the past}

- Editorial: Past ice sheet dynamics and sea level_-placing the future in context

51

\section{Science Highlights:}

- Recent Antarctic and Greenland ice-mass fluxes from satellite observations J. Bamber

- U-series dating of fossil coral reefs: Consensus and controversy

M.B. Andersen, C.D. Gallup, D. Scholz, C.H. Stirling and W.G. Thompson

- Using models to inform the field community: Far-field sea level data applications G.A. Milne

- PLIOMAX: Pliocene maximum sea level project

M.E. Raymo, P. Hearty, R. De Conto, M. O'Leary, H.J. Dowsett, M.M. Robinson and J.X. Mitrovica

- The dimensions of the Greenland Ice Sheet since the Last Glacial Maximum M.A. Kelly and A.J. Long

- Extending the U-series dating of fossil coral reefs back to MIS 15 C.H. Stirling and M.B. Andersen

- Ice sheet retreat and sea level rise during the last deglaciation P.U. Clark

- A new chronology of sea level highstands for the penultimate interglacial

A. Dutton, F. Antonioli and E. Bard

- Tempo of global deglaciation during the early Holocene: A sea level perspective S.-Y. Yu, Y.-X. Li and T.E. Törnqvist

- Coastal vegetation evidence for sea level changes associated with Heinrich Events 70 C. González and L.M. Dupont

- Ice sheet climate interactions during the ice age cycle A. Abe-Ouchi and B. Otto-Bliesner

\section{Program News}

- ADOM - Atmospheric circulation dynamics during the last glacial cycle

\section{Science Highlights: Polar Paleoscience Addendum}

- Termination of the MWP: Linking N. Atlantic circulation changes to ENSO

A. Kuijpers, B.A. Malmgren, M.-S. Seidenkrantz

- Reading the first early Cenozoic central Arctic sediment record

F. Sangiorgi, A. Sluijs, J. Barke and H. Brinkhuis

\section{Science Highlights: Open section}

- Imprint of changes in multidecadal climate variability on temperature reconstructions 80 M. Schulz and M. Prange

\section{Workshop Reports}

- Global monsoon in observations, simulations and geological records 82

- First international cave monitoring field workshop

- Integrated analysis of interglacial climate dynamics

- Compiling records of Holocene erosion and sediment transport

- Sustainable water and land management in semi-arid regions
Zähringerstrasse 25

3012 Bern - Switzerland

Tel.: +41316315611

Fax: +41316315606

pages@pages.unibe.ch www.pages-igbp.org/

\section{Editors:}

Series Editors:

Louise Newman and Thorsten Kiefer

Guest Editors:

Mark Siddall, William G. Thompson and Claire Waelbroeck

Text Editing: Leah Witton Layout: Louise Newman

Hardcopy circulation: 2000

\section{ISSN 1563-0803}

Printed on recycled paper by Läderach AG - Bern, Switzerland

Cover images:

Antarctic iceberg - L. Newman Coral Acropora palmata, Belize H.A. Curran
The PAGES International Project Office and its publications are supported by the Swiss and US National Science Foundations and NOAA. 